\title{
Analyse de « l'infodémie » de Covid-19 en Belgique francophone
}

Perceptions du coronavirus, mésinformation, anxiété et confiance dans les sources d'information et le gouvernement en période de confinement en Belgique francophone

Grégoire Lits

Louise-Amélie Cougnon

Alexandre Heeren

Bernard Hanseeuw

Nathan Gurnet 



\section{Analyse de "l'infodémie " de Covid-19 en Belgique francophone}

Perceptions du coronavirus, mésinformation, anxiété et confiance dans les sources d'information et le gouvernement en période de confinement en Belgique francophone.

Enquête réalisée en le 30 mars et le 10 avril 2020 en Belgique francophone.

\section{Auteurs}

Grégoire Lits : Professeur de sociologie des médias à l'Observatoire de Recherche sur les Médias et le journalisme (ORM), Institut Langage et Communication de l'UCLouvain

Louise-Amélie Cougnon : Logisticienne de recherche à l'Institut Langage et Communication de l'UCLouvain, Research Director du Media Innovation \& Intelligibility Lab (MiiL) de I'UCLouvain

Alexandre Heeren : Professeur de psychologie et chercheur qualifié FNRS, Institut de Recherche en Sciences Psychologiques \& Institut de Neuroscience de l'UCLouvain

Bernard Hanseeuw : Professeur en neurosciences, Cliniques Universitaires Saint-Luc et Institut de Neuroscience de l'UCLouvain

Nathan Gurnet : Doctorant en sociologie à l'Institut d'analyse du changement dans les sociétés contemporaine (IACCHOS) de I'UCLouvain

Avec la collaboration de : Prof. Olivier Standaert (ORM), Margaux Guyot (ORM) et Prof. Pierre Baudewyns (ISPOLE)

Rapport de recherche de l'Observatoire de Recherche sur les Médias et le Journalisme (ORM), Université catholique de Louvain, mai 2020.

En collaboration avec le Media innovation \& intelligibility Lab (MiiL - UCLouvain).

\section{UCLouvain}

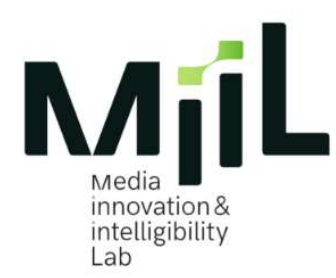

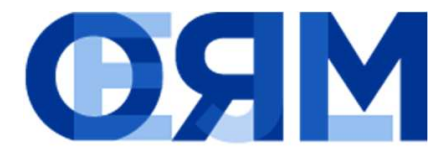

OBSERVATOIRE DE RECHERCHE SUR LES MÉDIAS ET LE JOURNALISME ÉCOLE DE JOURNALISME DE LOUVAIN 



\section{Résumé}

Selon l'OMS, l'épidémie de Covid-19 est accompagnée d'une " infodémie », c'est-à-dire un flux énorme et incessant d'informations, vraies et fausses, difficiles à gérer pour les individus. Cette infodémie est un problème car elle peut générer une incompréhension du virus ainsi que de l'anxiété et empêcher l'adoption de pratiques efficaces de lutte contre la pandémie. Cette étude, réalisée entre le 30 mars et le 10 avril auprès de 1.817 Belges francophones par l'Observatoire de Recherche sur les Médias et le Journalisme (ORM - UCLouvain), mesure l'ampleur de l'infodémie en Belgique francophone.

\section{Conclusions principales :}

- La majorité de la population s'informe principalement par le canal des médias traditionnels (90\%). Les sources d'information des médecins, en particulier, se distinguent de cette tendance : ils sont $87 \%$ à considérer les discussions avec d'autres professionnels de la santé comme une de leurs sources d'information principale.

- Il existe également des différences importantes entre les générations du point de vue des sources d'information principales sur l'épidémie. Les moins de 26 ans sont les plus nombreux à combiner médias traditionnels et réseaux sociaux (24\%). Ils sont $42 \%$ à considérer les réseaux sociaux comme une source principale (comparé à $24 \%$ en moyenne, pour la population belge francophone dans son ensemble, toutes classes d'âge confondues).

- Un Belge francophone sur deux (50\%) a partagé des informations relatives au coronavirus sur les réseaux sociaux. Proportionnellement, les plus nombreux à partager des informations sont les adultes entre $26-65$ ans (62\%, comparé à $35 \%$ pour les $16-25$ ans et $38 \%$ pour les 66 ans et plus). Parmi les Belges qui ont partagé de l'information sur le coronavirus, $10,4 \%$ reconnaissent avoir partagé par inadvertance de fausses informations (ce qui représente environ 214.000 personnes).

- Si les jeunes sont plus nombreux que les générations plus âgées à accorder le statut de source d'information principale aux réseaux sociaux, ils ne sont cependant pas le groupe le plus à risque dans l'infodémie. En effet, ils sont en proportion plus nombreux à avoir conscience d'avoir été exposés à de fausses informations (62\%, comparé à $49 \%$ pour l'ensemble de la population et seulement $18 \%$ pour les 66 ans et plus). Les moins de 26 ans sont moins nombreux à partager de l'information sur le coronavirus et moins nombreux à s'être rendu compte d'avoir partagé de fausses informations. Ils sont également moins nombreux à croire la théorie selon laquelle le coronavirus est issu d'un laboratoire (8\% contre $12 \%$ des 26 à 65 ans). S'ils Les moins de 26 ans s'informent davantage que les autres classes d'âge sur les réseaux sociaux, ils semblent en faire une utilisation plus critique et y partagent moins d'information relative à l'épidémie.

- Le groupe le plus à risque dans l'infodémie est le même que celui le plus exposé à l'épidémie de Covid-19, il s'agit des 66 ans et plus. Quatre seniors sur dix (38\%) ont partagé de I'information sur les réseaux sociaux et ils sont proportionnellement plus nombreux à reconnaitre avoir partagé des contenus faux sur les réseaux sociaux ( $25 \%$ des seniors ayant partagé de l'information reconnaissent avoir partagé une mauvaise information). 
- De manière générale, les experts et professionnels de la santé sont la source d'information à laquelle les Belges francophones font le plus confiance au sujet du coronavirus (entre $93 \%$ et $83 \%$ de confiance, selon la source d'expertise). De manière surprenante, en Belgique francophone, le gouvernement fédéral est jugé comme une source d'information plus fiable ( $81 \%$ de confiance) que l'ensemble des médias traditionnels (entre $78 \%$ et $67 \%$ selon les médias). Les articles de blog (21\%) et les influenceurs sur les réseaux sociaux (14\%) sont les sources les moins créditées de confiance.

- Au début de la période de confinement, plus d'un Belge sur deux (57\%) pense qu'en cette période de crise nous devrions uniquement faire confiance aux experts pour prendre des décisions et que le gouvernement devrait simplement les appliquer sans les questionner. Seul un belge francophones sur cinq $(19,7 \%)$ n'est pas d'accord avec cette affirmation. Le lancement d'une seconde vague d'enquête la semaine du 11 mai (qui coïncidera au démarrage de la deuxième étape du plan de déconfinement) permettra d'évaluer l'évolution de ce chiffre.

- Après deux à trois semaines de confinement, un Belge sur quatre éprouve un niveau d'anxiété élevé ou très élevé. Cette proportion est la plus élevée chez les moins de 26 ans (un jeune sur trois). Le niveau d'anxiété est également plus élevé chez les femmes et chez les personnes qui perçoivent le virus comme une menace importante à leur intégrité physique ou psychologique. Inversement, une plus grande confiance dans les mesures prises par le gouvernement pour faire face à l'épidémie, ou la croyance selon laquelle le virus est le fruit d'un complot politique est associée à un plus faible niveau d'anxiété. 


\section{Table des matières}

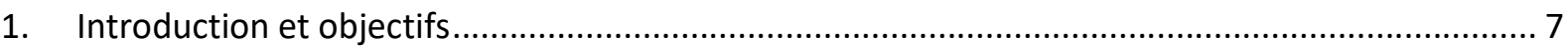

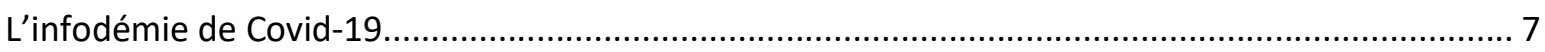

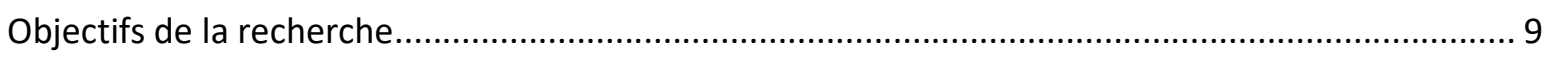

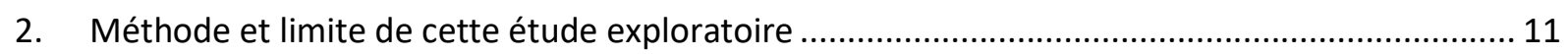

3. Analyse des sources d'information principales à propos du coronavirus ..................................... 13

4. Analyse de la confiance dans les sources d'information concernant le coronavirus.................... 18

5. Évaluation de la communication du gouvernement et de la confiance envers les mesures prises 21

6. Analyse de la confiance dans les experts et le gouvernement pour prendre des décisions en

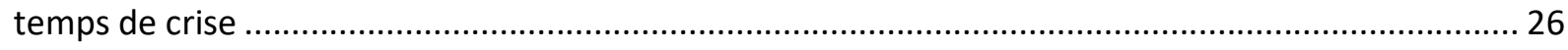

7. Fake news, théorie du complot et réseaux sociaux. Épidémie et infodémie en Belgique

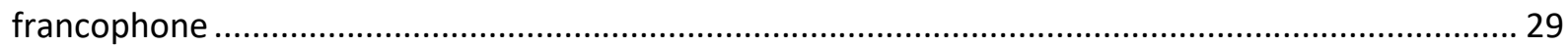

Analyse du degré d'information et de l'exposition aux fausses informations .................................... 29

Théorie du complot et manipulation de l'information par le gouvernement .................................. 31

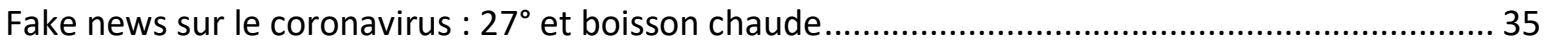

Controverse sur le mode de transmission : la transmission par aérosol. ......................................... 38

8. Niveau de connaissances factuelles sur le coronavirus et l'épidémie (différence médecins/grand

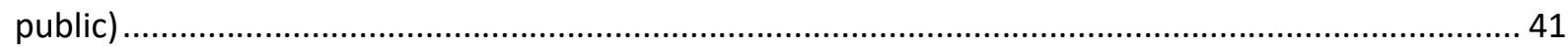

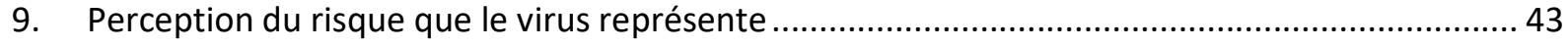

10. Analyse du niveau d'anxiété et de la capacité de mémorisation............................................. 46

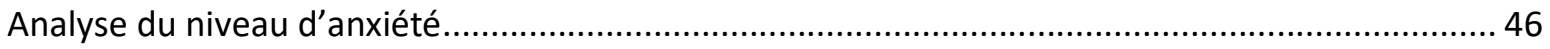

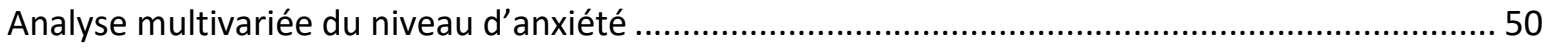

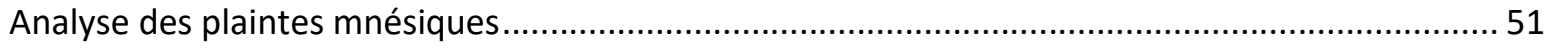

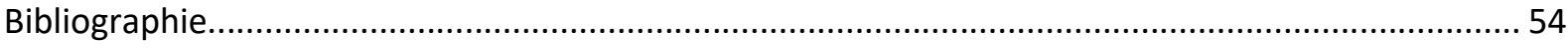

Annexe 


\section{Introduction et objectifs}

\section{L'infodémie de Covid-19}

À quelques exceptions près, l'apparition du terme "infodémie " est liée au déclenchement de l'épidémie de Covid-19 (Nielsen et al. 2020), à partir du moment où il est utilisé par l'OMS pour désigner : "Le vaste volume de nouvelles et d'informations concernant le Covid-19 - et l'ambiguïté, l'incertitude, et parfois la mauvaise qualité, le caractère trompeur ou la nature carrément fausse de certaines d'entre elles. » (Nielsen $2020: 5$, traduit de l'anglais).

Illustration 1 : occurrence des termes " Fake News " et " Infodémie " dans les tweets de la population belge (source MiiL, UCLouvain, 2020)

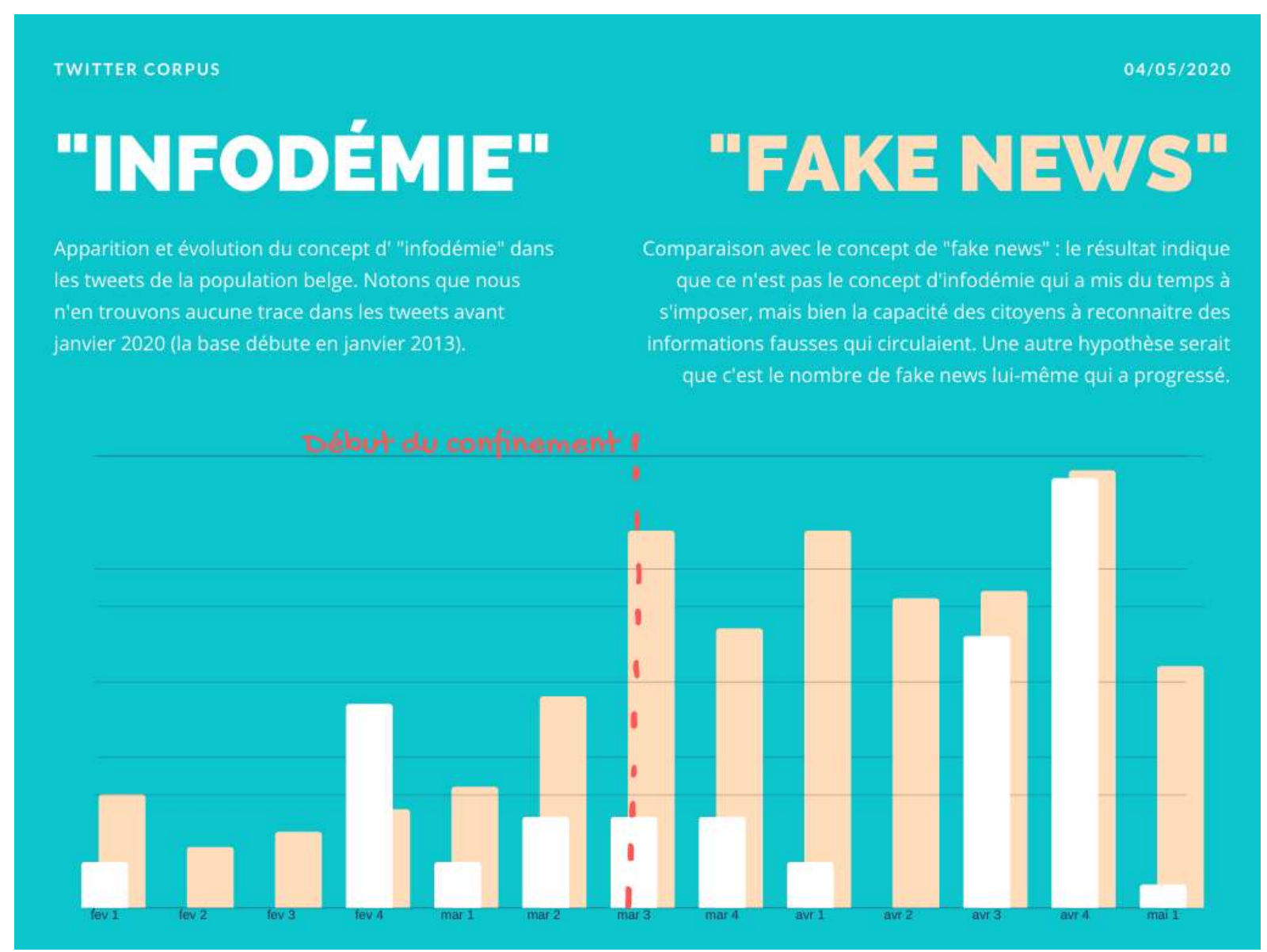

Rapidement après le déclenchement de l'épidémie en Chine, l'OMS considère en effet la lutte contre cette infodémie comme étant une des dimensions importantes de la lutte globale contre la propagation du virus. Les propos du directeur général de l'OMS datant du 15 février 2020 sont évocateurs :

"We're not just fighting an epidemic; we're fighting an infodemic. Fake news spreads faster and more easily than this virus, and is just as dangerous. ",

Tedros Adhanom Ghebreyesus, Directeur général de l'OMS (cité par Nielsen et al 2020). ${ }^{1}$

\footnotetext{
${ }^{1}$ https://www.who.int/dg/speeches/detail/munich-security-conference
} 
L'extrait suivant permet de comprendre pleinement le sens donné par l'OMS a cette nouvelle dimension de l'épidémie :

"De nombreux types d'informations ont été largement diffusées pendant la pandémie de COVID-19, en telle quantité qu'elles ont créé une 'infodémie' parallèle - la propagation rapide de toutes sortes d'informations - qui rend la solution plus difficile encore ». (OMS 2020 : 145).

L'infodémie (cf. également Zarocastas 2020) ne se résume donc pas à l'existence et à la circulation de fausses informations. Elle se rapporte autant au fait que le volume d'informations (vraies ou fausses) est très élevé et que leur diffusion est extrêmement rapide aujourd'hui grâce, notamment, aux réseaux sociaux ou aux chaines d'information en continu, et que, parmi les informations diffusées, une proportion importante se révèle de qualité médiocre, voire fausse. Le climat d'incertitude qui entoure ce nouveau virus a également comme conséquence le caractère très éphémère de certaines informations diffusées dans les médias qui peuvent être rapidement nuancées, voire contredites, selon les avancées de la recherche. Les positions parfois divergentes entre les différents experts abondamment sollicités dans les médias constituent également une des dimensions de l'infodémie. En plus d'un volume d'information élevé, un nombre important des informations diffusées sont instables, fragiles, voire au cœur de controverses encore vives quant à leur validité scientifique.

L'infodémie est donc davantage liée au phénomène de " mésinformation " (le fait d'être mal informé, voire trop informé ou informé trop rapidement) qu'à celui de l'existence et de la diffusion de « fake news » (de fausses informations produites et diffusées intentionnellement, cf. Tandoc 2018) ou qu'au phénomène de " désinformation " (des informations produites et diffusées intentionnellement dans le but de déstabiliser la société de réception et de générer des profits à son émetteur, généralement un pays étranger) (UE 2018: 11)2. Fake news et désinformation sont une des dimensions de l'infodémie, mais elles n'en constituent pas à elles seules le noyau³ ${ }^{3}$.

Sous un vocable nouveau, cette notion renvoie au constat réalisé par ailleurs (notamment WagnerEgger et al. 2001) que les épidémies sont généralement sujettes à des phénomènes de « dramatisation médiatique » qui en font un type " d'événement médiatique » (Véron 1981) très particulier.

Pour faire face à cette infodémie, l'OMS a mis en place dès le mois de janvier un dispositif de communication appelé « Le Réseau d'information de l'OMS pour les épidémies " (EPI-WIN), qui a pour mission " de réduire la mésinformation en fournissant une grande quantité de messages de santé publique destinés à informer les individus et les populations sur les moyens de se protéger et de contribuer à enrayer l'épidémie. » (OMS 2020: 146).

Sur la base de recherches empiriques menées lors d'épidémies précédentes et de recherches classiques en communication des risques, I'OMS a identifié deux objectifs à atteindre pour " neutraliser l'influence négative de la mésinformation » : " faire en sorte que la proportion de conseils avisés sur les moyens de se protéger par rapport à la mésinformation soit d'au moins 60/40 ; et faire un travail de pédagogie pour " immuniser » $20 \%$ des personnes sensibles aux fausses informations de façon qu'elles n'en tiennent pas compte ou ne les relaient pas ". (OMS 2020 : 146). Elle reprend également un des constats classiques des études sur la perception des risques par le public: " La propension à croire les fausses informations est étroitement liée à la perte de confiance dans les

\footnotetext{
${ }^{2}$ L'initiative EUvsDiSiNFO de l'Union Européenne analyse de près l'évolution de la désinformation au sujet du Covid-19. Un rapport identifiant les principaux récits de désinformation circulant en Europe entre le 2 et le 22 avril a été publié le 24 avril 2020 : https://euvsdisinfo.eu/eeas-special-report-update-2-22-april/. Voir également pour une autre analyse : (Brennen S. J. et al. 2020)

${ }^{3}$ Pour une première modélisation de l’infodémie voir : (Cinelli et al. 2020)
} 
autorités et le gouvernement ". Le niveau de confiance dans les différentes autorités impliquées dans la gestion de la crise est donc central. Un niveau de confiance élevé est important pour la mise en place de stratégies efficaces de lutte contre l'épidémie ${ }^{4}$.

Pour atteindre ces objectifs, le réseau EPI-WIN diffuse en grande quantité des messages de santé publique destinés à informer correctement les individus ${ }^{5}$. Le relais de ces messages passe par des " amplificateurs » locaux, " c'est-à-dire les sources d'information fiables pour des publics particuliers " (OMS 2020: 146), propres à chaque pays et à différents types de publics. Ces amplificateurs (par exemple, en plus des autorités, des employeurs de différents secteurs d'activité, des syndicats, des organisations confessionnelles, etc.) transmettent alors les messages de l'OMS à leur communauté.

\section{Objectifs de la recherche}

Dans ce contexte où la lutte contre l'infodémie est un des objectifs centraux de lutte mondiale contre la pandémie, la recherche exploratoire que nous avons menée a été animée par les 3 objectifs suivants :

1. Analyser le niveau de confiance accordé par différents types de public à différentes sources d'information sur le Covid-19 en Belgique francophone. Quelles sont les sources d'information jugées les plus dignes de confiance ? La communication du gouvernement est-elle suffisamment claire?

2. Analyser la diffusion de certaines informations (vraies, fausses ou controversées) et comprendre la manière dont les individus perçoivent le virus et l'épidémie. Comprendre ces perceptions est important car, comme le montre la littérature sur la perception des risques (pour une synthèse, cf. Pidgeon et al. 2003), c'est sur la base de ces perceptions, et non sur la base des connaissances objectives et scientifiques existantes et disponibles, que les individus forgeront leurs comportements face aux risques et à l'épidémie.

3. Évaluer l'anxiété et les difficultés mnésiques des individus. De nombreuses études expérimentales en psychologie cognitive et en neurosciences affectives indiquent un effet délétère des situations d'incertitudes ou de menaces potentielles sur le traitement cognitif de l'information (FeldmanHall \& Shenhav 2019 ; Yoshida \& Ishii 2006). Des données d'enquêtes réalisées lors de crises sanitaires précédentes ont par ailleurs souligné l'importance du niveau de confiance accordé aux sources $d^{\prime}$ 'informations dans l'avènement d'inquiétudes et d'anxiété chez les personnes en confinement (pour une discussion, cf. Brooks et al. 2020). Par conséquent, nous cherchons à évaluer le niveau d'anxiété de la population pendant les premières semaines du confinement. La capacité à retenir des informations nouvelles a-t-elle été modifiée en raison de la situation ? Quelles sont les relations entre ces deux variables et le niveau de confiance accordé par différents types de public à différentes sources d'information sur le Covid-19 en Belgique francophone?

Pour répondre à ces 3 questions, notre étude s'intéresse à deux types de public distincts.

Elle vise à comparer les perceptions et les sources d'informations des différentes catégories d'âges (16-25 ans, 26-65 ans et 66 ans et plus). Le rapport à l'information des jeunes et des seniors est souvent décrit de manière stéréotypée sur le mode de l'opposition entre une génération de " digital natives " dont l'activité d'information principale s'oriente vers les réseaux sociaux et une génération de seniors

\footnotetext{
${ }^{4}$ Une étude menée sur l'épidémie de grippe H1N1 en 2009 montre par exemple que le niveau de confiance dans les autorités politiques et médicales est un bon prédicteur de l'acceptation de la vaccination. (Gilles et al. 2011)

${ }^{5}$ Pour une explication de la stratégie d' « infodemic management » voir : https://www.who.int/teams/riskcommunication/infodemic-management
} 
plus critiques, habitués à s'informer au travers de médias traditionnels. II s'agira d'étudier les différences entre les groupes des jeunes (16-25 ans), des actifs (26-65 ans) et des seniors (66 ans et plus) pour décrire de manière factuelle le rapport de chacun de ces groupes à l'information et à la mésinformation.

Notre étude vise également à comparer les perceptions et sources d'information du grand public et des professionnels de la santé (médecins). Cet élément est important car de nombreuses études réalisées sur d'autres problèmes à risque (catastrophe naturelle, gestion des déchets radioactifs, etc...) (Slovic 1987 ; Wynne 1992, Jasanoff 1994, Callon et al. 2001) montrent que très généralement les perceptions des experts divergent fortement de celles des publics non experts quand il s'agit d'évaluer des risques sanitaires et environnementaux et des situations d'incertitude. Mettre en évidence les divergences de perceptions entre les médecins et le grand public est donc important car les médecins sont (avec les médias) amenés à jouer un rôle important d'information du public dans la gestion du coronavirus et de l'épidémie sur le long terme. 


\section{Méthode et limite de cette étude exploratoire}

Dans cette recherche exploratoire, nous rendons compte de données collectées au moyen d'une enquête en ligne menée en Belgique francophone principalement entre le 30 mars et le 10 avril $2020^{6}$. 3.676 personnes ont répondu au questionnaire qui a été principalement diffusé via les réseaux sociaux Facebook, Linkedln et Twitter (échantillonnage non probabiliste par méthode dite de "boule de neige »). Certains médias traditionnels (La radio La Première, ainsi que TV Com) ont fait écho de l'enquête et ont encouragé leurs auditeurs à y répondre. Des campagnes d'emailing ciblées et de diffusion via différents réseaux associatifs ont également été réalisées afin de toucher certaines catégories particulières en fonction de l'âge et du niveau d'étude.

Sur la base de ces réponses, nous avons extrait un échantillon de répondants en suivant une méthode d'échantillonnage par quota sur la base des classes d'âge, du sexe et du niveau d'étude. Cet échantillon a ensuite été pondéré en fonction du sexe et du niveau d'étude (à partir des données fournies par l'enquête sur les forces de travail EFT Statbel 2019) pour être représentatif des caractéristiques de la population francophone des Régions Wallonne et Bruxelloise âgée de plus de 16 ans.

L'échantillon final est constitué de 1.817 répondants, ce qui donne une marge d'erreur générale de $2,3 \%$ pour un niveau de confiance de $95 \%$.

Cette méthode d'enquête en ligne et d'échantillonnage par quota présente certaines limitations. Notre échantillon comporte une surreprésentation des habitants de la région Bruxelloise et une sousreprésentation des habitants des provinces de Liège et du Hainaut. Cependant, nous avons testé l'effet du lieu d'habitation sur un nombre important de variables et il ne semble pas jouer de rôle important dans les différentiels de réponses.

Nous avons également, comme cela est généralement le cas dans les enquêtes en ligne, une sousreprésentation des personnes très peu diplômées (principalement du niveau primaire), nous avons corrigé cela en pondérant notre échantillon sur la base des réponses obtenues $(\mathrm{N}=55)$. Notre échantillon se limite également aux utilisateurs d'Internet (en Belgique en 2018, 87\% des ménages disposent d'une connexion internet selon les données du SPF Économie). Finalement, la classe d'âge des plus de 75 ans est également légèrement sous-représentée dans notre échantillon, et cela, malgré le fait que nous avons pu toucher un nombre relativement important (100) de 75 ans et plus grâce à différentes stratégies mises en place lors de la collecte de données (via différents réseaux et association).

En complément de l'échantillon portant sur la population francophone belge, nous avons également constitué un échantillon supplémentaire au cours de la même période, rassemblant 305 médecins via la diffusion de l'enquête dans différentes mailing listes ou groupes Facebook professionnels. La comparaison entre ces deux échantillons nous permettra de mettre en évidence de possibles différences de perception de l'épidémie du Covid-19 et du coronavirus entre professionnels de la santé et grand public.

Les conclusions présentées ici sont donc le résultat d'une étude exploratoire et devraient être confirmées par des études ultérieures. Les niveaux de confiance dans les sources d'informations ainsi

\footnotetext{
${ }^{6} 95 \%$ des observations ont été réalisées entre le 30 mars et le 10 avril c'est-à-dire entre 12 et 23 jours apprès le 18 mars, date du début de la période de confinement en Belgique. L'enquête est cependant restée disponible en ligne jusqu'au 23 avril, principalement en vue de compléter l'échantillon de médecins.
} 
que la prévalence de certaines perceptions évolueront certainement sur la durée de l'épidémie. Le suivi de ces niveaux devrait être réalisé au-delà de cette période. 


\section{Analyse des sources d'information principales à propos du coronavirus}

Il existe différentes manières de s'informer au sujet du coronavirus. Pour le public belge francophone, la source jugée le plus souvent comme étant une source principale d'information est composée de l'ensemble des médias dits traditionnels : télévision, radio, journaux papier et en ligne. Neuf Belges francophones sur dix jugent ces sources comme principales dans leurs pratiques d'information. Viennent ensuite les discussions avec des professionnels de la santé (pour près d'un Belge sur trois) et enfin les discussions avec des proches et les réseaux sociaux. II est possible que les réseaux sociaux soient fortement employés (notre étude, basée sur des déclarations, ne permet pas d'analyser les pratiques d'information mais uniquement la valorisation des différentes sources), notamment pour accéder à des contenus en ligne de médias traditionnels, mais, de manière générale, ils n'apparaissent pas comme une source " principale » d'information. Les discussions avec les professionnels de la santé apparaissent donc comme le second canal le plus valorisé pour s'informer sur le virus.

Lorsque l'on s'intéresse aux sources d'information des professionnels (médecin) qui sont donc amenés à informer le public, on observe une mise en avant différente des sources principales. Leur source principale est constituée des discussions avec d'autres professionnels de la santé (valorisée par près de neuf médecins sur dix).

Figure 1. Les principales sources d'information au sujet du coronavirus (médecins vs. grand public)

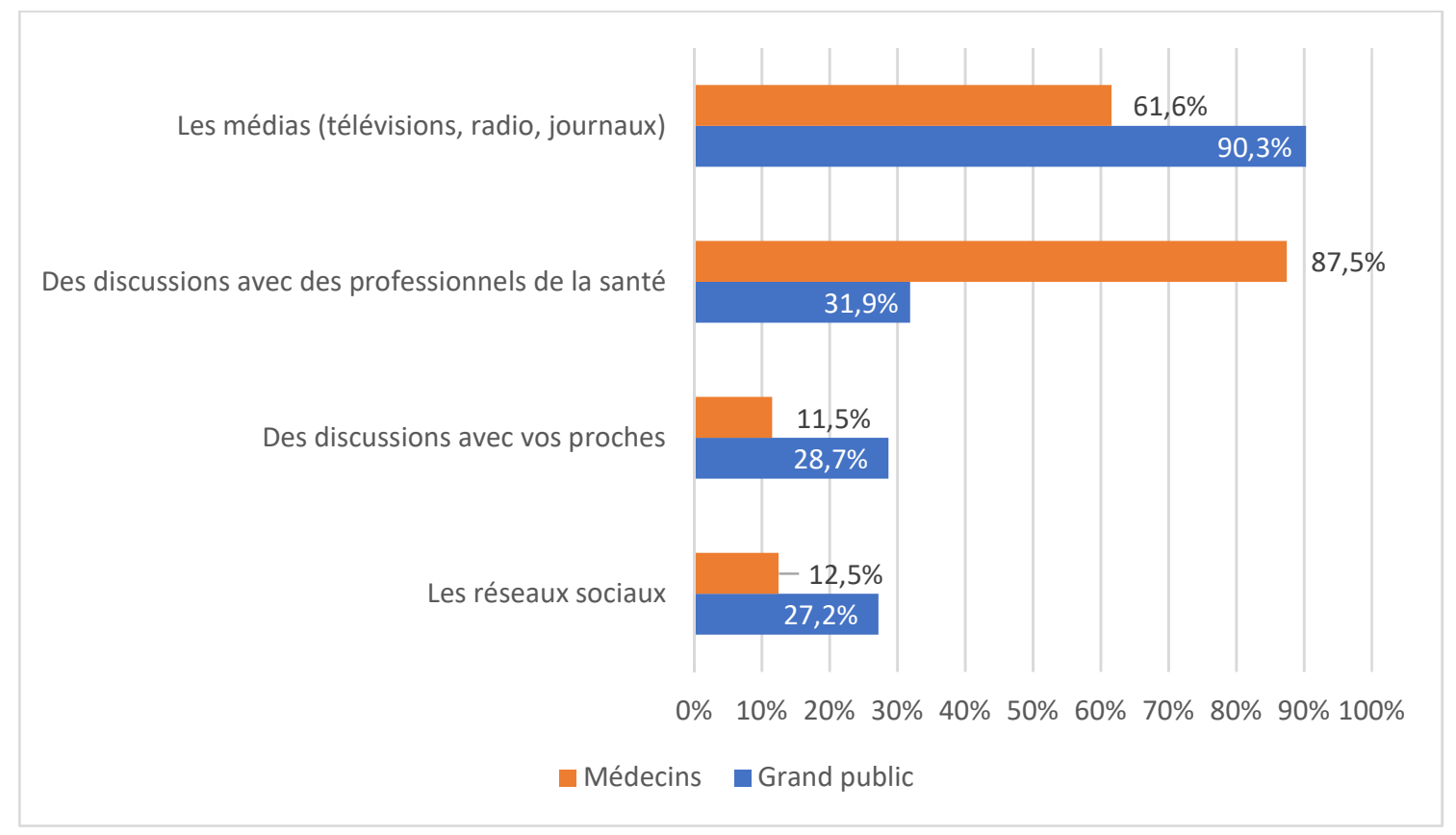

Q15 : Quelles sont vos principales sources d'information à propos du coronavirus (Covid-19) ? (Oui, Non)

Il existe de fortes différences entre les générations quant à la valorisation des réseaux sociaux comme source d'information principale. Seuls $8 \%$ des 66 ans et + accordent à cette source le statut de source principale. Cette proportion monte à $26 \%$ pour les 26 à 65 ans et atteint $42 \%$ pour les jeunes de 16 à 25 ans. De manière inattendue les 66 ans et + sont les moins nombreux ( $22 \%$ comparé à $36 \%$ des 26 à 65 ans) à considérer les discussions avec des professionnels de la santé comme une source d'information principale. 


\section{Fig. 2. Les principales sources d'information au sujet du Coronavirus en fonction de l'âge}

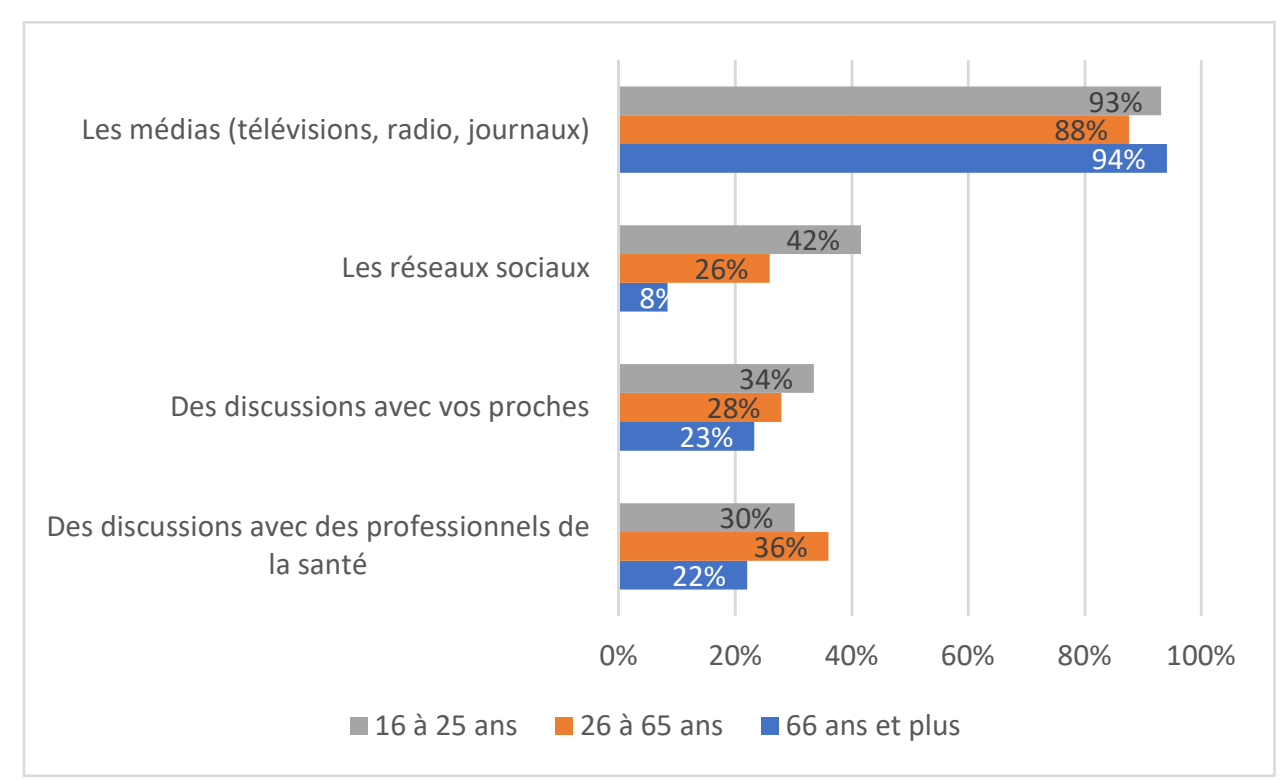

Q15 : Quelles sont vos principales sources d'information à propos du coronavirus (Covid-19) ?

Lorsqu'on s'intéresse à la combinaison des sources médiatiques principales (réseaux sociaux et/ou médias traditionnels), on observe une très faible proportion des Belges francophones qui accorde un statut de source principale uniquement aux réseaux sociaux (4\%). Il est notable que $35 \%$ des médecins (comparé à seulement $9 \%$ du grand public) ne s'informent de manière principale ni dans les médias traditionnels, ni sur les réseaux sociaux. Le rapport à l'information diffère donc fortement entre experts (médecin) et non experts (grand public).

Fig. 3 Analyse de la combinaison des sources principales d'informations : Médias traditionnels et/ou réseaux sociaux - Médecin et grand public

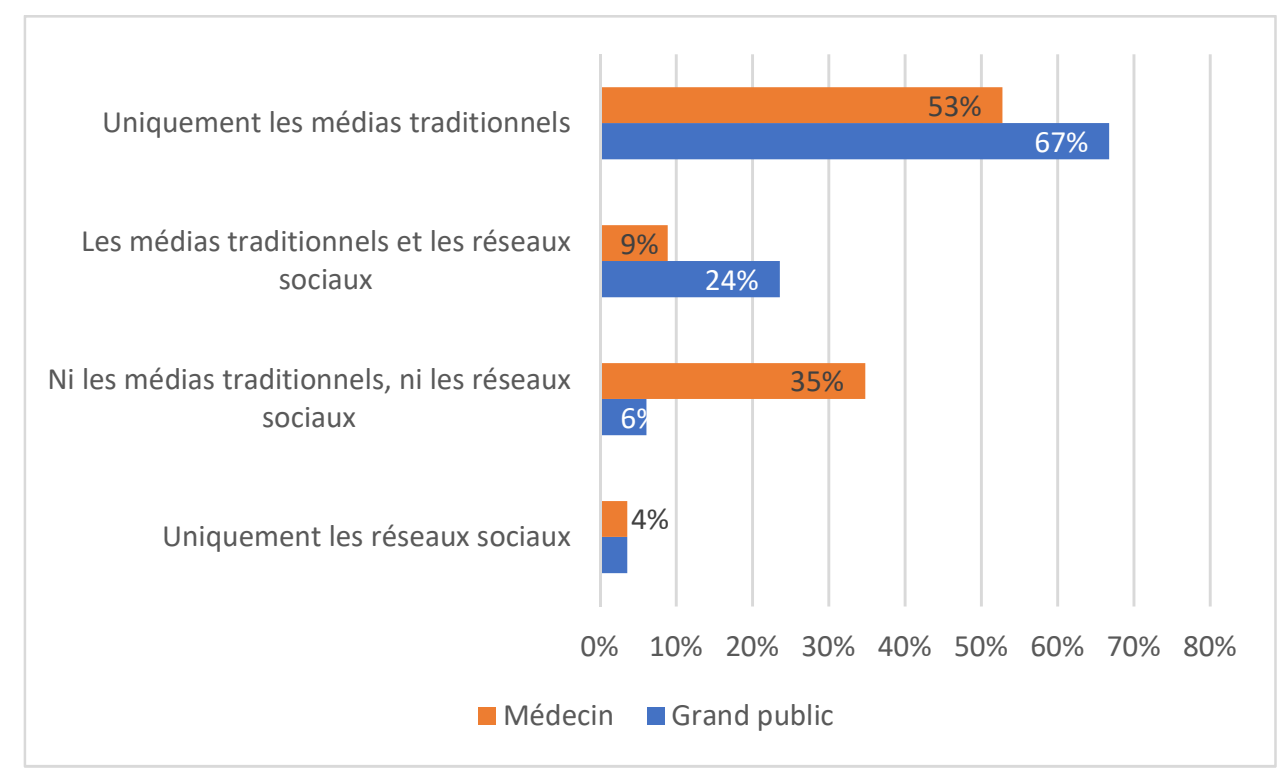

Q15 : Quelles sont vos principales sources d'information à propos du coronavirus (Covid-19) ?

La très faible proportion d'individus ne valorisant que les réseaux sociaux comme source médiatique principale s'observe dans toutes les classes d'âge. Si les moins de 26 ans sont beaucoup plus nombreux à considérer les réseaux sociaux comme une source d'information principale, ils ne sont que $4 \%$ à ne 
pas la considérer comme principale sans considérer également les médias traditionnels comme source principale. Plus les individus sont jeunes, plus ils combinent sources médiatiques traditionnelles et réseaux sociaux. Plus ils sont âgés, moins ils diversifient leurs sources, au profit d'une seule source médiatique (les médias traditionnels). Notons que près d'un actif sur dix (classe d'âge des 26 à 65 ans) n'accorde le statut de source principale à aucune des deux sources médiatiques.

Fig. 4 Analyse de la combinaison des sources principales d'informations : Médias traditionnels et/ou réseaux sociaux - différence entre génération

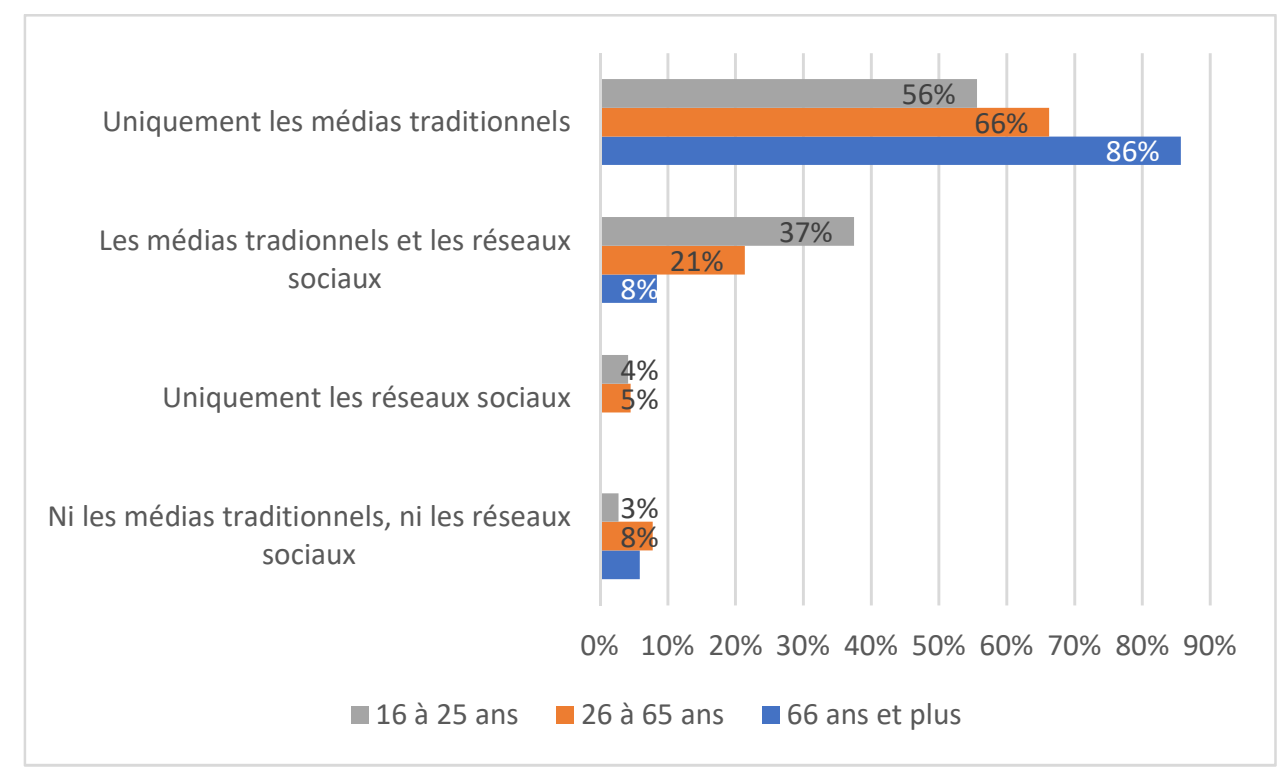

Q15 : Quelles sont vos principales sources d'information à propos du coronavirus (Covid-19) ?

Fig. 5. Utilisation des réseaux sociaux et des messageries de type WhatsApp pour partager de l'information sur le coronavirus par classe d'âge

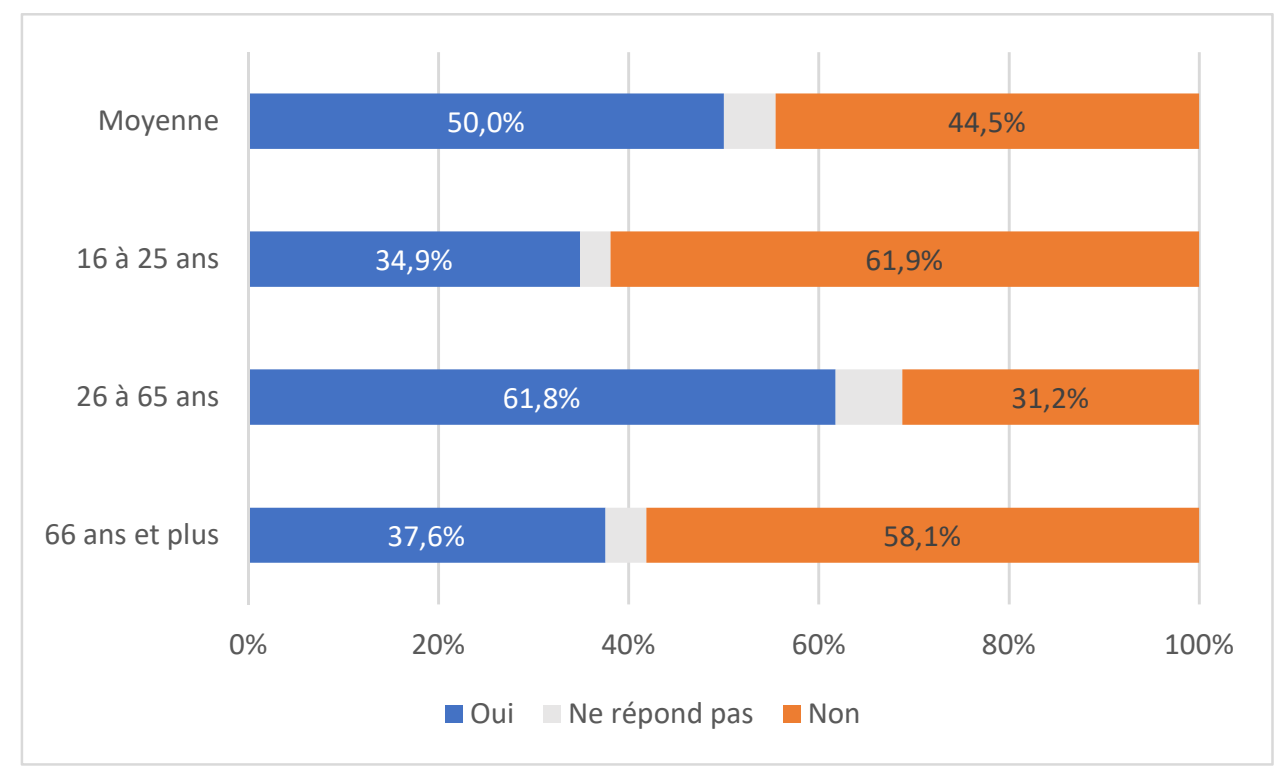

Q13a : Avez-vous partagé de l'information sur le coronavirus sur les réseaux sociaux (Facebook, Instagram, Twitter) ou une messagerie du type WhatsApp ?

L'utilisation des réseaux sociaux pour partager des informations liées au coronavirus diffère en fonction des classes d'âge. Contrairement à ce que certains stéréotypes véhiculent, nous voyons que la classe d'âge qui affirme avoir le moins partagé des contenus sur les réseaux sociaux est celle de 
jeunes âgés de 16 à 25 ans (35\%). Les 26 à 65 ans sont de loin les plus nombreux à avoir partagé des informations sur les réseaux sociaux et les messageries avec six Belges francophones sur dix de cet âge (62\%) qui ont partagé de l'information. Les seniors de 66 ans et plus sont également plus nombreux que les 16-25 ans à partager de l'information sur le coronavirus (38\%, soit quatre seniors sur dix). Sur cette base, il n'est pas possible de conclure que les jeunes sont de plus grands utilisateurs des réseaux sociaux que les 26-65 ans ou que les seniors. Si les jeunes valorisent davantage les réseaux sociaux comme source d'information principale (le plus souvent en combinaison avec les médias traditionnels), ils sont moins actifs dans la propagation d'information (quelle qu'elle soit) sur les médias numériques.

Fig. 6. Avez-vous été géné(e) par une incapacité à suivre les informations dans les médias ?

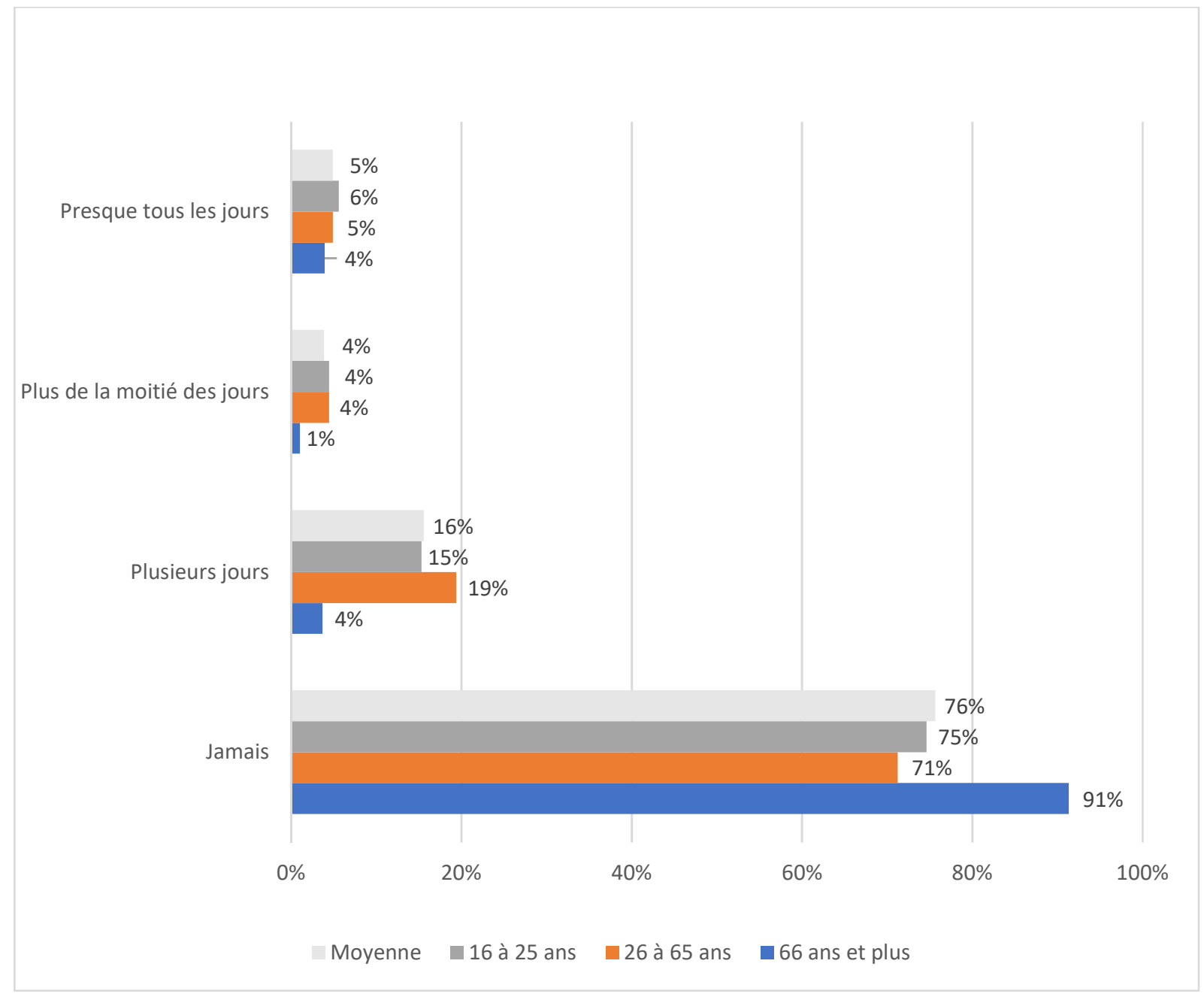

Q11 : Depuis le début de la période de confinement, selon quelle fréquence avez-vous été géné(e) par les problèmes suivants ? : Une incapacité à suivre les informations dans les médias.

Nous avons interrogé les individus sur les difficultés ressenties à l'égard des informations dans les médias, en leur posant la question suivante : «Depuis le début de la période de confinement, selon quelle fréquence avez-vous été géné(e) par les problèmes suivants ? : Une incapacité à suivre les informations dans les médias ". Cette question état intégrée dans un ensemble de questions visant à évaluer l'anxiété ressentie pendant la crise en cours. Elle mesure donc une gêne liée au suivi des informations dans les médias, manifestée par une incapacité à suivre ces informations. En moyenne 3 Belges francophones sur quatre $(76 \%)$ ne ressentent jamais de gêne les empêchant de suivre les informations dans les médias. Cela signifie donc que c'est effectivement le cas pour en moyenne 1 belge sur quatre. Parmi ceux-ci, $16 \%$ des Belges n'ont pas pu suivre les informations pendant plusieurs 
jours, $4 \%$ plus de la moitié des jours, et $5 \%$ (un Belge francophone sur vingt) presque tous les jours. Le groupe d'âge ayant étant le moins affecté est celui des 66 ans et plus (seuls $9 \%$ ont ressenti une incapacité à suivre les informations); celui le plus affecté est celui des 26 à 65 ans, une classe d'âge qui comporte le plus d'actifs et de dispensateurs de soins (care) aux enfants et aux personnes âgées dépendantes. 


\section{Analyse de la confiance dans les sources d'information concernant le coronavirus}

Sans conteste, en Belgique, les sources d'information créditée du plus haut niveau de confiance au sujet du coronavirus sont les experts. Les quatre premières places sont tenues par : 1 / "Des experts en épidémiologie et virologie" (score moyen de 3,12; " 4 " signifiant avoir "extrêmement confiance »). 2/ Des professionnels de la santé (2,95; " 3 » signifiant avoir " beaucoup confiance »). $3 /$ Emmanuel André, le porte-parole interfédéral francophone de lutte contre le Convid-19 au moment de l'enquête $(2,84)$ et l'OMS $(2,67)$.

Vient ensuite le gouvernement fédéral $(2,39$; « 2 " signifiant "moyennement confiance »), qui devance de peu les gouvernement régionaux $(2,16)$.

Viennent ensuite les principaux médias traditionnels (dans l'ordre : le journal télévisé, la presse écrite, des émissions radio), puis les sources d'informations liées aux proches (discussions et articles partagés sur les réseaux sociaux) ou à l'employeur.

Les sources les moins créditées de confiance sont les articles de blog $(0,75 ;$ « 1 » signifiant : « un peu confiance $)$ et les influenceurs sur les réseaux sociaux $(0,49 ;$; 0 » signifiant «pas du tout confiance $"$ ).

Cette distribution est relativement similaire à celle observée dans les six pays (États-Unis, RoyaumeUni, Corée du Sud, Espagne, Argentine et Allemagne) étudiés par Nielsen et al (2020:16-17). Une spécificité de la Belgique est le niveau de confiance plus élevé envers le gouvernement fédéral qu'envers les médias traditionnels. Caractéristique qui ne se retrouve que dans un des six pays étudiés par Nielsen et al. (l'Espagne). Cet écart est spécialement dû à la classe d'âge des 16 à 25 ans qui accorde une confiance plus élevée que les autres classes d'âge au gouvernement fédéral. 
Fig. 7. Confiance dans les différentes sources d'information concernant le coronavirus

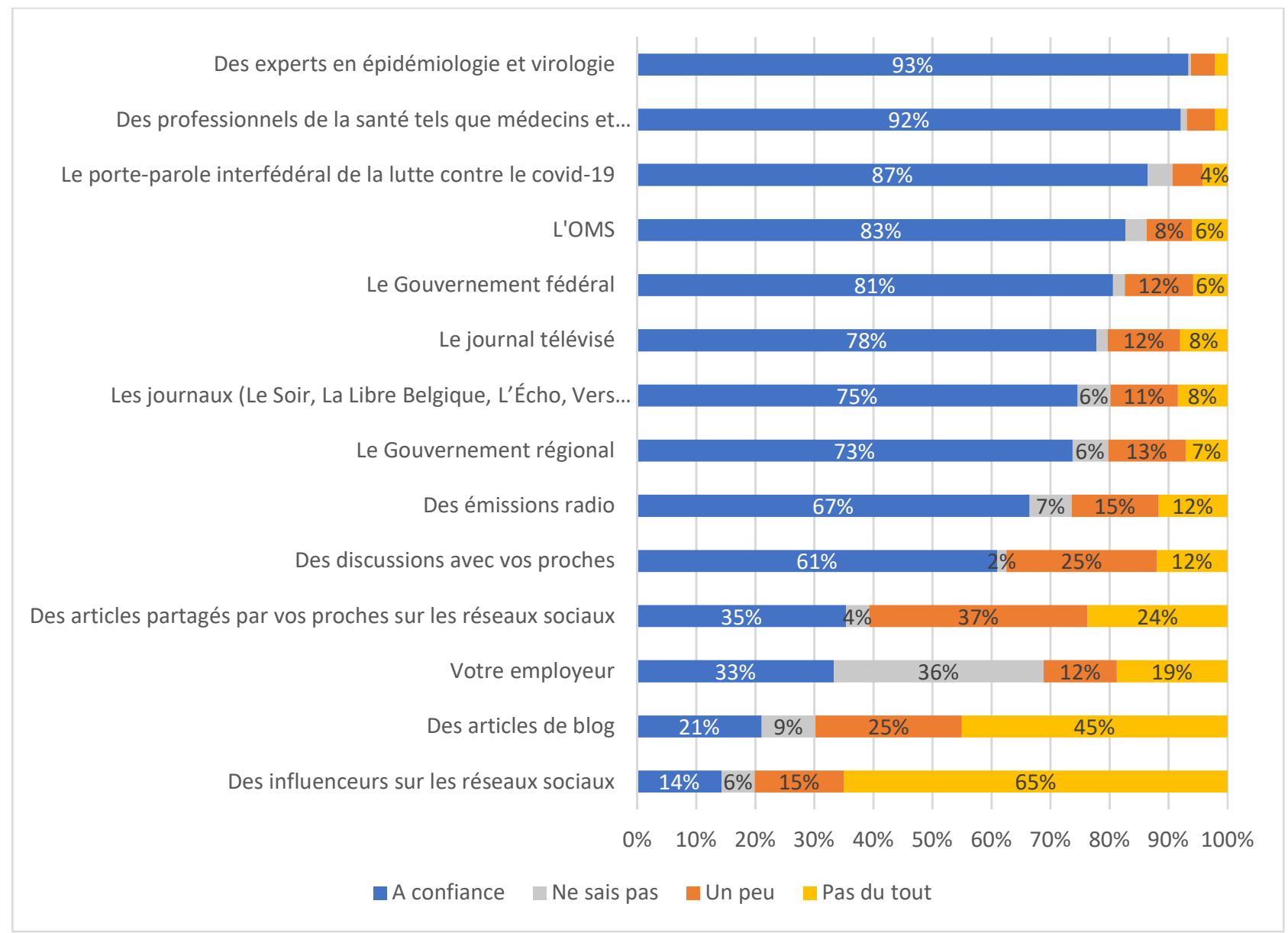

Q14 : Pour vous informer concernant le coronavirus (Covid-19), à quel point avez-vous confiance dans les sources d'information suivantes ? ( 4 = Extrêmement ; 3 = Beaucoup ; 2 = Moyennement ; 1 = Un peu ; 0 = Pas du tout.)

Il est notable que les jeunes (16 à 25 ans) accordent plus de confiance aux experts, et particulièrement à l'OMS, que la moyenne (elle est la deuxième la plus créditée de confiance avec un score moyen de 3,1 contre 2,7), ainsi qu'aux gouvernements fédéraux et régionaux. Ils accordent également très légèrement plus de confiance aux influenceurs sur les réseaux sociaux que la moyenne, bien que ce niveau reste extrêmement faible (score moyen de 0,6 contre 0,5). À l'inverse, ils accordent un peu moins de confiance que la moyenne aux articles partagés par des proches sur les réseaux sociaux.

Les 66 ans et plus accordent plus de confiance que la moyenne aux discussions avec leurs proches, aux articles partagés par leurs proches sur les réseaux sociaux ainsi qu'aux professionnels de la santé. À I'inverse, ils accordent moins de confiance que la moyenne à l'OMS, aux différents gouvernements, et à leur employeur (ce qui doit sans doute être relativisé par le fait que de nombreux 66 et + ne sont plus à l'emploi).

La distribution de confiance de la classe des 26 à 65 ans est proche de la moyenne. 


\section{Fig. 8. Degré de confiance moyen dans les différentes sources d'information concernant le coronavirus en fonction de l'âge (classement pour les 16 à 25 ans)}

Des experts en épidémiologie et virologie

L’Organisation mondiale de la santé (OMS)

Des professionnels de la santé tels que médecins et infirmières

Le porte-parole interfédéral de la lutte contre le covid-19

Le gouvernement fédéral

Le gouvernement régional

Le journal télévisé

Les journaux (Le Soir, La Libre Belgique, L’Écho, Vers l'Avenir...)

Des émissions radio

Des discussions avec vos proches (amis, famille, entourage)

Votre employeur

Des articles partagés par vos proches sur les réseaux sociaux

Des articles de blogs

Des influenceurs sur les réseaux sociaux

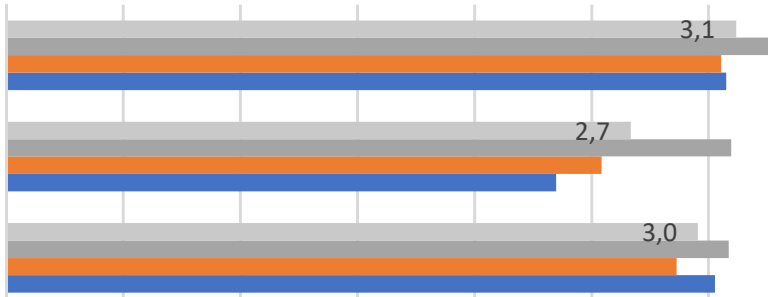

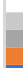
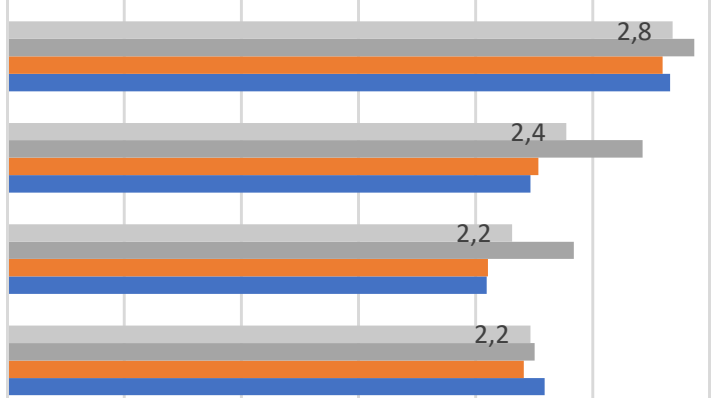

\section{.}

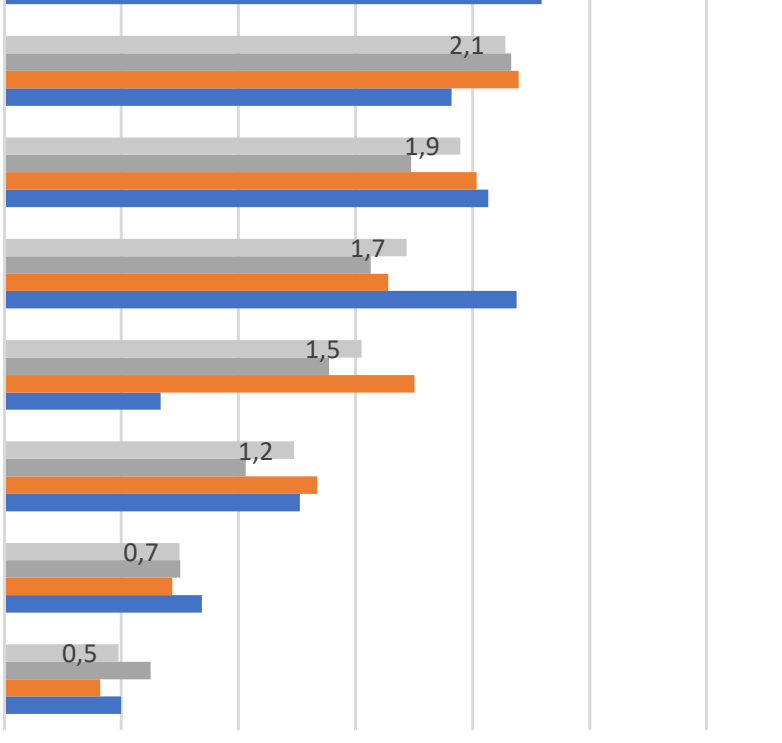

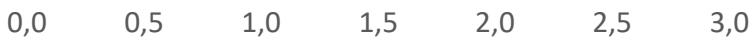

$\square$ Moyenne $\square 16$ à 25 ans $\square 26$ à 65 ans $\quad \square 66$ ans et plus

Q14 : Pour vous informer concernant le coronavirus (Covid-19), à quel point avez-vous confiance dans les sources d'information suivantes ? ( $4=$ Extrêmement ; 3 = Beaucoup ; 2 = Moyennement ; $1=$ Un peu ; 0 = Pas du tout.) 


\section{5. Évaluation de la communication du gouvernement et de la confiance envers les mesures prises}

Après nous être intéressés à la confiance accordée par les Belges francophones à différentes instances comme source d'information, nous les avons interrogés sur la confiance qu'ils accordent aux mesures prises par le gouvernement pour résoudre la crise (notre étude porte donc sur le mesures prises au début de la période de confinement), ainsi que sur leur évaluation de la clarté de ces mesures.

Fig. 9. Analyse de la confiance envers les mesures prises par le gouvernement et de la clarté de sa communication (différence médecins/grand public)

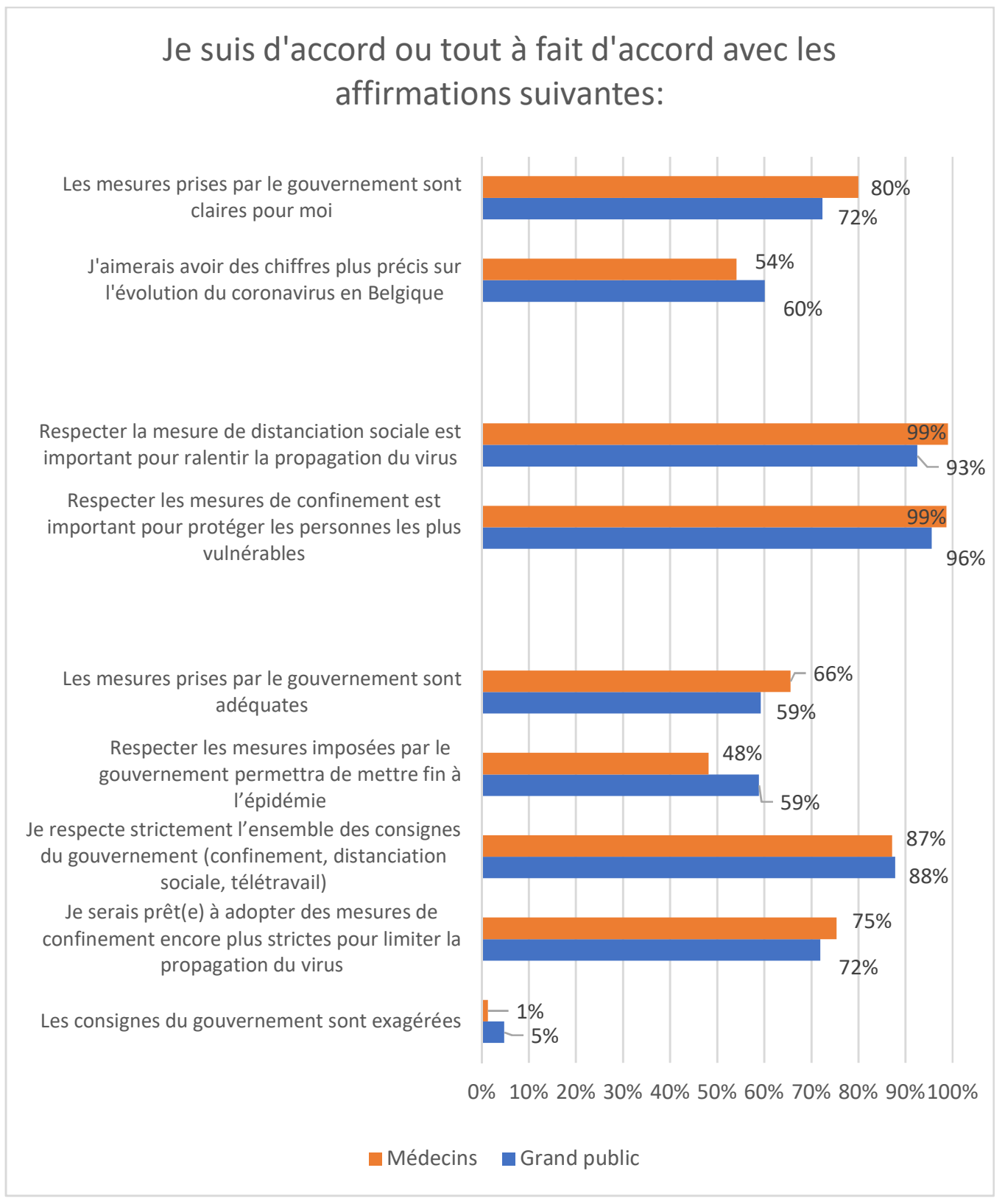

Q10 : Sur une échelle de 1 (pas du tout d'accord) à 5 (tout à fait d'accord), comment évaluez-vous les affirmations suivantes? 


\section{Analyse de la confiance dans les mesures prises}

Pour $72 \%$ des personnes interrogées, les mesures prises par le gouvernement sont bien comprises. Cette proportion monte à $80 \%$ chez les médecins. La communication du gouvernement concernant les mesures à suivre semble donc efficace, même si pour plus d'une personne sur quatre les mesures ne sont pas tout à fait claires.

$59 \%$ des personnes interrogées (66\% des médecins) sont d'accord ou tout à fait d'accord avec l'affirmation selon laquelle " Les mesures prises par le gouvernement sont adéquates » (Seuls $22 \%$ ne sont pas d'accord ou pas du tout d'accord et $19 \%$ ne sont ni d'accord ni pas d'accord). $5 \%$ des belges francophones pensent que les "mesures du gouvernement sont exagérées ». Parallèlement, au moment de l'étude, donc deux à trois semaines après le début du confinement, $72 \%$ des répondants se disent prêts « à adopter des mesures de confinement encore plus strictes ». Si quatre personnes sur dix ne trouvent pas les mesures adéquates, ces chiffres indiquent que pour beaucoup le confinement aurait pu être plus strict.

La confiance dans le type de mesures prises (distanciation sociale, confinement) pour lutter contre l'épidémie et protéger les plus vulnérables est extrêmement élevée, tant dans la population générale que parmi les médecins. Plus de $90 \%$ des répondants pensent que respecter la distanciation sociale et les mesures de confinement est important. $87 \%$ estiment également respecter "strictement " les mesures de confinement.

\section{Analyse de la controverse autour de l'open data}

La question de la production de chiffres sur l'évolution de l'épidémie est devenue centrale dans de nombreux pays, certains étant accusés de produire des chiffres top peu élevés, d'autres, comme la Belgique, à inclure dans les chiffres de décès des décès non liés directement eu Covid-197. II est évident que la mise en scène des chiffres est au cœur de l'activité de production d'information sur la crise du covid-19 par les médias. En Belgique, le rituel est devenu quotidien. Le porte-parole interfédéral annonce le nombre de nouveaux décès et de nouvelles hospitalisations vers 11 heures du matin. Ce chiffre va ensuite faire l'ouverture de tous les bulletins d'information radio et télévision de la journée et être, chaque jour, largement commenté par différents experts.

Au moment de cette enquête, une controverse a émergé en Belgique quant à la qualité des chiffres mis à disposition par Sciensano, l'Institut scientifique de santé publique belge, permettant d'évaluer l'évolution de l'épidémie en Belgique. Le 24 mars certains spécialistes en analyse de données pointent sur Twitter le fait que les données produites par l'Institut ne sont que des données agrégées et ne permettant pas de produire les analyses qu'ils souhaiteraient mener. Cette demande va être ensuite fortement soutenue sur Twitter par différents journalistes, spécialement par des journalistes habitués à produire des infographies ou datavisualisations, puis reprise par des épidémiologistes belges reconnus (notamment Marius Gilbert, un épidémiologiste de l'Université libre de Bruxelles qui est intervenu presque quotidiennement dans les journaux télévisés pour expliquer les chiffres de l'évolution de l'épidémie au public). Cette demande d'ouverture des données a finalement été relayée directement par Emmanuel André, un virologue de la KULeuven, porte-parole officiel de la task force d'experts luttant contre la crise.

\footnotetext{
${ }^{7}$ Un article du New York Time du 21 avril analyse les différences entre pays sur ce point. À ce stade, le mode de comptage belge semble être un des plus précis :

https://www.nytimes.com/interactive/2020/04/21/world/coronavirus-missing-deaths.html
} 
Illustration 2 : Tweets demandant l'ouverture des données au sujet du coronavirus

Marius Gilbert @mariusgilbert.24 mars

La communauté scientifique n'a pas actuellement accès aux données brutes concernant le covid-19. C'est un problème majeur qui nous retarde dans les réponses qui peuvent être données à cette épidémie. II faut d'urgence passer en \#opendata comme le font I'Italie et la France

3 michel henrion @michelhenrion.24 mars

Question intéressante: pourquoi Maggie De Block ne donne-t-elle pas un accès ouvert à toutes les données \#Covid_19 du SPF @SanteBelgique pour permettre de créer de nouveaux services destinés à venir en aide au personnel hospitalier, à la population, etc... facebook.com/groups /davanac...
Q 19
ใน 228
○ 334
$\uparrow$

Emmanuel André

@Emmanuel_microb

En réponse à @mariusgilbert

En tant que scientifique, je soutiens totalement cette demande d'élargir le pool de compétences travaillant à analyser les données épidémiologiques. Les universités et les partenaires privés font partie des ressources nécessaires. \#TousEnsemble \#opendata

3:49 PM . 24 mars 2020 . Twitter Web App

39 Retweets 132 J'aime

Cette demande a par la suite été rapportée par les principaux médias belges francophones ${ }^{8}$. Dès le lendemain, une annonce d'ouverture de certaines données a été annoncée. Une ouverture effective ${ }^{9}$ a été réalisée à partir du 30 mars.

Nous avons interrogé les Belges francophones sur cette question). $60 \%$ sont d'accord ou tout à fait d'accord avec l'affirmation qu'ils aimeraient avoir des chiffres plus précis sur l'évolution du coronavirus en Belgique. C'est spécialement le cas de la classe d'âge des 66 ans et plus, qui sont plus de $75 \%$ à vouloir des chiffres plus précis.

\footnotetext{
${ }^{8}$ Par exemple dans cet article de La Libre Belgique du 25 mars :

https://www.lalibre.be/belgique/societe/coronavirus-l-absence-d-open-data-retarde-les-scientifiques-dans-lalutte-contre-I-epidemie-5e7b1a769978e228414232dc

${ }^{9}$ Annonce par exemple dans cet article : https://www.rtbf.be/info/belgique/detail_quand-le-federal-refuse-douvrir-les-donnees-sur-I-epidemie-de-coronavirus-un-probleme-majeur-qui-retarde-les-

scientifiques?id=10466339
} 


\section{Fig. 10. Analyse de la confiance envers les mesures prises par le gouvernement et de la clarté de sa communication (différence par classe d'âge)}

\section{JE SUIS D'ACCORD OU TOUT À FAIT D'ACCORD AVEC LES AFFIRMATIONS SUIVANTES:}

Les mesures prises par le gouvernement sont claires pour moi

J'aimerais avoir des chiffres plus précis sur l'évolution du coronavirus en Belgique.

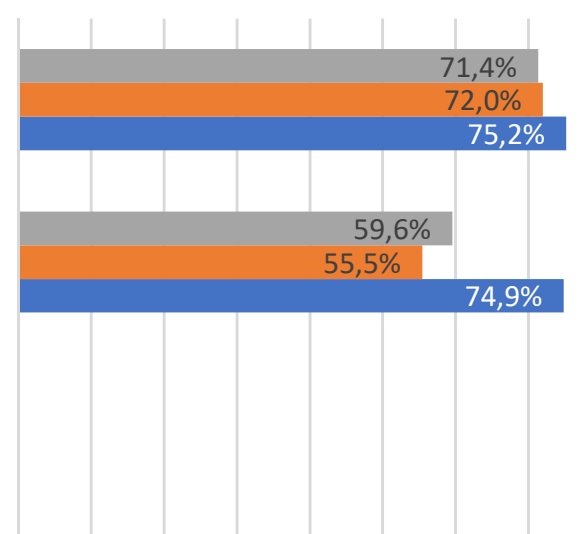

Respecter la mesure de distanciation sociale est important pour ralentir la propagation du virus

Respecter les mesures de confinement est important pour protéger les personnes les plus vulnérables

Les mesures prises par le gouvernement sont adéquates

Respecter les mesures imposées par le gouvernement permettra de mettre fin à l'épidémie

Je respecte strictement l'ensemble des consignes du gouvernement (confinement, distanciation sociale, télétravail)
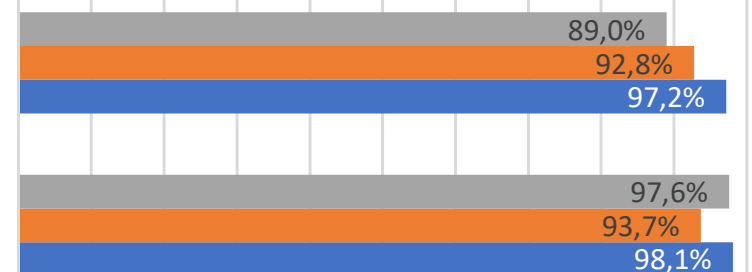

Je serais prêt(e) à adopter des mesures de confinement encore plus strictes pour limiter la propagation du virus

Les consignes du gouvernement sont exagérées

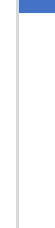
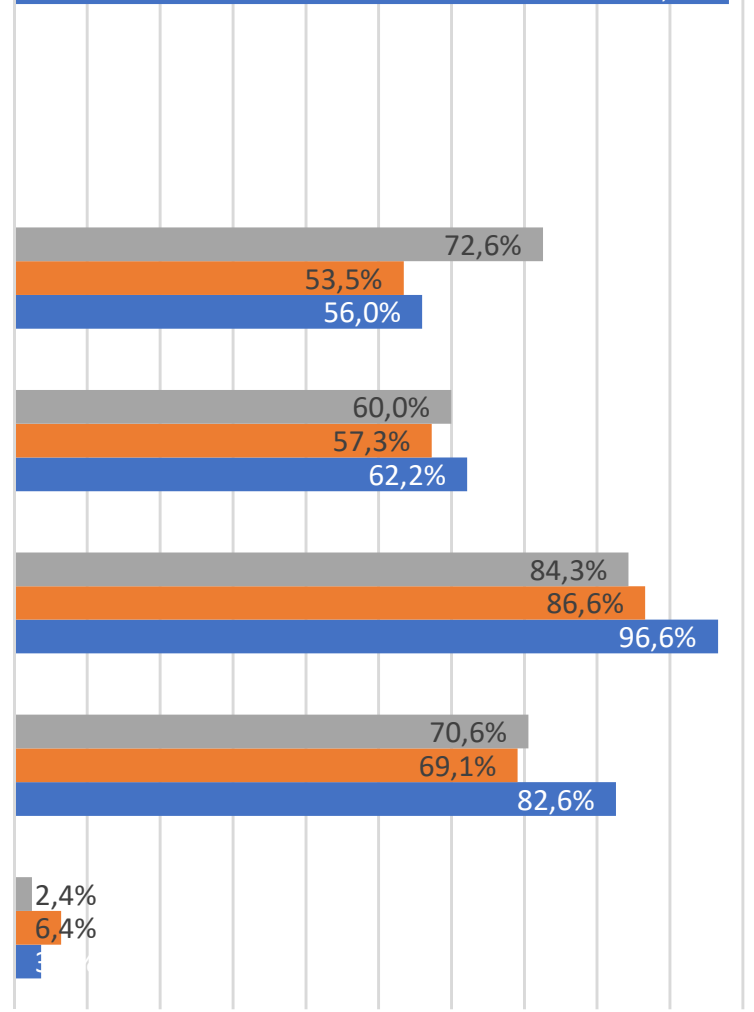

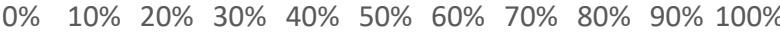

$\square 16$ à 25 ans $\quad 26$ à 65 ans $\quad 66$ ans et plus

Q10 : Sur une échelle de 1 (pas du tout d'accord) à 5 (tout à fait d'accord), comment évaluez-vous les affirmations suivantes? 
Si l'on s'intéresse aux différences entre les classes d'âge sur ces questions, nous voyons que, de manière générale, le niveau de confiance accordée aux mesures prises et le suivi des mesures imposées sont un peu plus élevés (environ 10\%) dans la classe d'âge des 66 ans et plus que dans les deux autres classes d'âge. 


\section{Analyse de la confiance dans les experts et le gouvernement pour prendre des décisions en temps de crise}

Un ensemble de questions porte spécifiquement sur la confiance du public envers les experts pour prendre des décisions à la place du gouvernement dans la période de crise liée à la pandémie de Covid19. Nous avons posé trois questions dont les résultats sont illustrés dans les figures ci-dessous.

La figure 11 présente les réponses à la question: "Dans le climat de crise actuel, nous devrions uniquement faire confiance aux experts pour prendre des décisions. Le gouvernement devrait simplement les appliquer sans les questionner. »

Fig. 11. Dans le climat de crise actuel, nous devrions uniquement faire confiance aux experts pour prendre des décisions. Le gouvernement devrait simplement les appliquer sans les questionner

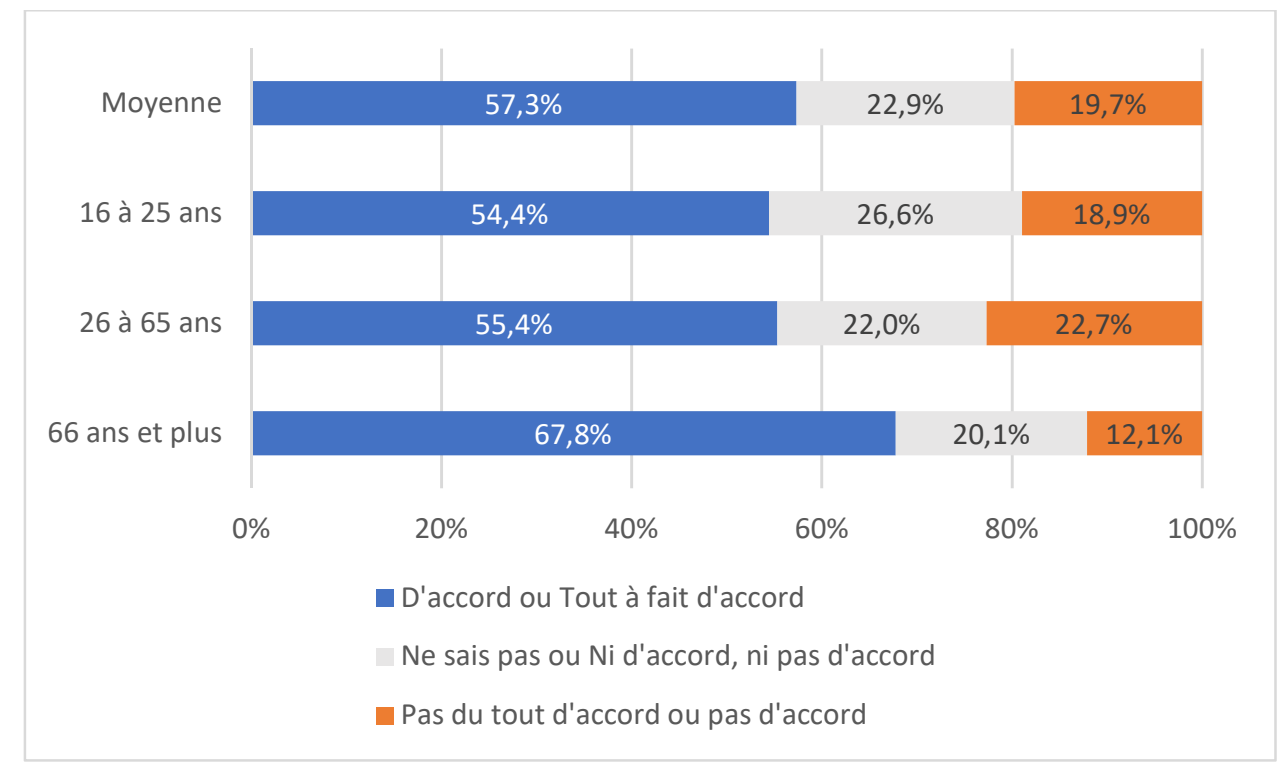

Q15Ba : Dans le climat de crise actuel, nous devrions uniquement faire confiance aux experts pour prendre des décisions. Le gouvernement devrait simplement les appliquer sans les questionner.

En moyenne, près de six Belges sur dix $(57,3 \%)$ pensent que seuls les experts devraient prendre de décision ${ }^{10}$. Seul 1 Belge sur cinq pense que ce n'est pas le cas. Ce sont les plus âgés qui sont en proportion les plus nombreux à avoir cette opinion, avec près d'un senior sur sept $(67,8 \%)$

La figure 12 ci-dessous présente les résultats à la question : «Par rapport à la gestion de l'épidémie, les experts sont les seules personnes capables de trouver les meilleures solutions pour le pays parce que leurs décisions ne sont pas guidées par une idéologie ». Elle évalue l'idée selon laquelle la qualité des experts à prendre de meilleures par rapport à la gestion de l'épidémie provient du caractère objectif (non idéologique) de leur démarche.

\footnotetext{
${ }^{10}$ Des résultats proches ont été observé aux Etas-Unis (cf. McFadden et al. 2020.). Notons par ailleurs qu'une étude réalisée simultanément dans quinze pays au moment de la période de confinement indique une augmentation générale de la confiance envers les gouvernements en place au moment de la crise (Blais, Bol, Giani et al. 2020).
} 
Fig. 12. Par rapport à la gestion de l'épidémie, les experts sont les seules personnes capables de trouver les meilleures solutions pour le pays parce que leurs décisions ne sont pas guidées par une idéologie

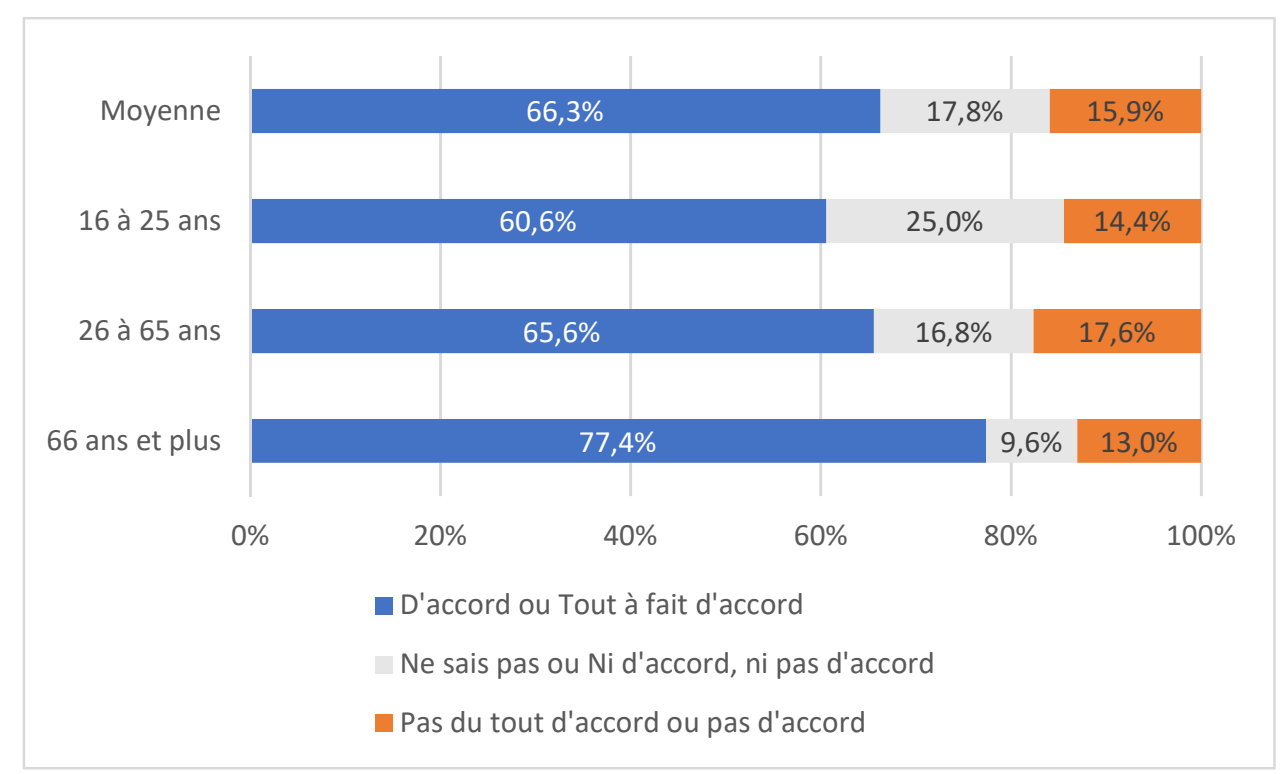

Q15Bb : Par rapport à la gestion de l'épidémie, les experts sont les seules personnes capables de trouver les meilleures solutions pour le pays parce que leurs décisions ne sont pas guidées par une idéologie

Les tendances de réponse à cette question sont relativement similaires à la question précédente. En moyenne plus de deux Belges sur trois $(66,3 \%)$ pensent que seuls les experts sont capables de trouver des solutions pour gérer l'épidémie. Les seniors sont en proportion plus nombreux, plus de trois sur quatre, à partager cette opinion $(77,4 \%)$.

Une dernière question permet de comparer le rôle des experts dans la gestion de l'épidémie à leur rôle dans la gestion de la crise économique : "Par rapport à la gestion de la crise économique, les experts sont les seules personnes capables de trouver les meilleures solutions pour le pays parce que leurs décisions ne sont pas guidées par une idéologie. ". 
Fig. 13. Par rapport à la gestion de la crise économique, les experts sont les seules personnes capables de trouver les meilleures solutions pour le pays parce que leurs décisions ne sont pas guidées par une idéologie

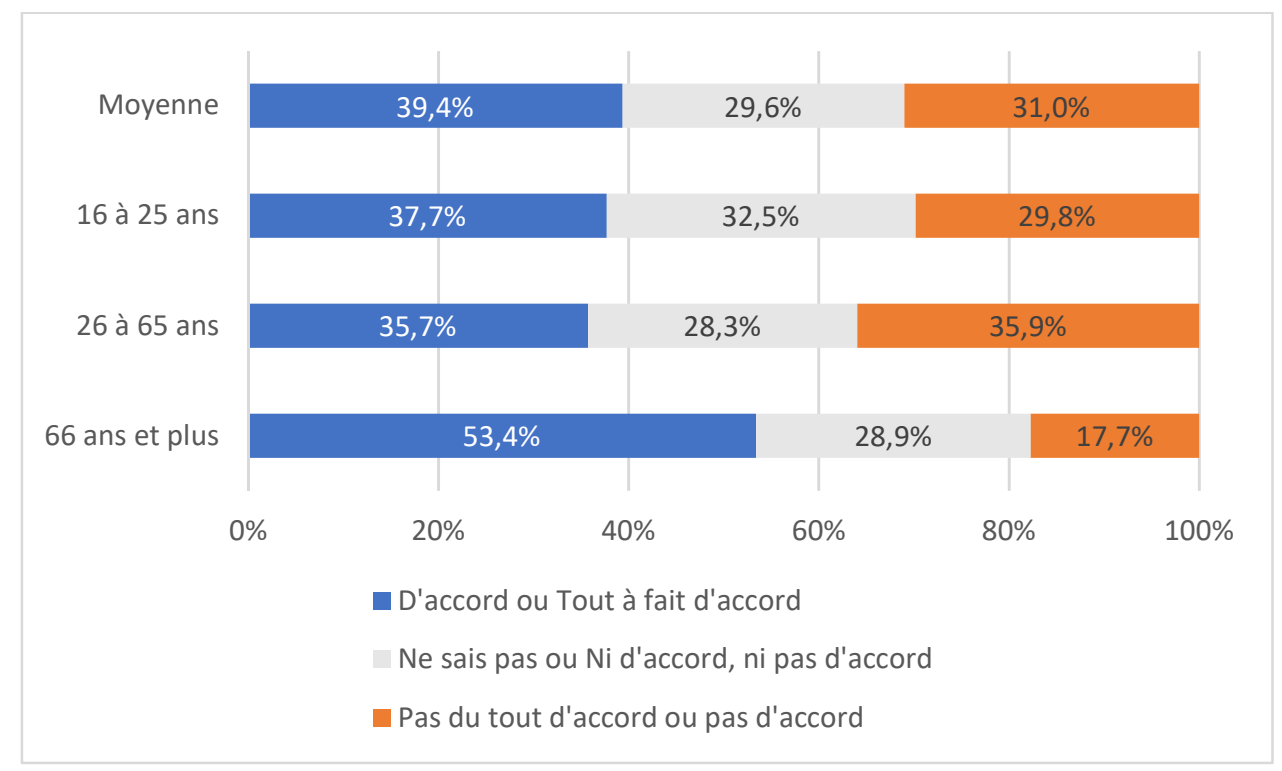

Q15Bc: Par rapport à la gestion de la crise économique, les experts sont les seules personnes capables de trouver les meilleures solutions pour le pays parce que leurs décisions ne sont pas guidées par une idéologie

De manière intéressante, nous voyons une forte différence entre les deux dernières questions. Si deux tiers (66,3\%) des Belges pensent que les experts devraient prendre les décisions pour gérer l'épidémie, ils ne sont plus que quatre sur dix $(39,4 \%)$ à penser cela lorsqu'il s'agit de gérer la crise économique.

Notons que la différence de réponse entre les classes d'âge ici est inverse à celle observée sur le niveau de confiance par rapport aux sources d'information. La catégorie des 66 ans et plus accorde plus facilement sa confiance aux experts lorsqu'il s'agit de décider à la place du gouvernement (question 1), alors qu'elle accorde moins de confiance que les moins de 26 ans aux experts, lorsqu'ils sont considérés comme source d'information uniquement. 


\section{Fake news, théorie du complot et réseaux sociaux. Épidémie et infodémie en Belgique francophone}

\section{Analyse du degré d'information et de l'exposition aux fausses informations}

La première mesure relative à l'infodémie à laquelle nous nous sommes intéressés est celle du niveau d'information à propos du coronavirus que les individus estiment posséder. Le graphique ci-dessous nous montre qu'en moyenne, $41 \%$ des répondants estiment posséder toutes les informations nécessaires pour bien comprendre le coronavirus. 59\% pensent que ce n'est pas le cas ou qu'ils ne savent pas répondre à cette question. Le niveau d'incertitude de la population à l'égard du virus est donc très important.

De manière générale, nous voyons dans les questions portant sur la connaissance du coronavirus (voir infra) que le niveau d'incertitude (réponse = Ne sait pas) est très élevé (entre $20 \%$ et $39 \%$ ). Plus d'une personne sur cinq n'est pas en mesure de répondre aux questions posées.

Fig. 12. J'estime déjà posséder toutes les informations nécessaires pour me permettre de bien comprendre le coronavirus

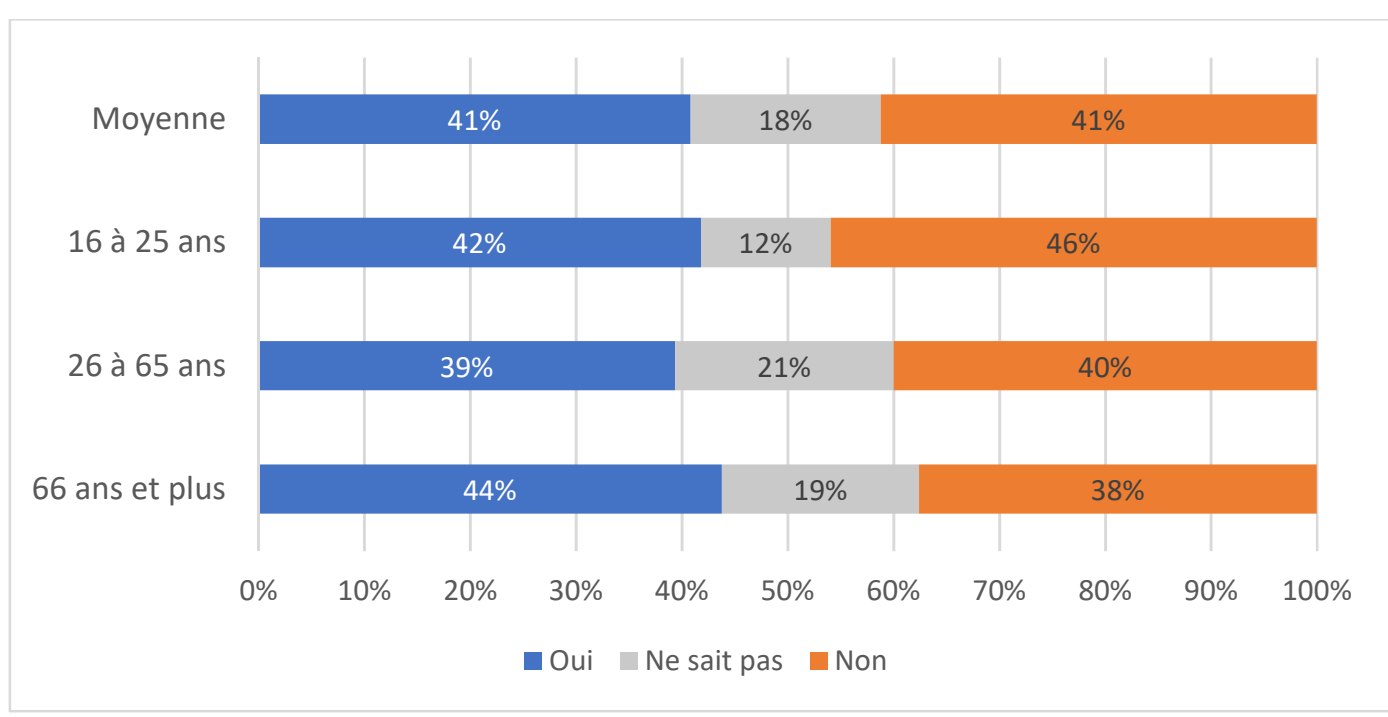

Q17b : Veuillez indiquer dans quelle mesure les affirmations suivantes correspondent à votre perception sur la crise du coronavirus (Covid-19) : «J'estime déjà posséder toutes les informations nécessaires pour me permettre de bien comprendre le coronavirus » (Oui, Non, Ne sait pas).

Il est difficile de mesurer l'exposition réelle d'une personne à de fausses informations. Nous pouvons cependant l'interroger sur la perception qu'elle a de son exposition à ces fausses informations (question : J'estime avoir été exposé à une nouvelle qui s'est avérée fausse au sujet du coronavirus ; oui ; non ; Ne sait pas).

Seuls 30\% des individus pensent ne pas avoir été exposés à de fausses informations au sujet du coronavirus. En moyenne $49 \%$ pensent avoir déjà été exposés à une fausse nouvelle. On note une différence très importante entre les générations, spécialement entre les $16-25$ ans et les 66 ans et plus (respectivement $62 \%$ et $18 \%$ ).

Même si cette question ne porte pas spécifiquement sur les fausses informations véhiculées par les réseaux sociaux, les chiffres de la figure 5 (Utilisation des réseaux sociaux et des messageries de type 
WhatsApp pour partager de l'information sur le coronavirus par classe d'âge) peuvent également s'avérer informatifs dans ce domaine. Alors que les 16 à 25 ans sont les moins nombreux en proportion à avoir partagé des informations sur les réseaux sociaux (39\%), ils sont les plus nombreux à penser avoir été exposés à une fausse information. Parmi les 26 à 65 ans, une personne sur deux estime avoir été exposée (ils sont $66 \%$ à partager des informations) et parmi les 66 ans et plus, ils ne sont que $18 \%$ à penser avoir été exposés (ils sont $36 \%$ à avoir partagé de l'information). Le rapport entre le nombre de partageurs et le nombre des personnes pensant avoir été exposées est donc inverse pour les 16 à 25 ans par rapport aux deux autres catégories.

\section{Fig. 14. Exposition aux fausses informations}

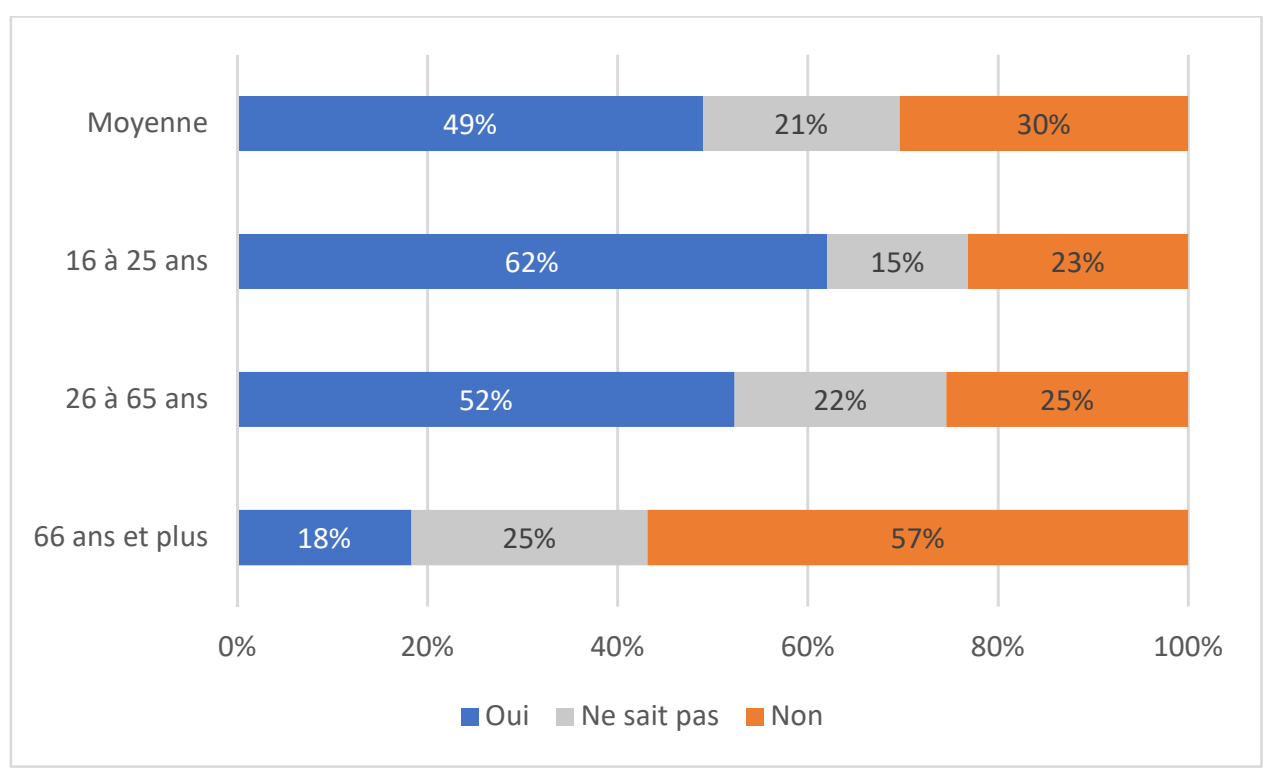

Q17c : Veuillez indiquer dans quelle mesure les affirmations suivantes correspondent à votre perception sur la crise du coronavirus (Covid-19) : "J'estime avoir été exposé à une nouvelle qui s'est avérée fausse au sujet du coronavirus » (Oui, Non, Ne sait pas).

Nous pouvons également évaluer dans quelles mesures les individus pensent avoir participé à la propagation de mauvaises informations. La figure 15 ci-dessous montre les réponses à la question : "Avez-vous par inadvertance partagé de mauvaises informations sur les réseaux sociaux ou une messagerie du type WhatsApp ? ». Elle ne permet pas de mesurer le taux de personnes qui ont effectivement partagé de mauvaises informations, mais donne une idée de la perception que les individus ont de leurs propres pratiques face à cette question. En moyenne, une personne sur vingt reconnait avoir partagé sans le vouloir de mauvaises informations. Elles sont deux fois plus nombreuses dans la classe d'âge des plus de 66 ans (une sur dix, 10\%). Parmi les Belges francophones qui ont déclaré avoir partagé de l'information sur le coronavirus sur les réseaux sociaux ou des services de messagerie instantanée, 10,3\% reconnaissent avoir partagé de mauvaises informations. Cette proportion monte à $25,6 \%$ pour la classe d'âge des 66 ans et plus. 
Fig. 15. Avez-vous par inadvertance partagé de mauvaises informations sur les réseaux sociaux ou une messagerie du type WhatsApp ?

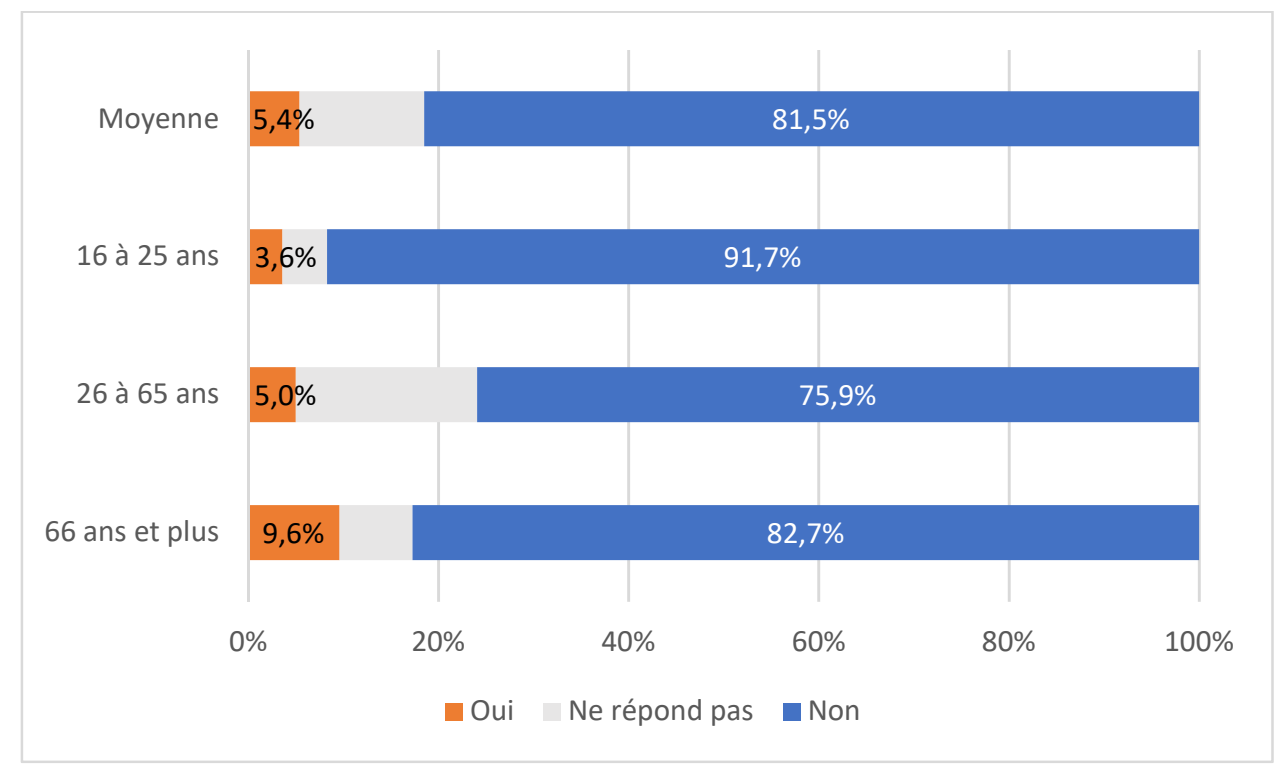

Q13b. Avez-vous par inadvertance partagé de mauvaises informations sur les réseaux sociaux ou une messagerie du type WhatsApp ? (Oui, Non, Ne répond pas).

\section{Théorie du complot et manipulation de l'information par le gouvernement}

L'origine du virus étant encore en partie incertaine, différentes théories ont été véhiculées dans les médias. À l'heure d'écrire ces pages, la réponse officielle de l'OMS à ce sujet est la suivante :

« Pour le moment, nous ne savons pas quelle est l'origine du SARS-CoV-2, le coronavirus (CoV) responsable de la COVID-19. Toutes les données scientifiques disponibles laissent supposer que le SARS-CoV-2 a une origine animale naturelle et n'est pas un virus artificiel. II est plus que probable que les chauves-souris en sont le réservoir naturel. Le SARS-CoV-2 appartient à un groupe de virus génétiquement apparentés, dans lequel on retrouve également le SARS-CoV et plusieurs autres coronavirus isolés chez certaines populations de chauves-souris. Bien qu'appartenant au même groupe, le MERS-CoV en est plus éloigné. $»^{11}$

Malgré cette information claire sur le fait que le virus n'est très vraisemblablement pas d'origine artificielle, circule l'information que ce virus aurait été créé dans un laboratoire pharmaceutique situé dans la région de Wuhan en Chine. La circulation importante de cette théorie aurait commencé au début du mois d'avril, soit à une date antérieure aux relais qu'en ont fait les médias traditionnels belges suite à des propos d'officiels américains affirmant qu'une enquête sur le sujet était en cours. ${ }^{12}$. Nous avons cherché à évaluer dans quelle mesure cette opinion était présente dans la population belge

\footnotetext{
${ }^{11}$ https://www.who.int/fr/emergencies/diseases/novel-coronavirus-2019/advice-for-public/q-a-coronaviruses consulté le 28 avril 2020.

12 Voir par exemple : RTBF Info 17 avril : https://www.rtbf.be/info/societe/detail fuite-de-virus-d-unlaboratoire-le-risque-zero-n-existe-pas-selon-les-scientifiques?id=10484429

La Libre Belgique le 16 avril : https://www.lalibre.be/international/asie/un-coronavirus-venu-de-wuhan-ouimais-d-un-marche-ou-d-un-laboratoire-5e988552d8ad58632c73b0b8

Le Soir 17 avril : https://www.lesoir.be/295255/article/2020-04-17/ce-que-lon-sait-sur-le-labo-chinoissuspecte-detre-lorigine-du-coronavirus

La Dernière Heure 6 avril : https://www.dhnet.be/actu/monde/le-coronavirus-s-est-il-echappe-d-unlaboratoire-en-chine-c-est-en-tout-cas-I-avis-partage-par-certains-politiciens-britanniques-

5e8b361b9978e228414e9631
} 
francophone. Avant de nous pencher sur ces chiffres, nous pouvons les contextualiser, en regard de la proportion d'individus qui estiment clairement que le gouvernement leur cache des informations importantes au sujet du coronavirus. Le graphe ci-dessous illustre le fait qu'une personne sur trois en Belgique francophone (32\%) pense que le gouvernement leur cache des informations importantes. Seuls $41 \%$ de Belges francophones pensent que ce n'est pas le cas.

Fig. 16. J'estime que mon gouvernement cache des informations importantes entourant le coronavirus

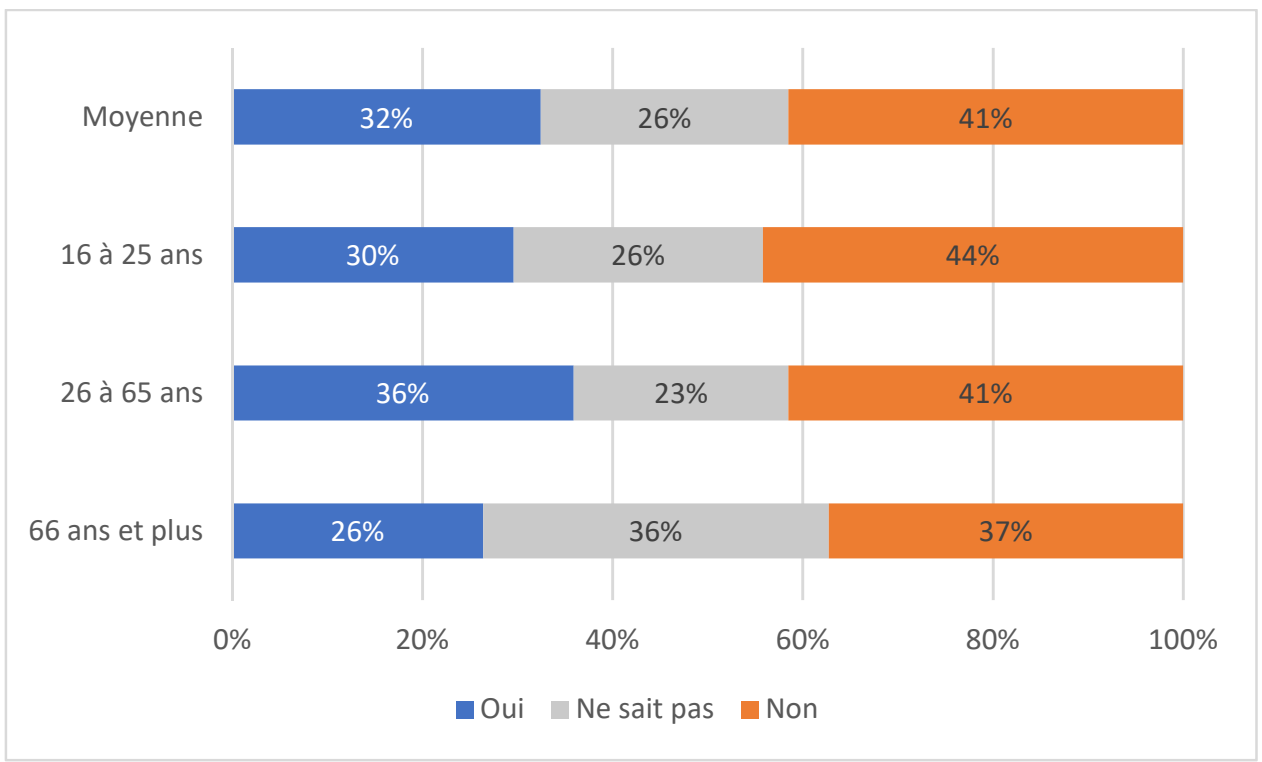

Q17d : Veuillez indiquer dans quelle mesure les affirmations suivantes correspondent à votre perception sur la crise du coronavirus (Covid-19) : J'estime que mon gouvernement cache des informations importantes entourant le coronavirus »(Oui, Non, Ne sait pas).

Nous avons posé deux questions relatives à l'origine du coronavirus. Dans une première question, nous voulions savoir si, pour le répondant, le coronavirus était un " phénomène naturel »; dans la seconde, nous demandions précisément si le coronavirus était « issu d'un laboratoire ».

Concernant la première question, un Belge sur deux pense que le coronavirus est un phénomène naturel. Une différence forte existe entre les générations quant au degré d'incertitude face à cette question (réponse « Ne sait pas »). En moyenne $27 \%$ des répondants sont incertains, cette proportion monte à $36 \%$ pour les 66 ans et plus. Les 66 ans et plus sont les plus nombreux à douter du fait qu'il s'agisse d'un phénomène naturel (63\%). Les moins de 26 ans sont les moins nombreux à douter qu'il s'agisse d'un phénomène naturel (40\%).

Près de $90 \%$ des réponses à notre enquête datant d'avant le 17 avril, il serait intéressant d'étudier l'évolution de cette information au-delà de cette date. 
Fig. 17. J'estime que le coronavirus est un phénomène naturel

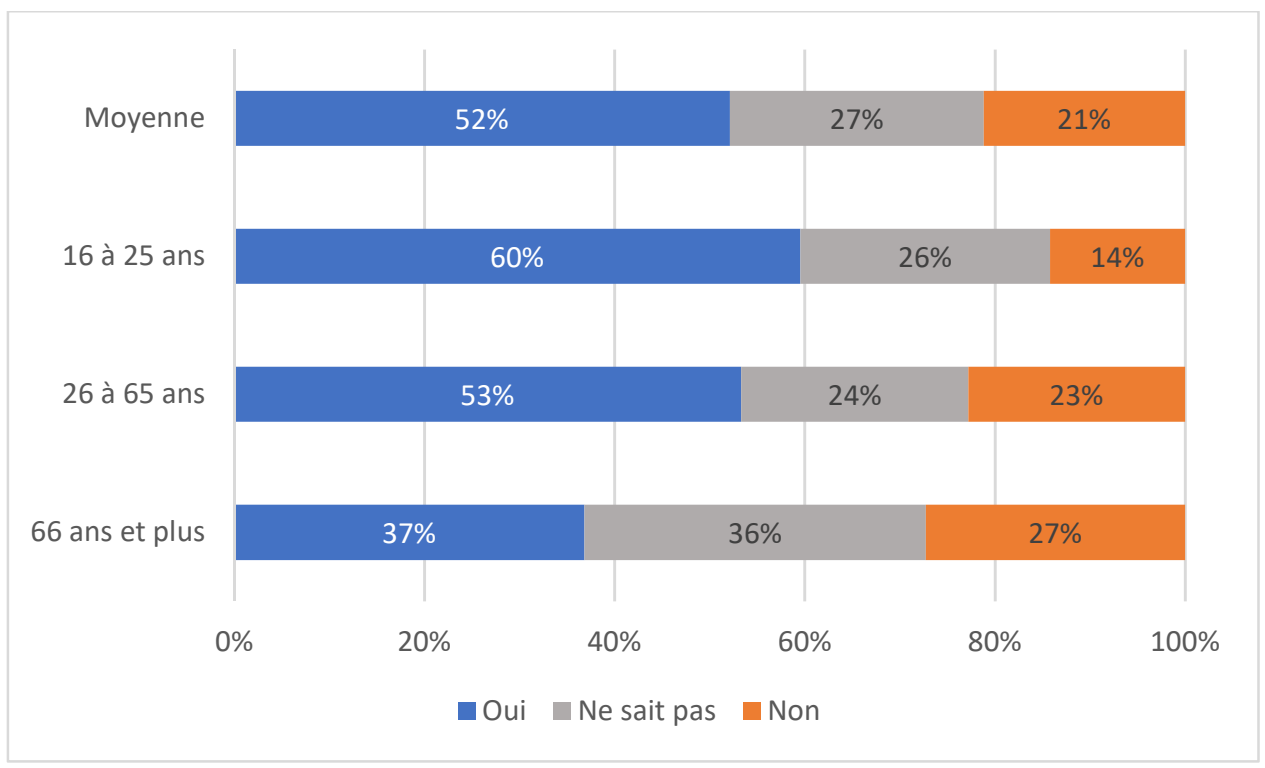

Q17a : Veuillez indiquer dans quelle mesure les affirmations suivantes correspondent à votre perception sur la crise du coronavirus (Covid-19) : J'estime que le coronavirus est un phénomène naturel » (Oui, Non, Ne sait pas).

Concernant la seconde question qui teste la théorie selon laquelle le coronavirus aurait été créé dans un laboratoire, $11 \%$ des répondants le pensent effectivement. II faut noter que le niveau d'incertitude sur cette question est aussi élevé que pour les autres et s'élève à $29 \%$. Notons également que si $71 \%$ des 16-25 ans pensent que ce n'est pas le cas, cette proportion descend à 59\% pour les 26-65 ans et à $50 \%$ pour les 66 ans et + . Les jeunes seraient donc plus critiques face à cette théorie que les plus âgés. 
Fig. 18. J'estime que le coronavirus est issu d'un laboratoire

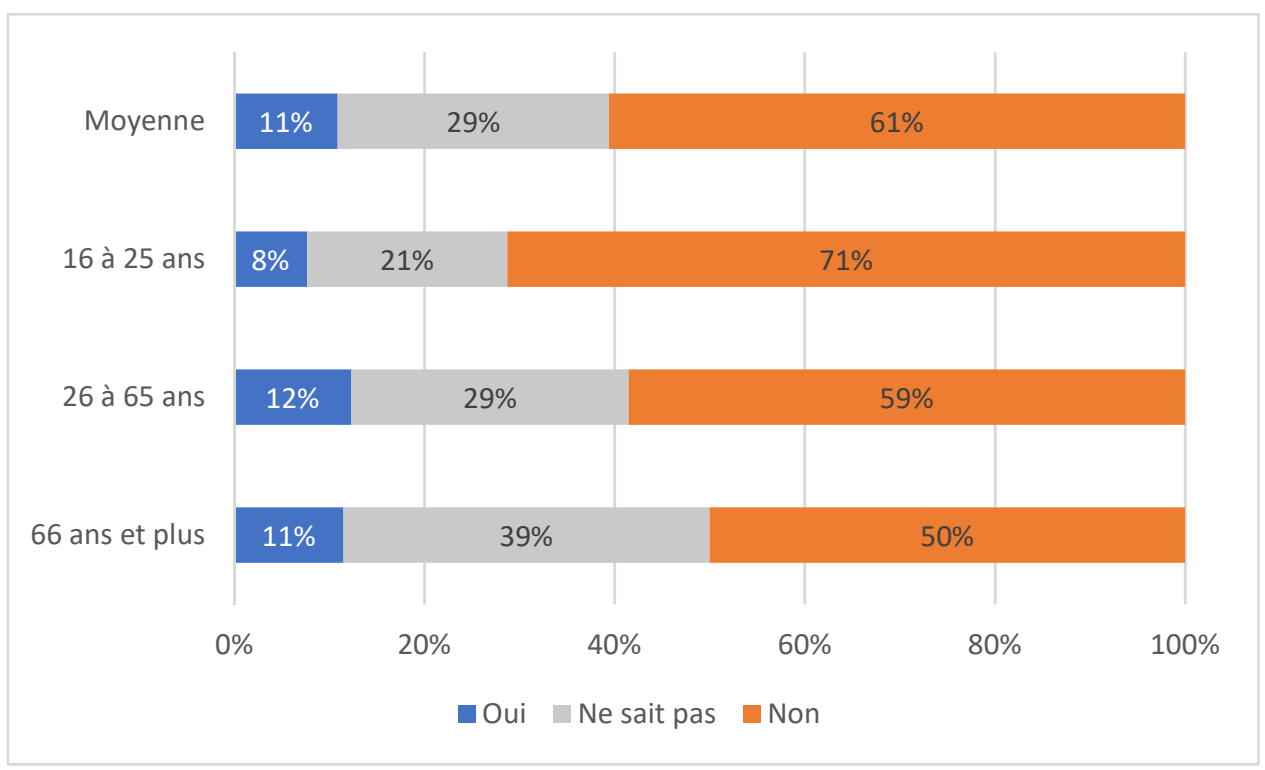

Q17e : Veuillez indiquer dans quelle mesure les affirmations suivantes correspondent à votre perception sur la crise du coronavirus (Covid-19) : J'estime que le coronavirus est issu d'un laboratoire » (Oui, Non, Ne sait pas).

Une autre théorie qui circule au sujet du coronavirus est celle de la préexistence d'un vaccin ou d'un médicament permettant de le soigner ${ }^{13}$. La question des médicaments existants est également au cœur d'une controverse très vive en France relative à l'efficacité de l'hydroxychloroquine, un médicament antipaludique existant, pour lutter contre le covid-19 ${ }^{14}$.

Selon l'OMS cependant, « rien ne prouve que les médicaments actuels permettent de prévenir ou de guérir la maladie ${ }^{15}$. Nous avons voulu tester la prévalence de l'opinion selon laquelle un médicament existerait déjà pour soigner le Covid-19. Le niveau de prévalence de cette idée parmi nos répondants est relativement similaire à celui de l'idée de la création du coronavirus dans un laboratoire et s'élève à $12 \%$. La distribution du niveau d'incertitude entre les générations est également relativement similaire. Les moins de 26 ans sont plus sûrs d'eux et plus nombreux à affirmer que ce n'est pas le cas (69\%).

\footnotetext{
${ }^{13}$ https://fr.wikipedia.org/wiki/D\%C3\%A9sinformation sur la pand\%C3\%A9mie de Covid-

19\#Pr\%C3\%A9existence du vaccin

${ }^{14}$ Les controverses autour de l'hydroxychloroquine ont été particulièrement relayée dans les médias qui ont couvert les travaux, et controverses liées, du professeur français Didier Raoult. Voir par exemple parmi beaucoup d'autres : RTBF Info le 10 avril 2020 https://www.rtbf.be/info/societe/detail la-chloroquine-pourlutter-contre-le-coronavirus-nouveaux-resultats-et-nouvelles-critiques-pour-raoult?id=10479997. Ou DH Les Sports 2 avril 2020 : https://www.dhnet.be/actu/sante/chloroquine-le-professeur-raoult-defend-son-bilan$\underline{5 e 86348 c d 8 a d 581631 a 49 f 06}$

15 https://www.who.int/fr/emergencies/diseases/novel-coronavirus-2019/advice-for-public/q-a-coronaviruses consulté le 29 avril 2020.
} 
Fig. 19. J'estime qu'il existe déjà un médicament contre le coronavirus

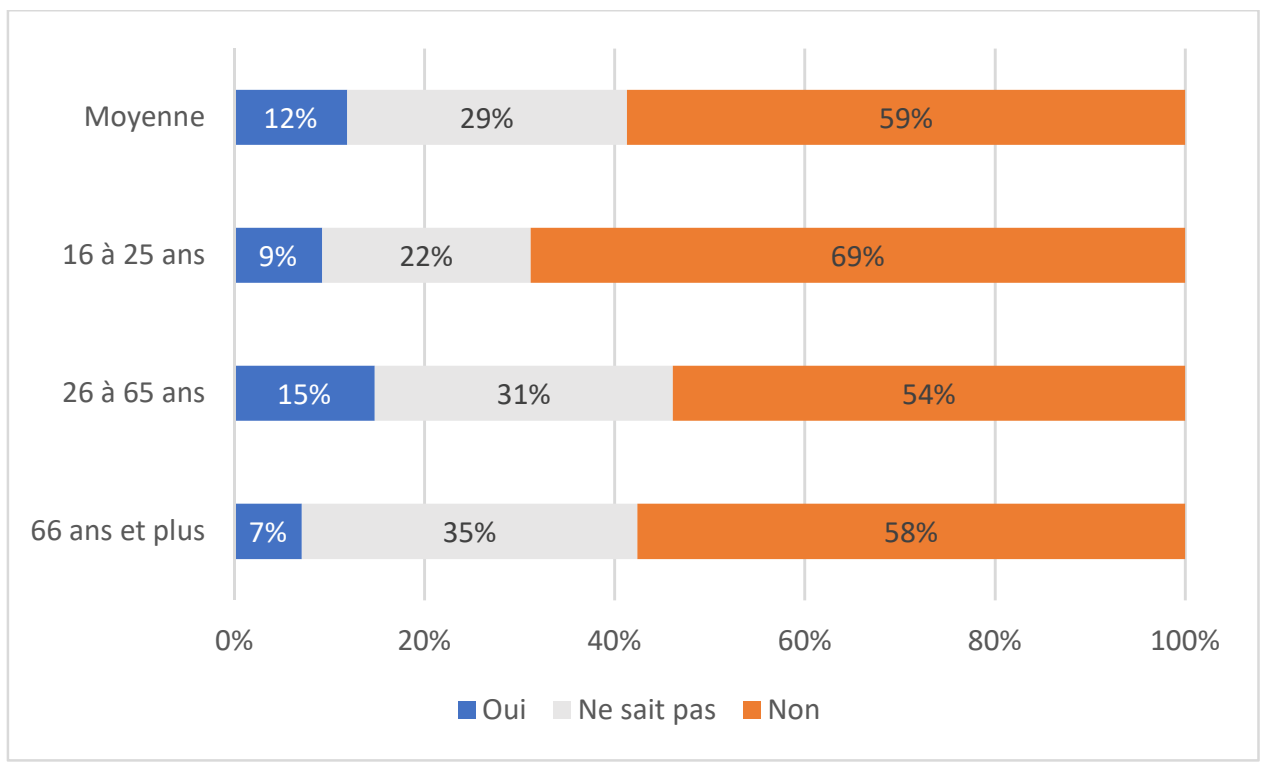

Q17f : Veuillez indiquer dans quelle mesure les affirmations suivantes correspondent à votre perception sur la crise du coronavirus (Covid-19) : J'estime qu'il existe déjà un médicament contre le coronavirus » (Oui, Non, Ne sait pas).

\section{Fake news sur le coronavirus : $27^{\circ}$ et boisson chaude}

Lors de la seconde moitié du mois de mars, un message reprenant différents conseils de protection contre le coronavirus a été largement partagé en Belgique et en France ${ }^{16}$ par différents canaux, notamment la messagerie WhatsApp. Se présentant comme étant "les conseils d'un ami médecin ", ce message débutait en donnant le conseil suivant :

"Le virus ne résiste pas à la chaleur et meurt s'il est exposé à des températures supérieures à 26-27 degrés. II faut donc consommer abondamment pendant la journée des boissons chaudes comme des infusions, bouillons ou simplement de l'eau chaude : ces liquides chauds neutralisent le virus et sont faciles à ingérer. "

(Copie du contenu d'un message WhatsApp reçu le 27 mars 2020. )

\footnotetext{
${ }^{16}$ Source : voir notamment l'article paru sur le site de France Inter :

https://www.franceinter.fr/societe/message-d-un-ami-medecin-ces-conseils-recus-par-whatsapp-sur-lecoronavirus-sont-pleins-de-fake-news.
} 
Illustration 3 : Copie d'écran du message WhatsApp reçu le 27 mars 2020.

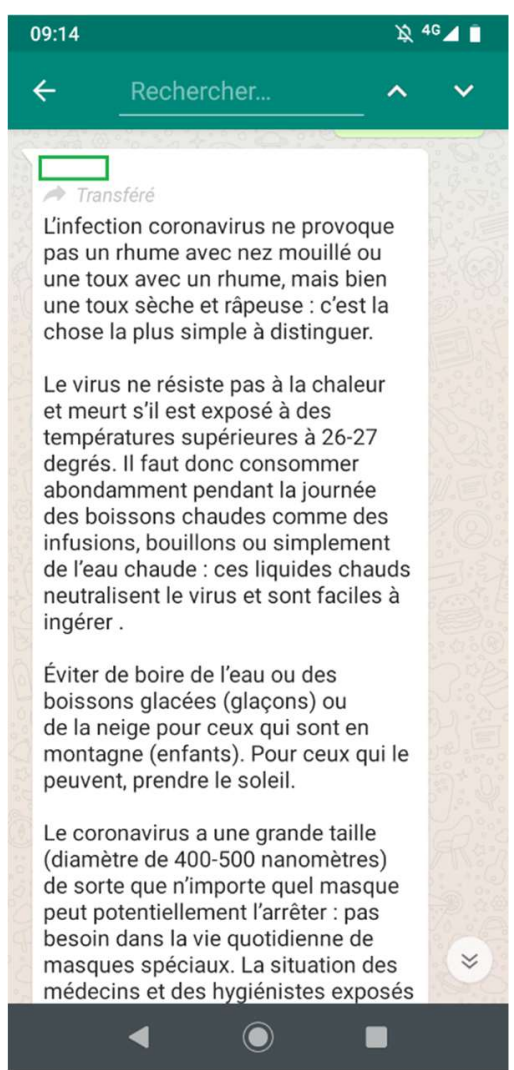

Nous avons voulu tester la diffusion de ces deux informations (" le virus meurt s'il est exposé à une température de 27 degrés " et « la consommation de boissons chaude est un moyen efficace de lutte contre le virus ».) en posant les deux questions suivantes :

Q18b : Veuillez indiquer dans quelle mesure les affirmations suivantes correspondent à votre perception sur la crise du coronavirus (Covid-19) : J'estime que le coronavirus meurt s'il est exposé à une température 27 degrés Celsius.

Q16b : Lesquelles des actions suivantes avez-vous prises spécifiquement pour vous protéger du coronavirus et de ses effets? Boire des boissons chaudes.

Au moment de l'enquête près d'une personne sur cinq (17\%) des répondants déclarent boire des boissons chaudes spécifiquement pour se protéger du coronavirus. Cette proportion est plus élevée pour les 66 ans et plus (21\%) et la moins élevée pour les 16 à 25 ans (15\%). 
Fig. 20. Je bois des boissons chaudes pour me protéger du coronavirus

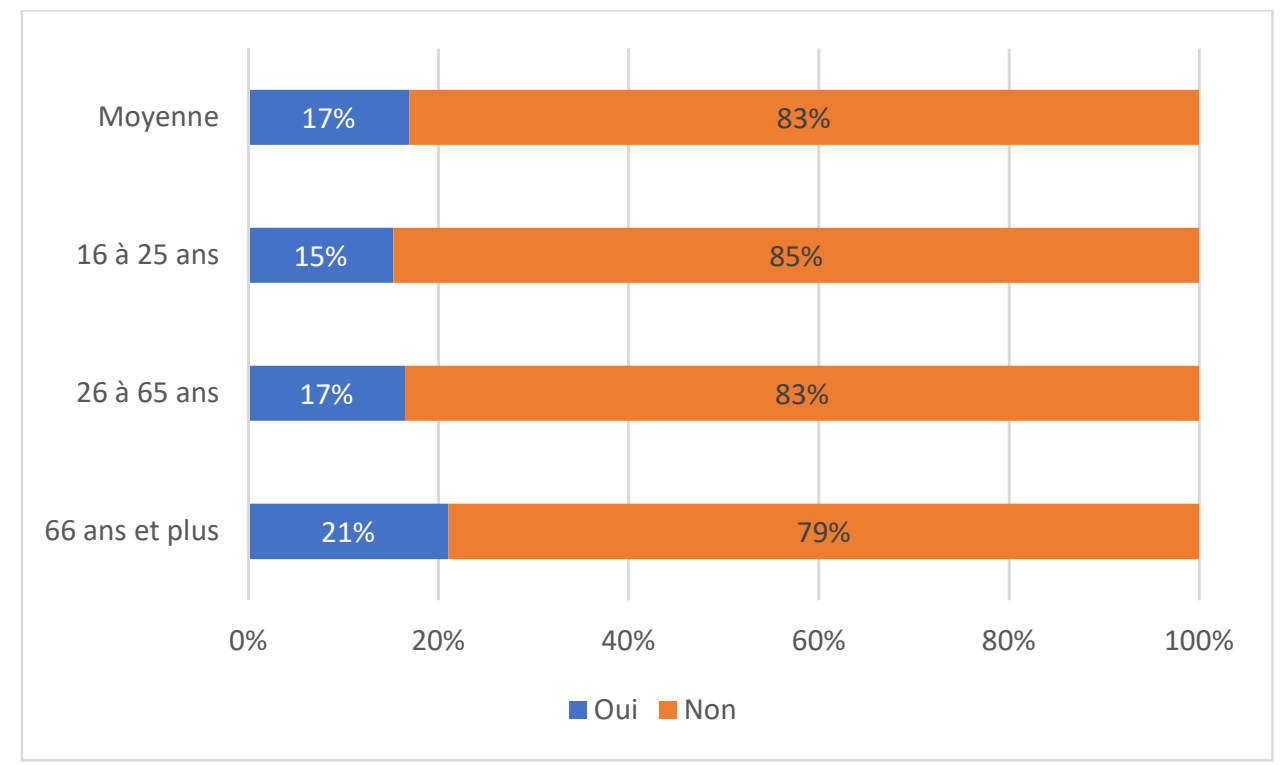

Q16b : Lesquelles des actions suivantes avez-vous prises spécifiquement pour vous protéger du coronavirus et de ses effets ? Boire des boissons chaudes. (Oui, Non)

L'information selon laquelle le virus meurt s'il est exposé à une température de 27 degrés est moins répandue. Elle n'est partagée que par une personne sur vingt (5\%). Le niveau d'incertitude (Ne sait pas) face à cette question est cependant particulièrement élevé (il est le plus élevé pour toutes les questions posées) et s'élève à $39 \%$.

À nouveau, les jeunes semblent plus critiques face à cette information, avec $61 \%$ des moins de 26 ans qui estiment cette information fausse. 
Fig. 21. Le coronavirus meurt s'il est exposé à une température 27 degrés Celsius

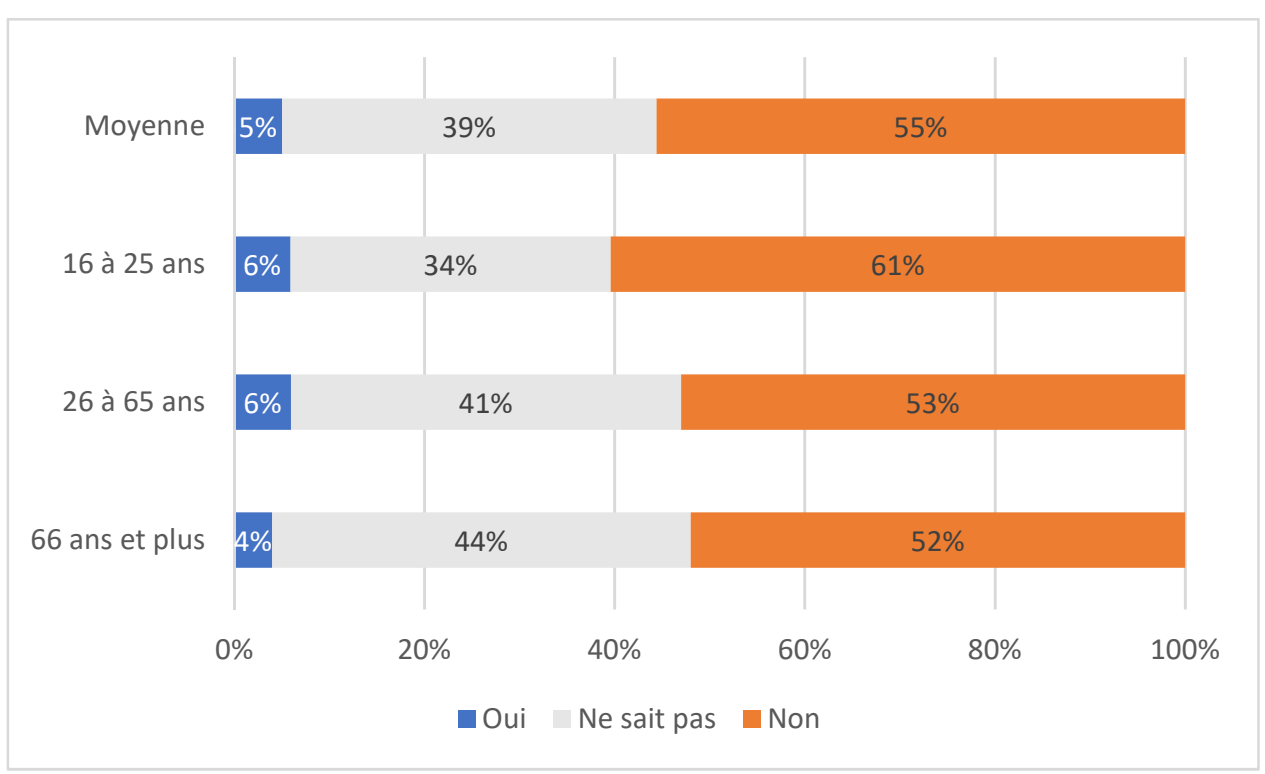

Q18b : Veuillez indiquer dans quelle mesure les affirmations suivantes correspondent à votre perception sur la crise du coronavirus (Covid-19) : J'estime que le coronavirus meurt s'il est exposé à une température 27 degrés Celsius. (Oui, Non, Ne sait pas).

\section{Controverse sur le mode de transmission : la transmission par aérosol.}

Nous nous sommes également intéressés à la question de l'incertitude régnant sur le mode de propagation du virus et à la controverse, largement relayée dans les médias belges, autour de la transmission possible du virus par aérosol.

Le 25 mars, le virologue indépendant Marc Wathelet publie une opinion dans le site web Sudlnfo (groupe SudPresse). Il y défend ouvertement un avis contraire à celui des « experts qui conseillent le gouvernement ${ }^{17}$ et s'oppose à l'avis officiel de l'OMS pour qui le virus se propage principalement « par contact avec des gouttelettes respiratoires, plutôt que par voie aérienne. ${ }^{18}$. Dans cette lettre ouverte, l'expert défend un point de vue opposé à celui de l'OMS et note que :

« La première faute de l'OMS était de ne pas reconnaître que la transmission par aérosol ${ }^{19}$ était substantielle et que donc il fallait changer les recommandations pour contenir la propagation du virus, ce qu'ils n'ont toujours pas fait. ".

\footnotetext{
${ }^{17}$ https://www.sudinfo.be/id175891/article/2020-03-25/il-y-urgence-la-lettre-ouverte-du-virologue-marcwathelet-qui-plaide-pour-un. Une première version de cet argument avait déjà été publiée dans le journal Le Spécialiste le 8 mars : https://www.lespecialiste.be/fr/debats/lettre-ouverte-nbsp-a-la-premiere-ministre-ilfaut-faire-passer-le-pays-en-phase-3-sans-plus-attendre-dr-marc-wathelet.html. Ainsi que le 28 février dans le Journal du médecin : https://www.lejournaldumedecin.com/actualite/coronavirus-lettre-ouverte-a-maggie-deblock/article-opinion-46013.html?cookie check=1587818845.

${ }^{18} \mathrm{https} / / /$ www.who.int/fr/emergencies/diseases/novel-coronavirus-2019/advice-for-public/q-a-coronaviruses consulté le 25 avril 2020.

${ }^{19}$ Dans un autre article publié sur le site web du journal (destiné aux médecins spécialistes belges), le spécialiste Marc Wathelet définit la notion d'aérosol et les dangers associés de la manière suivante: "Un aérosol, littéralement une solution dans l'air, consiste en microgouttelettes qui sont si petites qu'elles restent en suspension dans l'air ou retombent beaucoup plus lentement que des postillons. Elles sont produites lors d'une respiration normale et cette production est accélérée en parlant ou encore plus en chantant. Le danger des aérosols est qu'ils peuvent transmettre le virus sur de plus grandes distances et entre personnes qui n'interagissent pas face à face. »
} 
Il en découle que selon lui la mesure de distanciation sociale limitée à 1,5 mètre en Belgique n'est pas suffisante.

Cette opinion va être largement diffusée et reprise par les principaux journaux et médias belges francophones : par exemple par la RTBF dans son journal télévisé du 7 mars ainsi que sur son site web $^{20}$. Dans La Libre Belgique le 20 mars $^{21}$, dans l'Écho le 19 mars $^{22}$. Dans Le Soir du 3 avril cette proposition est nuancée en précisant que ce mode de transmissions est "secondaire ", mais qu'il « n'est pas à exclure » et renvoie à différentes études en cours sur le sujet ${ }^{23}$.

Notre étude montre que la thèse de la diffusion par aérosol est largement présente dans la perception du virus par le public. En moyenne, $67 \%$ des répondants (deux sur trois) pensent que le coronavirus se propage par aérosol et seuls $8 \%$ pensent que ce n'est pas le cas. Le niveau d'incertitude (" Ne sait pas $")$ est relativement similaire par rapport aux autres questions (25\%), ce qui montre que la notion de diffusion par aérosol, très technique, est donc relativement bien comprise par le public, sans quoi le niveau d'incertitude aurait été plus élevé ${ }^{24}$. Le niveau de prévalence de ce trait attribué au coronavirus est beaucoup plus élevé que les autres faits faux ou controversés étudiés (ce qui peut, peut-être en partie être expliqué par la tournure différente de la question et l'usage de verbe " peut »).

Notons à nouveau que la tranche d'âge la plus critique face à cette idée est le groupe d'âge des 16 à 25 ans, même si cela représente toute de même plus d'un jeune sur deux.

\footnotetext{
${ }^{20}$ https://www.rtbf.be/info/societe/detail_le-coronavirus-peut-il-etre-transmis-par-aerosol?id=10450509

${ }^{21}$ https://www.lalibre.be/debats/opinions/coronavirus-le-virologue-marc-wathelet-repond-au-virologue-marcvan-ranst-je-reste-mystifie-par-I-idee-qu-il-aurait-fallu-garder-les-ecoles-ouvertes-5e73c2e1f20d5a29c678fbc1 22 https://www.lecho.be/dossiers/coronavirus/si-le-coronavirus-se-transmet-par-l-air-la-distanciation-socialesuffit-elle/10215319.html.

${ }^{23}$ https://plus.lesoir.be/292208/article/2020-04-03/la-transmission-du-coronavirus-dans-lair-reste-secondaire

${ }^{24}$ Ce qui n'est pas le cas dans d'autres pays. Lors de la construction d'une étude similaire lancée au Canada francophone, nous avons par exemple dû supprimer cette question car nos collègues canadiens ne comprenaient pas le sens de cette notion de " diffusion par aérosol ».
} 
Fig. 22. J'estime que le coronavirus peut se propager de manière aérosol

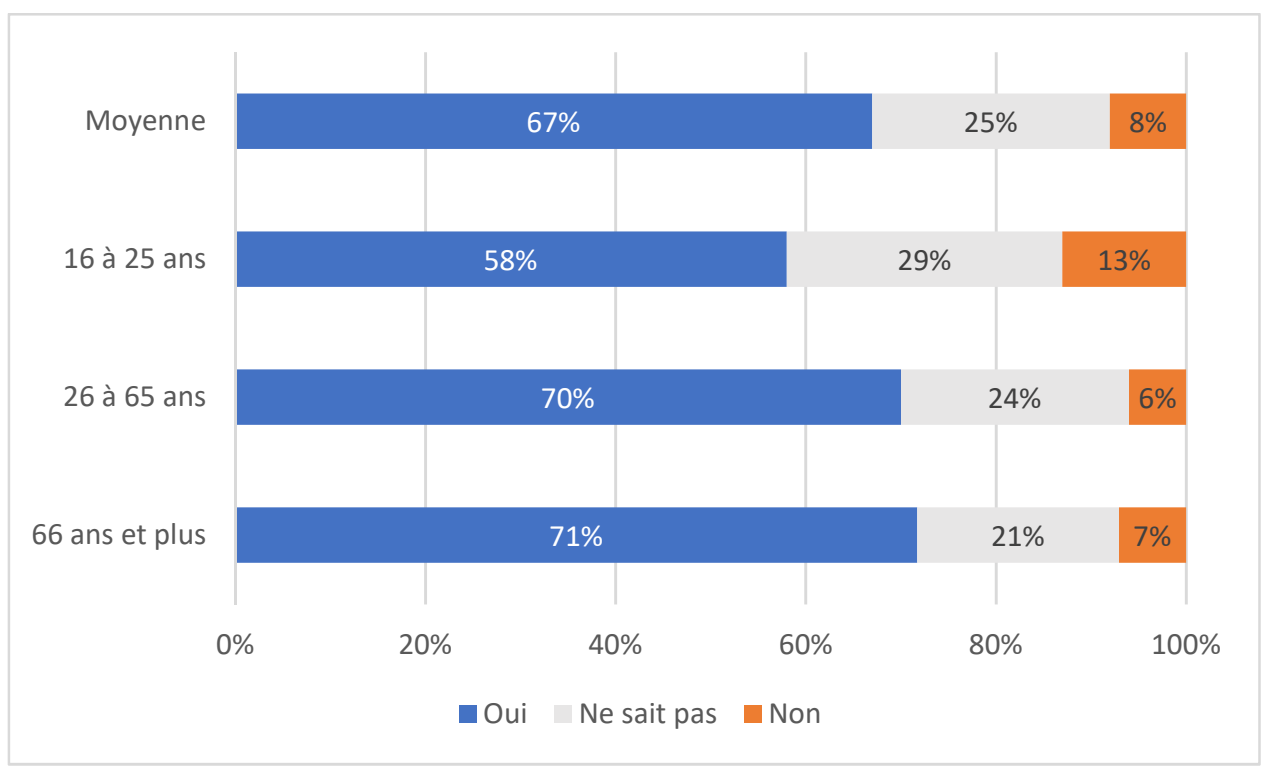

Q18a : Veuillez indiquer dans quelle mesure les affirmations suivantes correspondent à votre perception sur la crise du coronavirus (Covid-19) : J'estime que le coronavirus peut se propager de manière aérosol. (Oui, Non, $\mathrm{Ne}$ sait pas). 


\section{Niveau de connaissances factuelles sur le coronavirus et l'épidémie (différence médecins/grand public)}

Les figures ci-dessous reprennent les réponses à la question : "Veuillez indiquer dans quelle mesure les affirmations suivantes correspondent à votre perception sur la propagation du coronavirus (Covid-19). »

Nous voyons que pour certaines questions (notamment la dernière : «j'estime que la grande majorité de la population va attraper le coronavirus ", les réponses entre médecins et grand public peuvent différer plus ou moins fortement.

\section{Fig. 23. Niveau de connaissance sur le coronavirus}

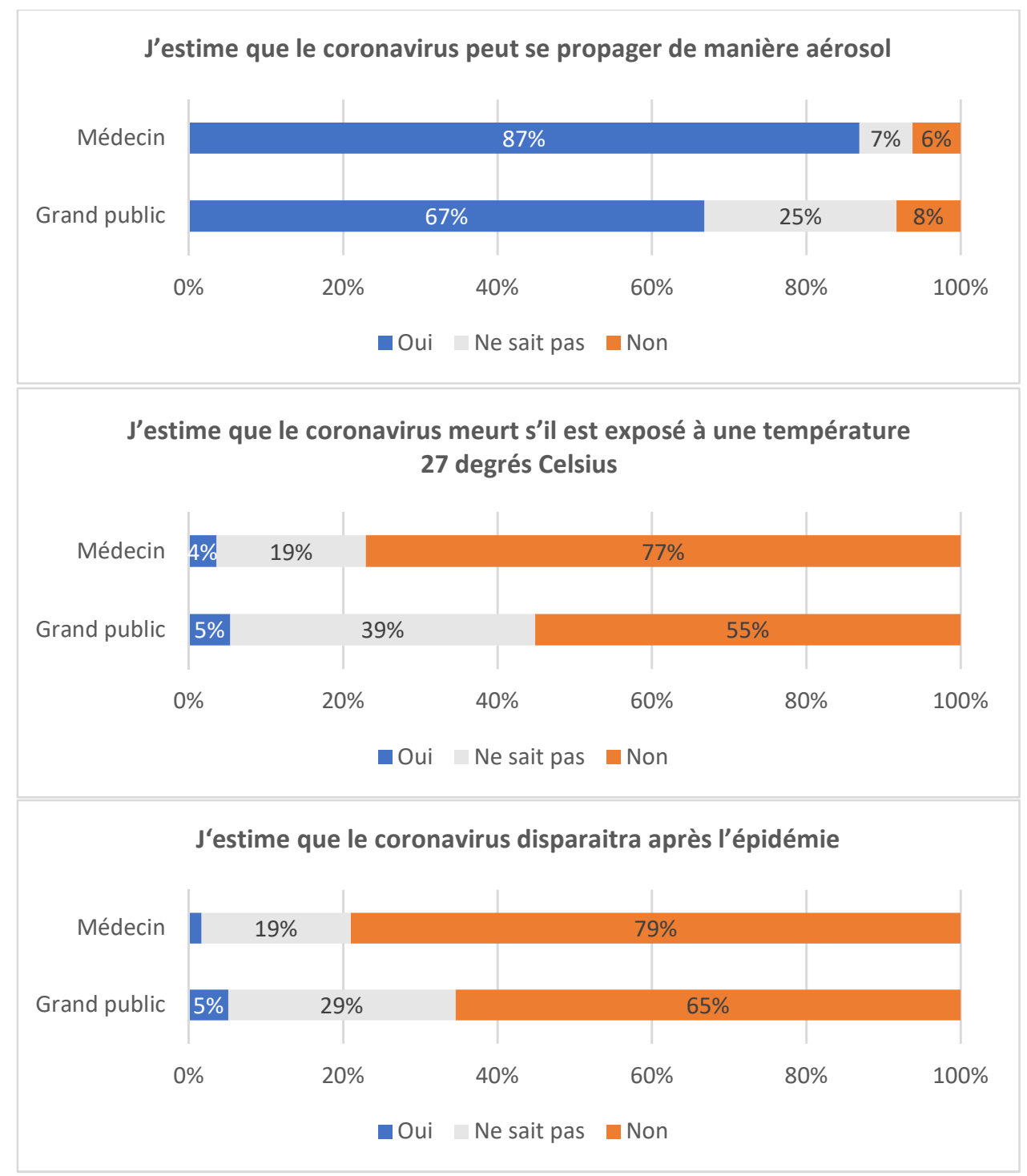




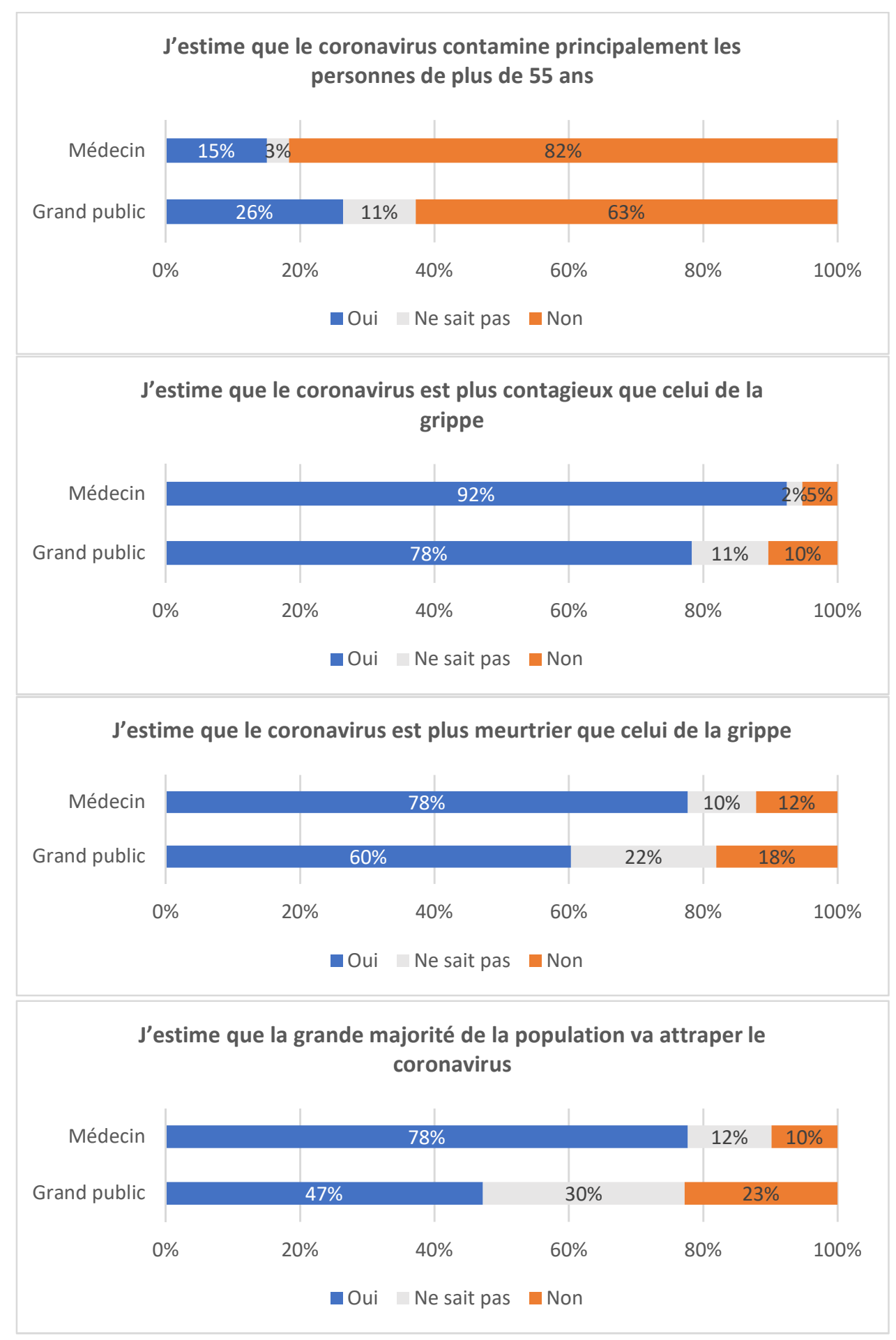

Q18 : Veuillez indiquer dans quelle mesure les affirmations suivantes correspondent à votre perception sur la propagation du coronavirus (Covid-19). 


\section{Perception du risque que le virus représente}

Nous avons interrogé les répondants sur la perception du risque que le coronavirus représente pour eux. Une première question permettant de réaliser cet objectif est formulée de la manière suivante : "Quel niveau de menace pensez-vous que le coronavirus représente : pour vous, pour votre famille et vos proches, pour votre communauté locale, pour votre pays, pour le monde ? ". Les répondants étaient invités à graduer leur ressenti de « 0 » = « très faible menace » à « 4 » = « menace très élevée ».

De manière générale, le coronavirus est davantage considéré comme menaçant pour la collectivité que pour soi-même. II est considéré comme très menaçant pour "le monde " et "moyennement menaçant » pour soi-même personnellement.

Fig. 24. Perception de la menace que représente le coronavirus

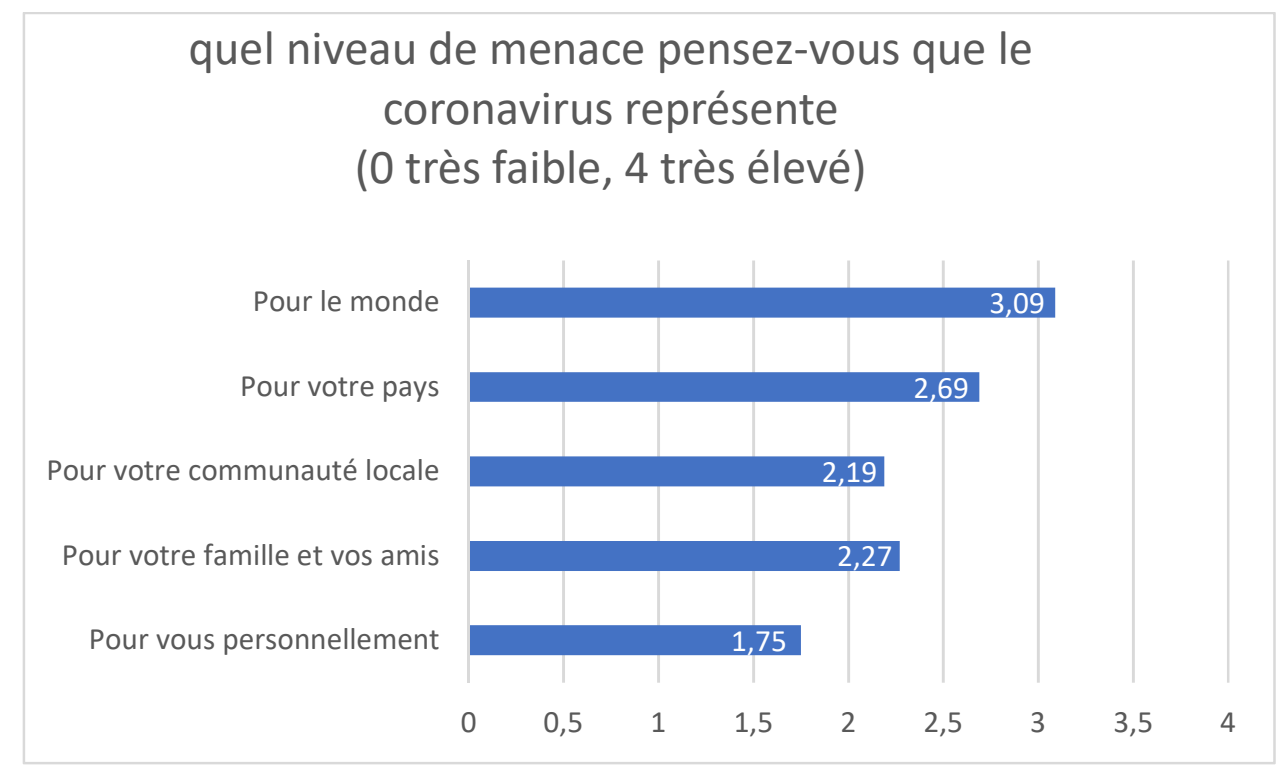

Q8 : Sur une échelle de 0 (très faible) à 4 (très élevé), quel niveau de menace pensez-vous que le coronavirus représente pour chacun des éléments suivants?

Une seconde manière de mesurer le risque perçu par les individus consiste à les interroger sur la perception de l'impact que le coronavirus pourrait avoir sur leur comportement ou sur leur santé. Nous avons posé différentes questions à ce sujet, dont la distribution des réponses est présentée dans le graphique ci-dessous (en différenciant les réponses des médecins et du grand public). Nous voyons que pour trois des cinq questions, les perceptions du public et des médecins sont divergentes.

Seuls $16 \%$ des Belges francophones pensent avoir plus de chance que les autres d'être contaminés par le virus (comparé à 63\% des médecins). À l'inverse, si un Belge sur deux (51\%) pense que sa santé se détériorera fortement s'il est contaminé par le virus, cette proportion tombe à un sur trois parmi les médecins (31\%). Enfin, un Belge sur quatre n'ira pas à l'hôpital s'il attrape une autre maladie en raison de la crise (c'est le cas d'un médecin sur dix). 
Fig. 25. Perception de l’impact du virus sur ma santé et mes comportements (médecins vs. grand public)

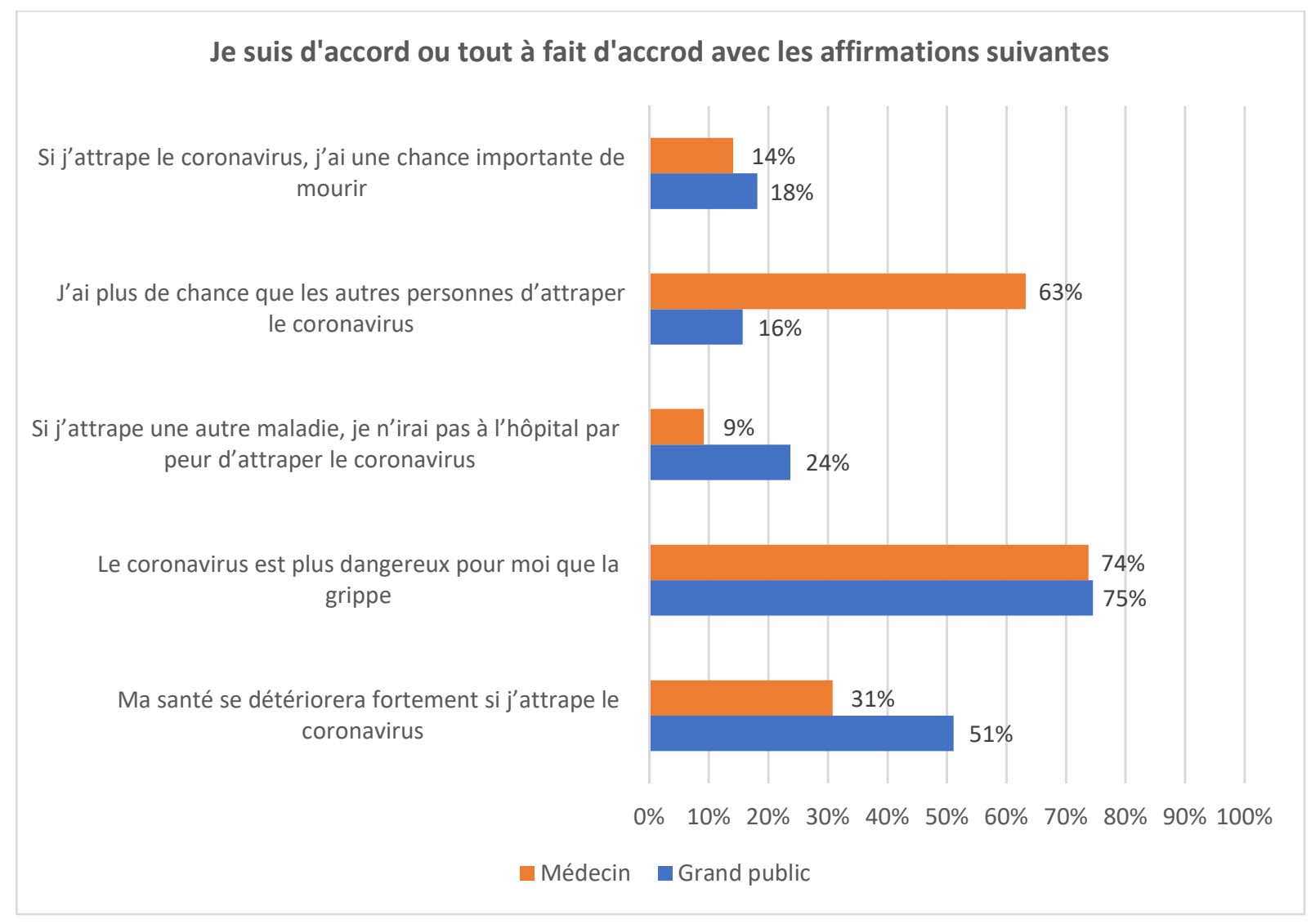

Q9 : Sur une échelle de 1 (pas du tout d'accord) à 5 (tout à fait d'accord), comment évaluez-vous les affirmations suivantes?

Si l'on regarde les différences de réponse entre les classes d'âge pour ces mêmes questions, nous observons sans surprise une perception du risque beaucoup plus forte dans la classe d'âge des 66 ans et plus. Près d'un senior sur deux pense qu'il a une chance importante de mourir contre seulement un jeune de moins de 26 ans sur dix (7\%).

Prêt d'un senior sur trois (34\%) estime qu'il n'ira pas à l'hôpital s'il attrape une autre maladie. 
Fig. 26. Perception de l'impact du virus sur ma santé et mes comportements (par classes d'âge)

\section{Je suis d'accord ou tout à fait d'accord avec les affirmations suivantes}

Si j’attrape le coronavirus, j'ai une chance importante de mourir

J'ai plus de chance que les autres personnes d'attraper le coronavirus

Si j'attrape une autre maladie, je n'irai pas à l'hôpital par peur d'attraper le coronavirus

Le coronavirus est plus dangereux pour moi que la grippe
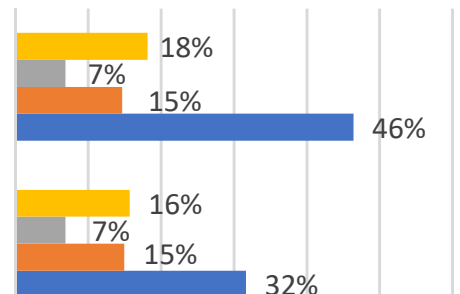

$15 \%$
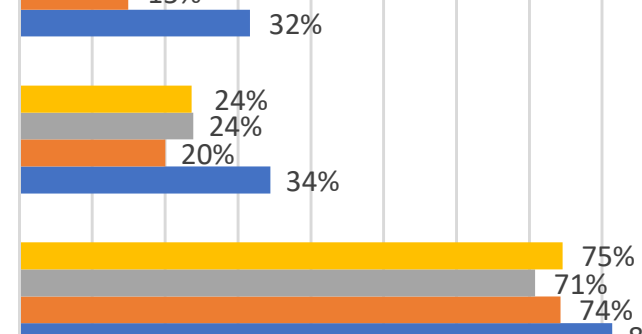

Ma santé se détériorera fortement si j'attrape le coronavirus

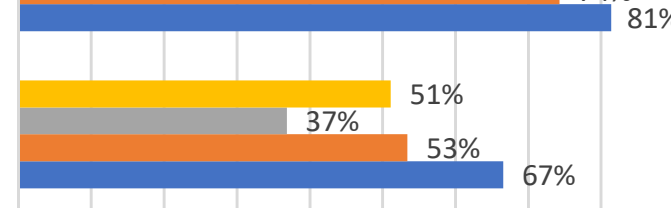

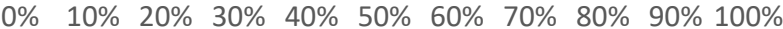
Moyenne $\quad 16$ à 25 ans $\square 26$ à 65 ans $\square 66$ ans et plus 


\section{Analyse du niveau d'anxiété et de la capacité de mémorisation}

\section{Analyse du niveau d'anxiété}

Nous avons interrogé les Belges francophones sur leur niveau d'anxiété au moyen de la version francophone du GAD-7 (Spitzer et al., 2006). Cet instrument de mesure contient 7 questions évaluant la fréquence de l'ensemble des symptômes d'anxiété généralisée (c'est-à-dire non spécifique), et ce de manière auto-rapportée par les répondants. Cet instrument est classiquement utilisé dans les études épidémiologiques. A l'instar des recherches antérieures utilisant cet instrument, nous avons calculé, à partir des 7 questions initiales, un score agrégé d'anxiété, pouvant varier d'un niveau minimum de « 0 » à un maximum de « 21 ».

Nous voyons que le niveau d'anxiété moyen est relativement bas (en moyenne un score de 5 sur 21). De légères différences existent à première vue entre les classes d'âge.

Fig. 27. Niveau d'anxiété des Belges en fonction de la classe d'âge

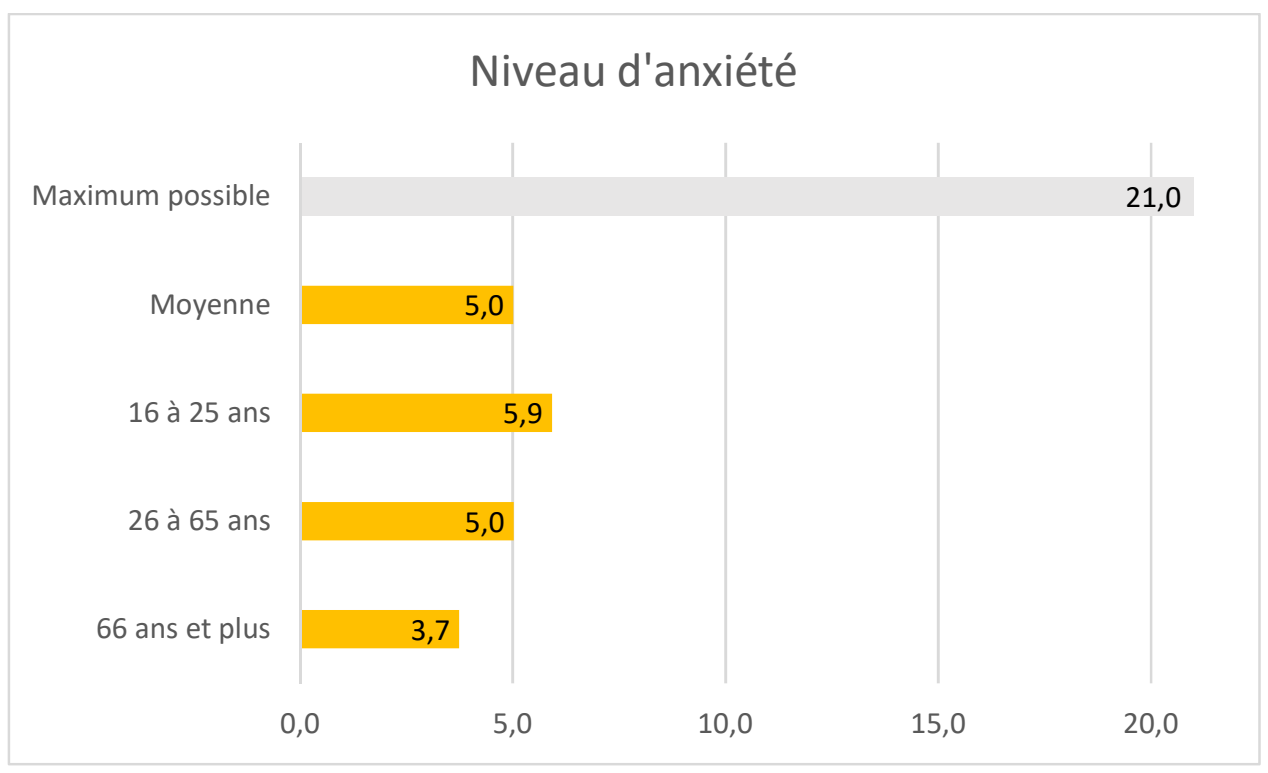

Q11 : Combinaison de l'évaluation de sept questions. Exemple :Q11a : Depuis le début de la période de confinement, selon quelle fréquence avez-vous été géné(e) par les problèmes suivants ? Un sentiment de nervosité, d'anxiété ou de tension. ( 0 = jamais, 1 = plusieurs jours, 2 = plus de la moitié des jours, $3=$ presque tous les jours $)$.

Nous pouvons affiner les analyses en distinguant trois types de profils d'anxiété : les peu anxieux (score de 0 à 7), les moyennement anxieux (score de 8 à 14) et les très anxieux (score de 15 à 21).

A l'instar d'autres enquêtes réalisées en Belgique durant la période de confinement (par exemple Sciensano 2020) ${ }^{25}$, cette analyse permet de voir que la catégorie des 16 à 25 est la plus anxieuse avec un jeune sur trois ayant un niveau d'anxiété dépassant 15 sur une échelle allant de 0 à 21 . Six jeunes de moins de 26 ans sur dix sont peu anxieux contre huit sur dix pour la classe des 26-65 ans.

\footnotetext{
${ }^{25}$ https://www.sciensano.be/sites/www.wiv-isp.be/files/report_final_fr.pdf
} 
Fig. 28. Niveau d'anxiété des Belges en fonction de la classe d'âge (en classe)

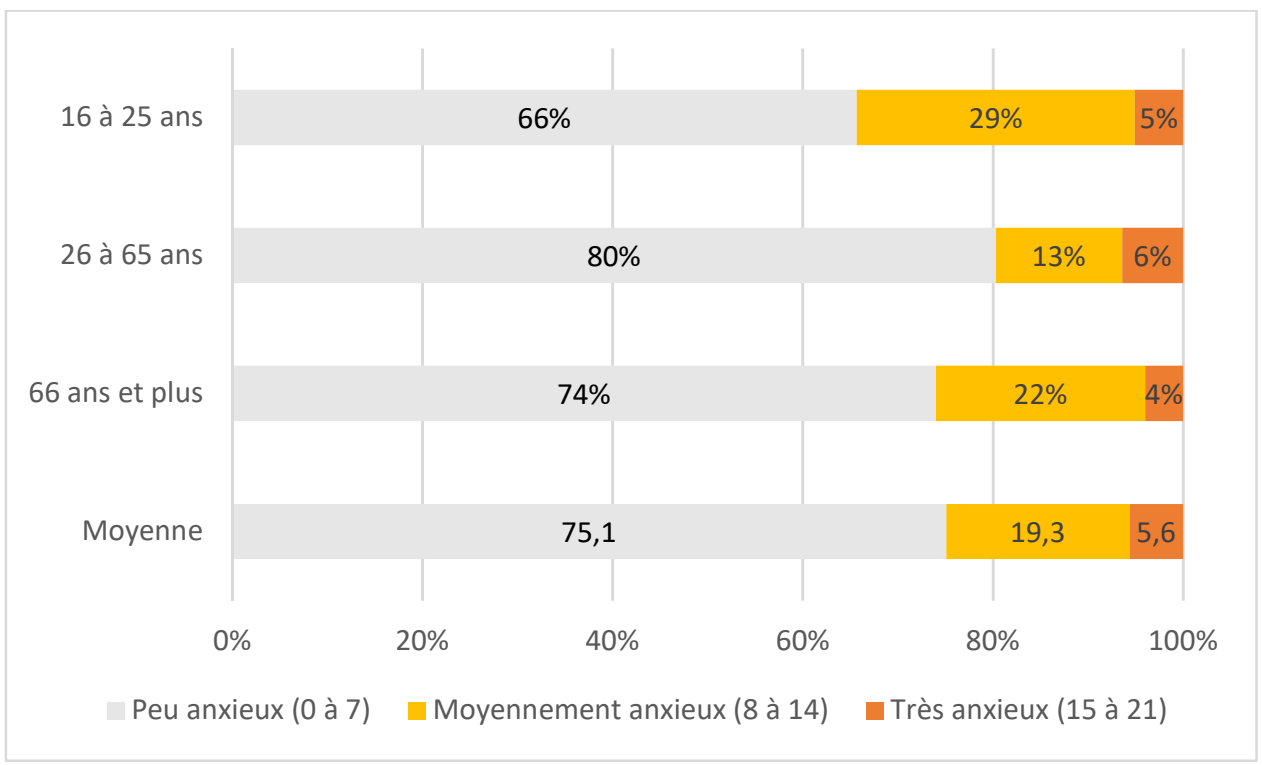

Comme le montre le graphique ci-dessous, une autre variable liée au niveau d'anxiété est celle du genre. Prêt d'une femme sur trois (31\%) est moyennement ou très anxieuse. Cette proportion diminue à un homme sur cinq (19\%). Cette observation corrobore d'autres enquêtes réalisées tant en Belgique qu'ailleurs dans le monde durant la période de confinement.

\section{Fig. 29. Niveau d’anxiété des Belges en fonction du sexe}

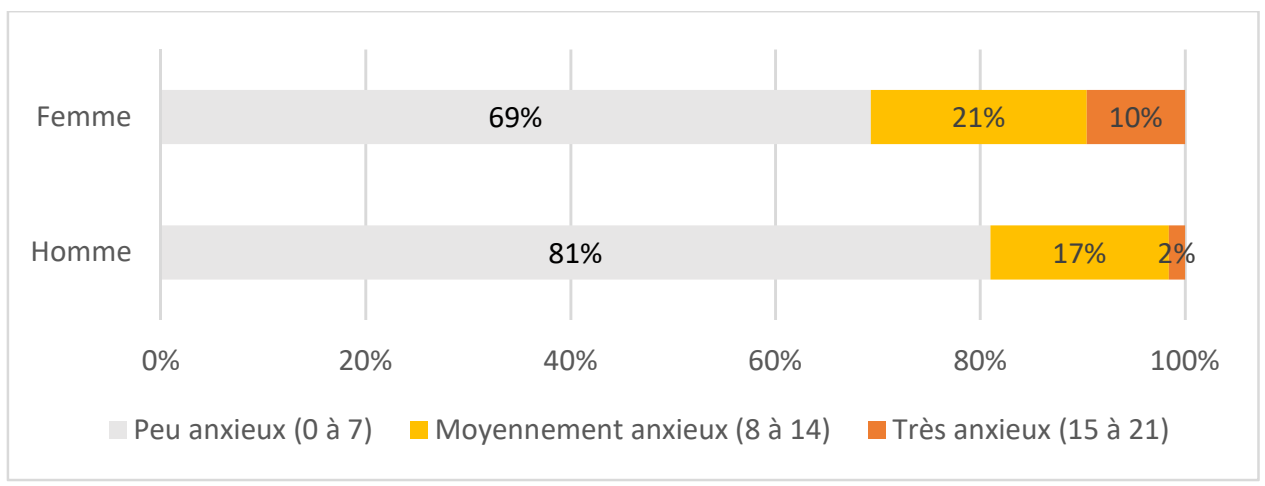

Un des objectifs de notre enquête est d'évaluer l'impact de la crise du coronavirus et des différents rapports à l'information sur le niveau d'anxiété. Ce rapport de recherche préliminaire se veut d'abord descriptif et ne discutera pas en détail l'ensemble des variables permettant de prédire le niveau d'anxiété. Nous pouvant cependant de manière rapide discuter les relations entre le niveau de menace perçu pour soi-même (voir figure 29) et le niveau d'anxiété.

Cette analyse (voir graphique ci-dessous) suggère que, de manière générale, le niveau d'anxiété est d'autant plus important que le niveau de menace perçu pour soi-même est grand. De manière surprenante, au-delà d'un certain niveau de menace perçue (à partir du dernier niveau où la menace est jugée très élevée), le niveau d'anxiété tend à diminuer. Des analyses ultérieures seront nécessaires pour détailler ce phénomène. 
Fig. 30. Niveau d'anxiété des Belges en fonction de la perception de la menace que le coronavirus représente pour soi-même

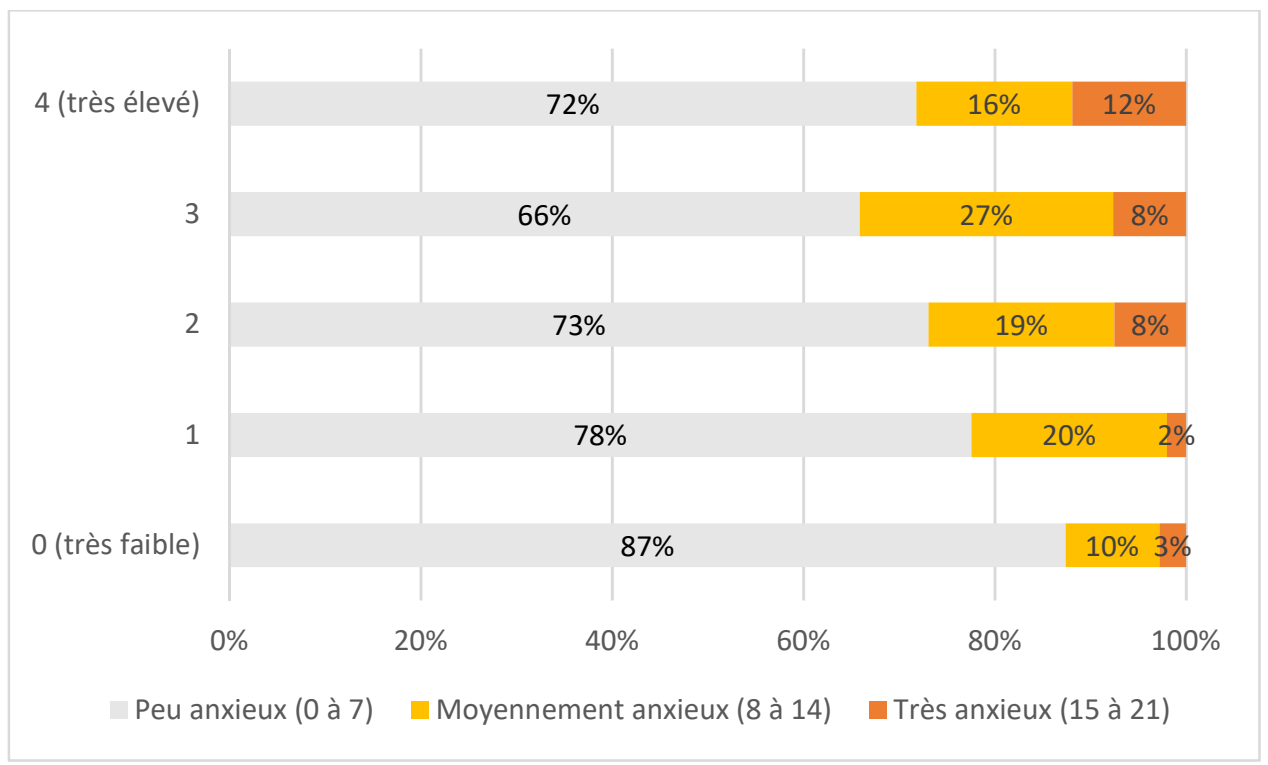

Nous pouvons également interroger l'idée que la confiance dans les mesures prises par le gouvernement est liée au niveau d'anxiété. Une mesure simple de cette relation peut être effectuée en mettant en relation la question sur la confiance accordée à l'action du gouvernement mesurée par la question "Dans quelle mesure êtes-vous d'accord avec l'affirmation selon laquelle les mesures prises par le gouvernement sont adéquates » avec le niveau d'anxiété.

Une comparaison des réponses à ces deux variables montre une différence claire entre le groupe des personnes en accord avec les mesures prises par le gouvernement et le groupe des personnes en désaccord. Une personne sur trois (36\%) en désaccord avec les mesures est moyennement ou fortement anxieuse durant le confinement alors que seule une personne sur cinq (22\%) qui trouve les mesures adéquates éprouve un niveau d'anxiété moyen ou fort. Les personnes qui ne se prononcent pas par rapport à l'adéquation des mesures, sont en moyenne celles qui sont les moins anxieuses durant le confinement (19\%). 
Fig. 31. Niveau d'anxiété des Belges en fonction de la confiance dans les mesures prises par le gouvernement

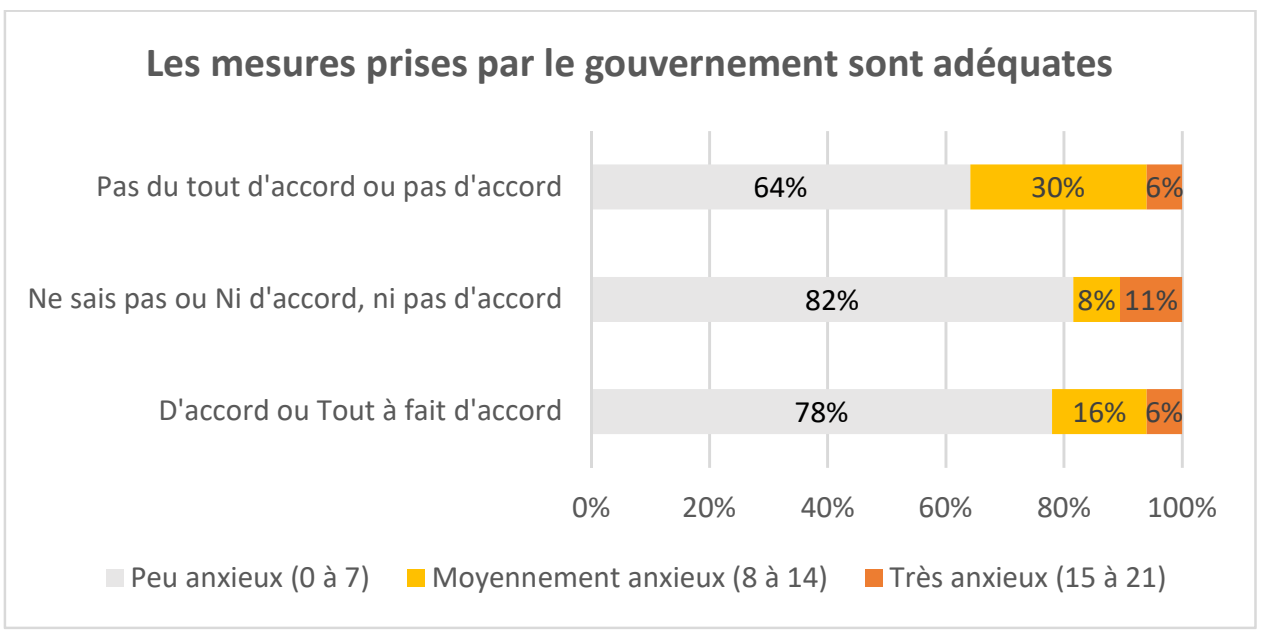

Q10a. Sur une échelle de 1 (pas du tout d'accord) à 5 (tout à fait d'accord), comment évaluez-vous les affirmations suivantes ? Les mesures prises par le gouvernement sont adéquates

De la même manière il est possible d'étudier le lien entre le niveau d'information que la personne considère avoir par rapport au coronavirus et son niveau d'anxiété à partir de la question : "Dans quelle mesure êtes-vous d'accord avec l'affirmation suivante: j'estime déjà posséder toutes les informations nécessaires pour me permettre de bien comprendre le coronavirus ".

Nous observons une différence importante entre les personnes qui se pensent non suffisamment informées (une personne sur trois, 34\%, est moyennement ou très anxieuse) et les personnes qui pensent posséder toute l'information nécessaire (une personne sur cinq, 13\%, est moyennement ou très anxieuse). Les personnes incertaines sont les moins anxieuses.

Ces résultats font échos à de nombreuses études issues du domaine de la psychologie cognitive expérimentale et rapportant l'existence d'une relation bidirectionnelle entre le niveau d'anxiété et un traitement cognitif préférentiel de l'information liée aux préoccupations (pour une revue de la littérature en français, cf. Coussement et Heeren 2015).

En d'autres termes, les personnes les plus anxieuses seraient davantage "hypervigilantes " par rapport à l'information liée à leurs préoccupations et, par conséquent, passeraient plus de temps à porter attention à l'information. Toutefois, cette relation peut être bidirectionnelle, car d'autres travaux expérimentaux ont également indiqué qu'une hypervigilance par rapport aux informations liées à la menace peut accroitre le niveau d'anxiété (par exemple : Heeren, Peschard et Philippot 2012). Toutefois, de par l'absence tant de perspective temporelle que d'approche expérimentale dans le présent projet de recherche, il est ici impossible d'inférer une quelconque relation de causalité entre ces variables. Des recherches supplémentaires devront être conduites pour mieux comprendre cet effet. 


\section{Fig. 32. Niveau d'anxiété des Belges en fonction du niveau d'information}

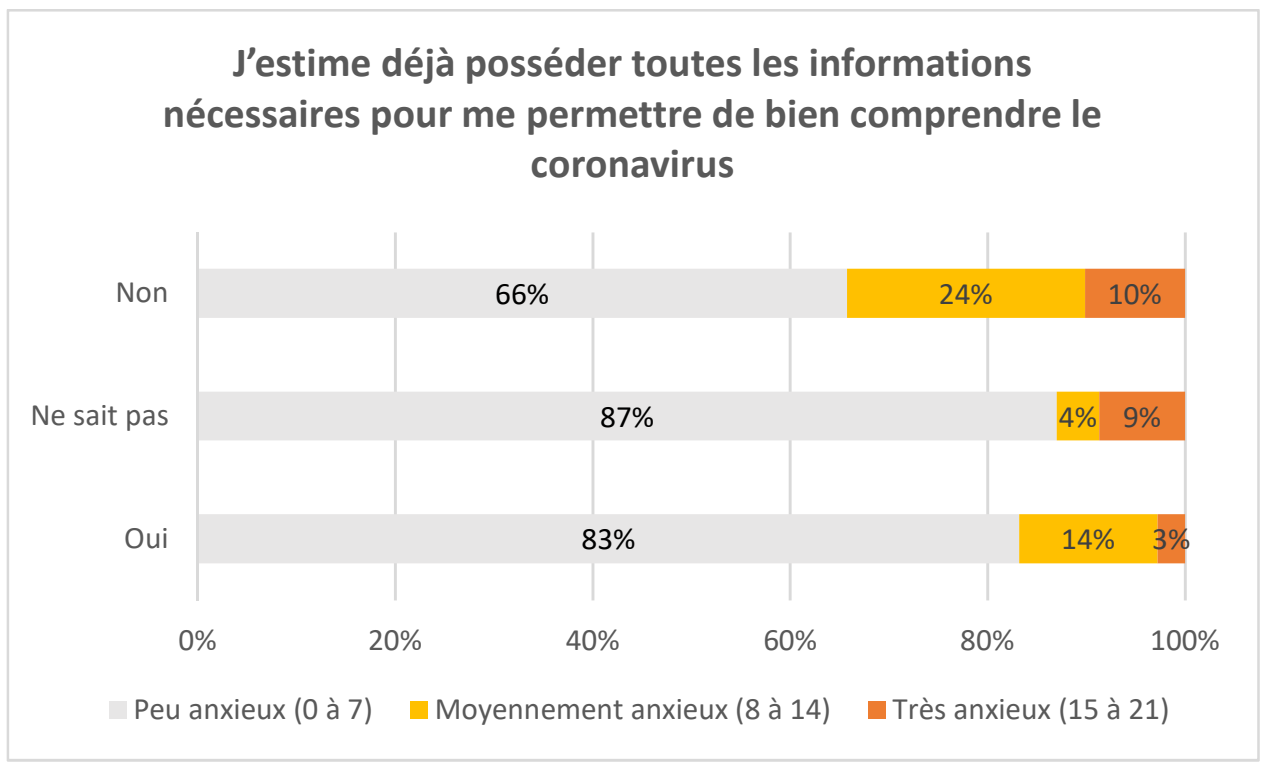

Q17b : Veuillez indiquer dans quelle mesure les affirmations suivantes correspondent à votre perception sur la crise du coronavirus (Covid-19). J'estime déjà posséder toutes les informations nécessaires pour me permettre de bine comprendre le coronavirus.

\section{Analyse multivariée du niveau d’anxiété}

En guise de conclusion à l'analyse du niveau d'anxiété, nous avons tenté de modéliser la manière dont l'ensemble des dimensions testées dans ce document affecte le niveau d'anxiété des belges ayant répondu à l'enquête. Le but de cette démarche est de sortir de l'unique description des variables, et des relations entre variables, afin de s'intéresser aux effets conjoints des différentes variables prises en considération. Cette analyse ${ }^{26}$ peut être résumée comme suit.

De façon générale, nous observons que, indépendamment de la manière dont le Belge s'informe, seule la confiance attribuée aux informations provenant des professionnels de la santé prédit un sentiment plus élevé d'anxiété durant le confinement.

À l'opposé, une confiance plus grande envers les actions entreprises par le gouvernement est apparue comme le prédicteur d'un moindre niveau d'anxiété ressentie durant le confinement.

La perception de la menace que représente le virus est également apparue comme prédicteur du niveau d'anxiété ressentie durant le confinement, alors que la croyance selon laquelle le virus est le fruit d'un complot politique est apparue comme prédicteur d'un moindre niveau d'anxiété. Par contre, nous n'avons identifié aucune relation entre l'estimation subjective de posséder une quantité d'information suffisante afin de comprendre les enjeux que pose la crise sanitaire et le niveau d'anxiété.

Enfin, les femmes (une femme sur trois) et les personnes plus jeunes (et, plus particulièrement, la catégorie 16 à 25 ans) semblent être davantage sujets à l'anxiété durant le confinent. À cet égard, un effet linéaire de l'âge est apparu : au plus le répondant est âgé, au moins le niveau d'anxiété est élevé. En outre, le niveau d'éducation des répondants, tout comme le fait qu'ils soient médecins ou non, n'affecte nullement le niveau d'anxiété.

\footnotetext{
${ }^{26}$ Voir tableau récapitulatif en annexe.
} 
Ces résultats sont donc consonants avec l'ensemble des analyses bivariées présentées tout au long du document.

\section{Analyse des plaintes mnésiques}

Une dernière mesure d'intérêt porte sur la difficulté exprimée par des répondants de retenir de nouvelles informations. Trois personnes sur quatre disent ne jamais éprouver de difficulté à retenir des nouvelles informations. Près de $4 \%$ éprouvent cette difficulté presque tous les jours.

\section{Fig. 33. Analyse des difficultés à retenir des informations}

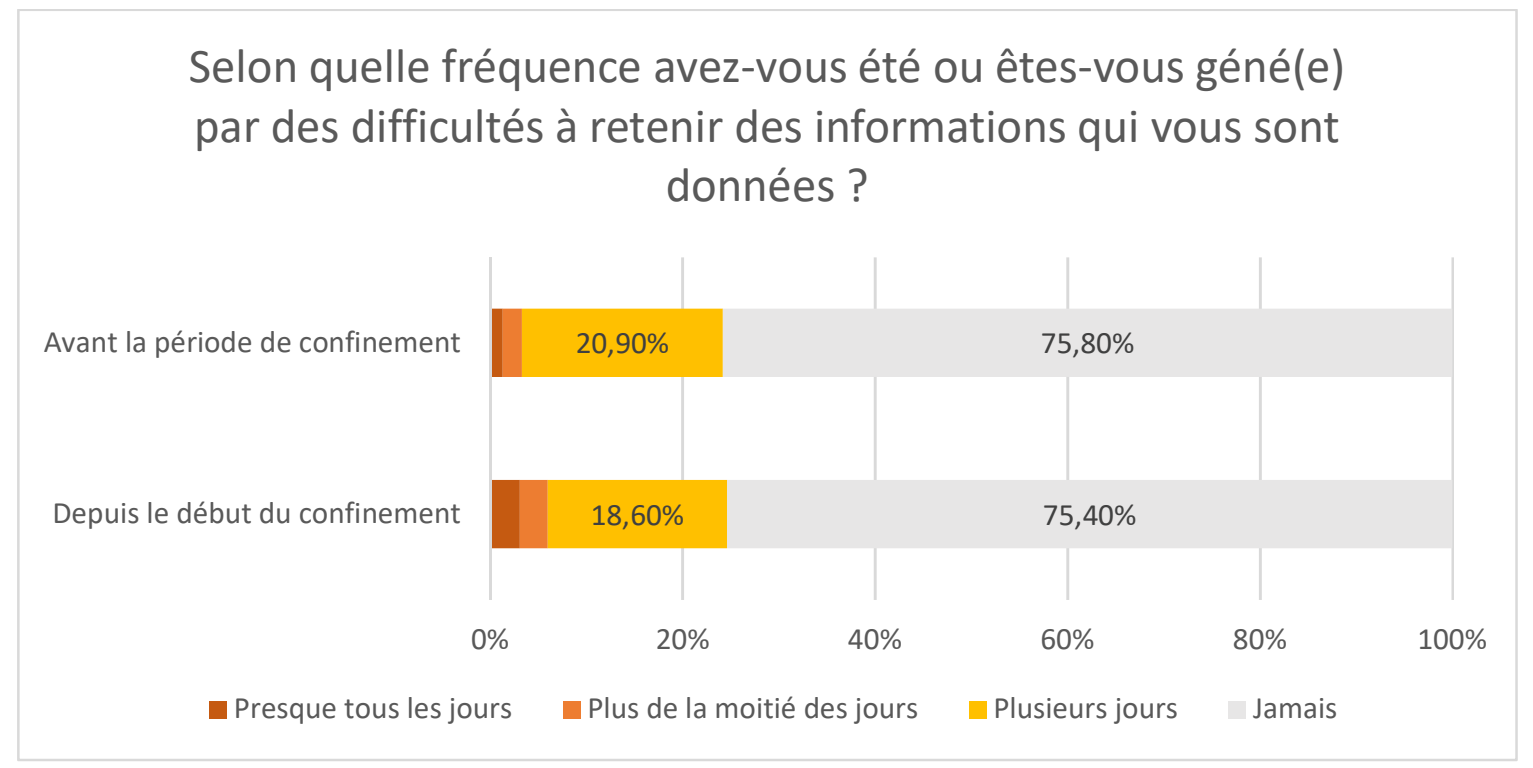

Q12b : [Avant la période du confinement] Selon quelle fréquence avez-vous été ou êtes-vous géné(e) par des difficultés à retenir des informations qui vous sont données?

Q12a : [Depuis le début du confinement] Selon quelle fréquence avez-vous été ou êtes-vous géné(e) par des difficultés à retenir des informations qui vous sont données?

Si l'on regarde le graphique ci-dessous qui permet une analyse des différences entre les classes d'âge, nous voyons que la classe d'âge dont la proportion d'individus ayant des plaintes pour retenir des nouvelles informations est celle de 16 à 25 ans. Quatre jeunes sur dix disent avoir éprouvé cette difficulté au moins plusieurs jours depuis le début du confinement. 


\section{Fig. 34. Analyse des plaintes mnésiques depuis le début de confinement par classe d'âge}

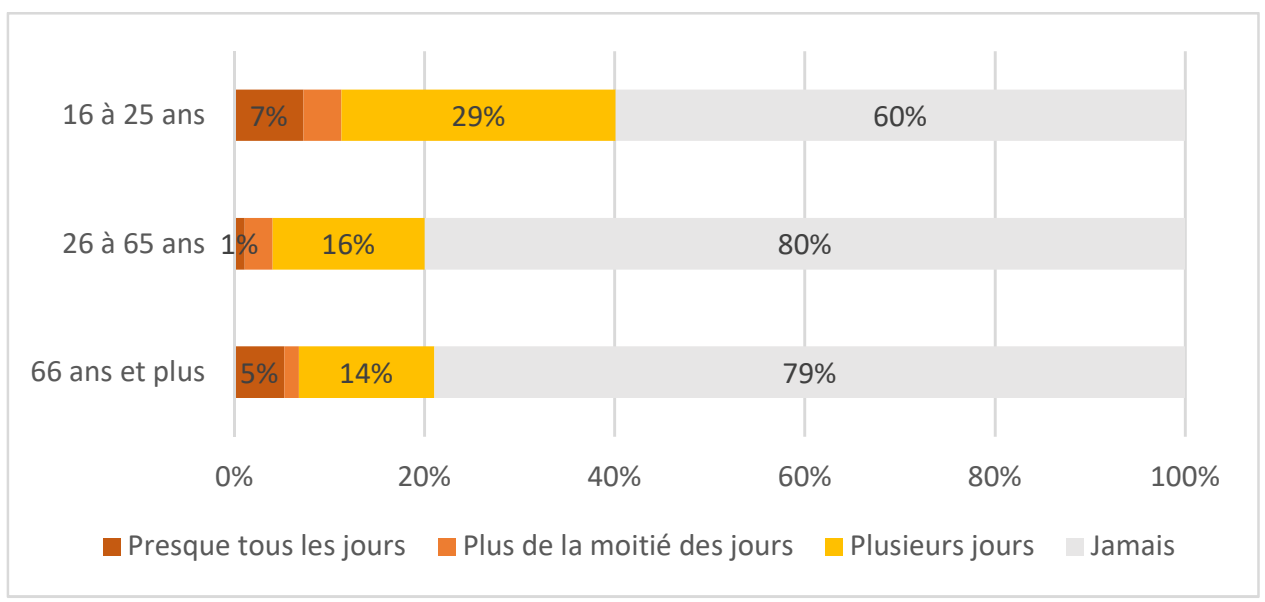

Q12a : Depuis le début de la période de confinement. Selon quelle fréquence avez-vous été ou êtes-vous géné(e) par des difficultés à retenir des informations qui vous sont données?

Nous avons également demandé aux personnes interrogées de répondre à la même question concernant la période avant le confinement. Ces réponses sont illustrées dans le graphique ci-dessous.

Fig. 35. Analyse des plaintes mnésiques avant le début de confinement par classe d’âge

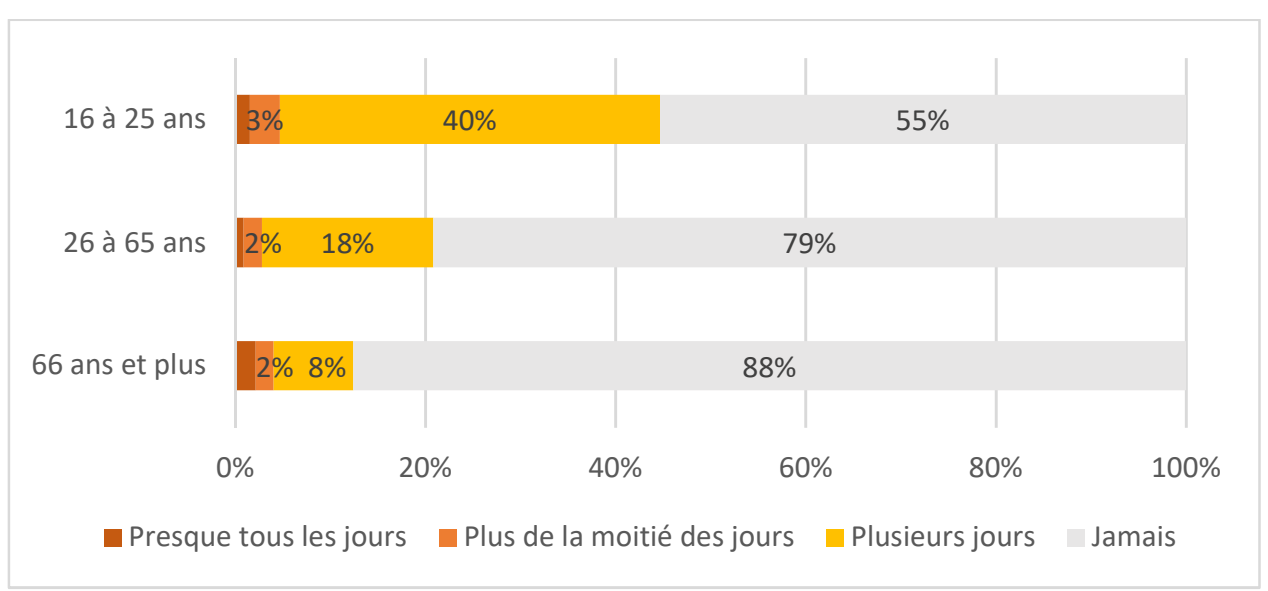

Q12b : Avant la période de confinement. Selon quelle fréquence avez-vous été ou êtes-vous géné(e) par des difficultés à retenir des informations qui vous sont données?

Pour analyser des différences entre ces deux périodes, il est préférable, plutôt que de comparer l'évolution des proportions entre les deux périodes, d'identifier tous les individus qui déclarent ressentir une dégradation de la capacité à retenir des informations entre la période pré-confinement et la période de confinement. La figure 33, ci-dessous, reprend la distribution de ces individus par catégorie d'âge. 
Fig. 36. Analyse de la dégradation subjective de la capacité à retenir des informations suite à l'entrée en période de confinement

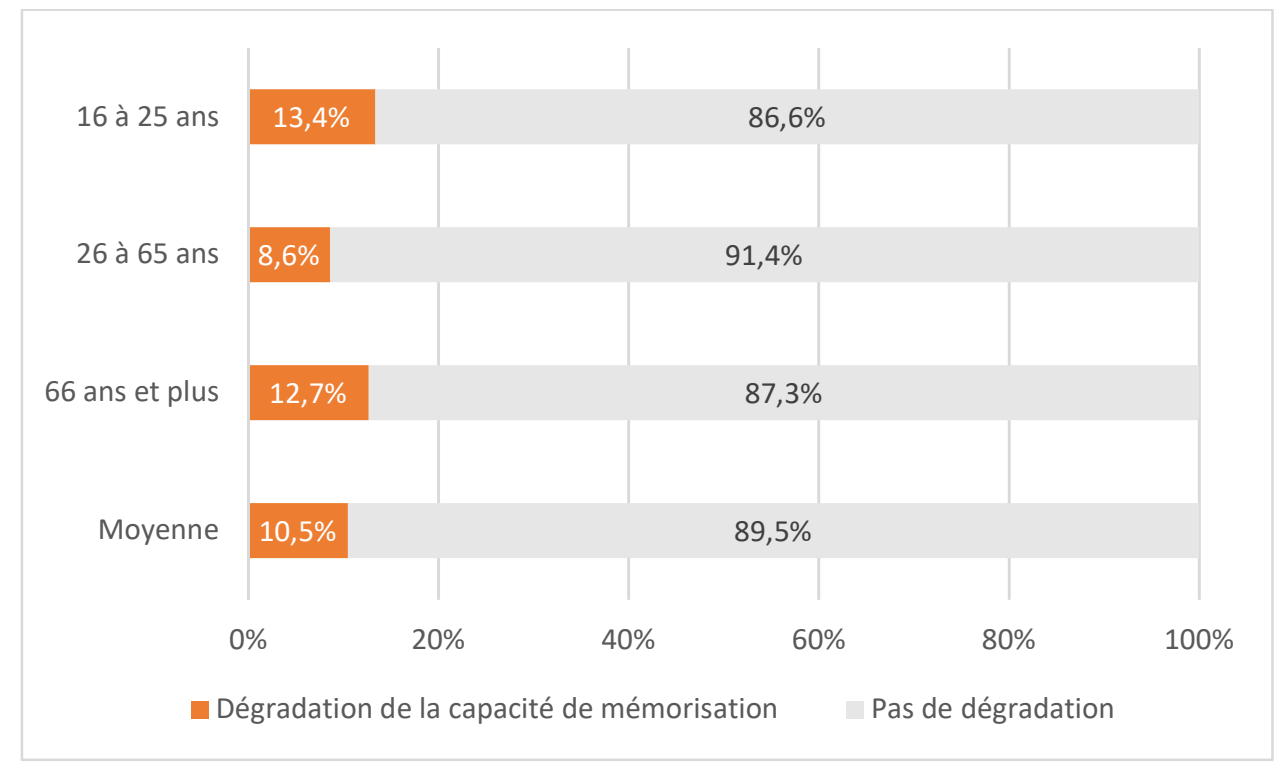

Ce graphique laisse penser que la période de confinement a eu un impact sur la capacité de mémorisation d'information d'une personne sur dix $(10,5 \%)$. Les classes d'âge les plus touchées sont celles des moins de 26 ans et des plus de 66 ans. Nous pouvons émettre l'hypothèse que les plus jeunes (16-25 ans) éprouvent des difficultés de mémorisation dans le cadre de leurs études, qui, suite au confinement, sont accrues dans $13,4 \%$ de la population étudiante. Nous pouvons également spéculer sur le lien entre certaines pathologies neurodégénératives d'apparition insidieuse et l'augmentation des plaintes mnésiques chez $12.7 \%$ de la population de plus de 65 ans. Le confinement, comme toute source de stress, pourrait en effet être révélateur de pathologies méconnues préalablement. Notons que la proportion de personnes déclarant des difficultés quotidiennes augmente significativement dans ces deux groupes d'âge alors qu'elle reste stable dans le groupe de référence, âgé de 26 à 65 ans (figure 33-34). Des analyses plus poussées devront être réalisées ultérieurement pour comprendre ces différences. 


\section{Bibliographie}

Blais A., Bol D., Giani M. et Loewen P.-J. (2020), « The effect of COVID-19 lockdowns on political support: Some good news for democracy? », preprint, SocArXiv, URL: https://osf.io/7hpj9.

Brennen S.J., Simon F., Howard P., Nielsen R.K. (2020), Types, sources, and claims of COVID-19 misinformation, Reuters Institute, University of Oxford, URL : https://reutersinstitute.politics.ox.ac.uk/types-sources-andclaims-covid-19-misinformation.

Brooks, S. K., Webster, R. K., Smith, L. E., Woodland, L., Wessely, S., Greenberg, N., \& Rubin, G. J (2020), « The psychological impact of quarantine and how to reduce it: Rapid review of the evidence ». Lancet, vol. 395, n¹0227, 912-920. https://doi.org/10.1016/S0140-6736(20)30460-8.

Callon M, Lascoumes P. et Barthe Y. (2001), Agir dans un monde incertain, Paris, Seuil.

Cinelli Matteo et al. (2020), " The COVID-19 Social Media Infodemic », preprint, arXiv, 2003.05004 [nlin, physics:physics]. URL : http://arxiv.org/abs/2003.05004.

Coussement C., Heeren, A. (2015), « Vers une architecture cognitive du maintien du biais attentionnel envers la menace dans l'anxiété : Une approche par comparaison de modèles ", L'Année Psychologique/Topics in Cognitive Psychology, vol. 115, n4, 665-690.

European Union (2018), A multi-dimensional approach to disinformation. Report of the independent High-level Group on fake news and online disinformation, Directorate-General for Communication. Networks, Content and Technology, Bruxelles, URL : http://ec.europa.eu/newsroom/dae/document.cfm?doc_id=50271.

FeldmanHall O., Amitai S. (2019), "Resolving uncertainty in a social world », Nature human behavior, vol. 3, $\mathrm{n}^{\circ} 5$, p. 426-435.

Gilles I.et al. (2011), « Trust in medical organizations predicts pandemic (H1N1) 2009 vaccination behavior and perceived efficacy of protection measures in the Swiss public ", European Journal of Epidemiology, vol. 26, $\mathrm{n}^{\circ} 3$, p. 203-210.

Heeren A., Peschard V., Philippot P. (2012), " The causal role of attentional bias to threat cues in social anxiety: A test on a cyber-ostracism task ", Cognitive Therapy and Research, 36, 512-521

Jasanoff S. (1994), Learning from disaster: risk management after Bhopal, University of Pennsylvania press.

McFadden S., Malik Amyn A., Aguolu Obianuju G., Willebrand Kathryn S., et al. (2020), « Perceptions of the Adult US Population regarding the Novel Coronavirus Outbreak ", preprint, medRxiv, p. 2020.02.26.20028308. URL : https://www.medrxiv.org/content/10.1101/2020.02.26.20028308v1.full.pdf

Nielsen R.K., Fletcher R., Newman N. et al. (2020), « Navigating the 'Infodemic': How People in Six Countries Access and Rate News and Information about Coronavirus ", Misinformation, science, and media (avril 2020), Reuters Institute, University of Oxford, URL : https://reutersinstitute.politics.ox.ac.uk/sites/default/files/202004/Navigating\%20the\%20Coronavirus\%20Infodemic\%20FINAL.pdf

OMS (2020), " Parer aux infodémies : un élément essentiel de la riposte mondiale à la COVID-19 », Weekly Epidemiological Record, vol.95, n¹6, 145-148, 2020. https://apps.who.int/iris/bitstream/handle/10665/331775/WER9516-145-148-engfre.pdf?sequence=1\&isAllowed=y

Pidgeon N., Kasperson R., Slovic P. (2003), The Social Amplification of Risk, Cambridge University Press.

Sciensano (2020), Enquête de santé Covid-19 : quelques résultats préliminaires. URL : https://www.sciensano.be/sites/www.wiv-isp.be/files/report_final_fr.pdf. 
Slovic P. (1987), « Perception of risk », Science, vol. 236, n²799, p. 280-285.

Spitzer RL, Kroenke K, Williams JBW, Löwe B. (2006), « A Brief Measure for Assessing Generalized Anxiety Disorder: The GAD-7 », Archives of Internal Medicine, vol. 166, n¹0, p.1092-1097, Doi : 10.1001/archinte.166.10.1092.

Tandoc E., Zheng Wei L. et Ling R. (2018), « Defining “Fake News” ». Digital Journalism, vol. 6, n², p. 137-153.

Véron E. (1981), Construire l'événement. Les médias et l'accident de Three Mile Island, Paris : Editions de minuit.

Wagner-Egger P., et al. (2011), « Lay perceptions of collectives at the outbreak of the H1N1 epidemic: heroes, villains and victims », Public Understanding of Science, 20 (4) p. 461-476.

Wynne B. (1992), " Misunderstood misunderstanding: social identities and public uptake of science », Public Understanding of Science, vol. 1, n³, p. 281-304.

Yoshida, W, Ishii, S. (2006), « Resolution of uncertainty in prefrontal cortex », Neuron, vol. 50, n5, p. 781-9.

Zarocostas J. (2020), « How to fight an infodemic », The Lancet, vol. 395, n¹0225, p. 676. 


\section{Annexe}

\section{Modèle multivarié.}

Variables Indépendantes Coefficient $\mathrm{p}>\mid \mathrm{t}$

Confiance dans les actions entreprises par le gouvernement

Les mesures prises par le gouvernement sont adéquates

$$
-0,08^{* * *} \quad-3,82<0,0001
$$

Confiance dans les actions déléguées aux experts de la santé

Dans le climat de crise actuel, nous devrions uniquement faire confiance aux experts pour prendre des

décisions. Le gouvernement devrait simplement les appliquer sans les questionner.

$0,051 \dagger \quad 1,9 \quad 0,058$

Par rapport a la gestion de l'epidémie, les experts sont les seules personnes capables de trouver les

meilleures solutions pour le pays parce que leurs décisions ne sont pas guidées par une idéologie.

Confiance dans l'information délivrée par

le gouvernement régional

le gouvernement fédéral

des professionnels de la santé tels que médecins et infirmières

Des experts en épidémiologie et virologie

Perception subjective de la menace que représente le coronavirus pour soi

J'ai plus de chance que les autres personnes d'attraper le coronavirus

Si j'attrape le coronavirus, j'ai une chance importante de mourir

Perception subjective du niveau de connaissance sur le coronavirus et l'épidémie

J'estime déjà posséder toutes les informations nécessaires pour me permettre de bien comprendre le coronavirus

Fake News et théories du complot

J'estime que le coronavirus est issu d'un laboratoire

$0,1089 * * * \quad 3,9<0,000$

$0,0009 \quad 0,03 \quad 0,978$

$0,142 \quad 0,45 \quad 0,652$

$0,067 * \quad 2,14 \quad 0,032$

$0,62 \dagger \quad 1,93 \quad 0,054$

$0,08 * * \quad 2,83 \quad 0,005$

$0,02 \quad 0,46 \quad 0,647$

Classe d'âge (classe de référence : 16-25 ans)

26 à 65 ans

66 ans et plus

Niveau d'éducation (classe de référence : diplômé au maximum de l'enseignement secondaire)

Diplômé de l'enseignement supérieur

Sexe (classe de référence : féminin)

Masculin

Profession (classe de référence $=$ non-médecin)

\begin{tabular}{|c|c|c|c|}
\hline Médecin & $-0,007$ & $-0,1$ & 0,917 \\
\hline Constance & $1,68 * * *$ & 7,83 & $<0,0001$ \\
\hline Effectifs & 1581 & & \\
\hline $\mathrm{F}(16,1564)$ & 13,73 & & \\
\hline $\mathrm{P}>\mathrm{F}$ & $<0,00001$ & & \\
\hline $\mathrm{R}^{2}$ & 0,12 & & \\
\hline
\end{tabular}

Note sur la lecture du tableau : Ce modèle mesure la façon dont chacune des variables insérées dans la modélisation affecte le niveau d'anxiété. Le coefficient indique la force avec laquelle la variable relative impacte positivement ou négativement le score d'anxiété. Les astérisques indiquent le seuil de probabilité que la variable a un effet significatif dans la modélisation $\left(+p<0.1,{ }^{*} p<0.05,{ }^{* *} p<0.01\right.$, *** $p<0.001$ ). Pour des raisons techniques, la variable dépendante a été transformée au logarithme népérien. Toutes les variables insérées dans le modèle ont été codées de telles sortes à ce qu'un plus haut score aille dans le sens de l'intitulé. 